University of Louisville

ThinkIR: The University of Louisville's Institutional Repository

Electronic Theses and Dissertations

8-2006

\title{
The re-innovation of Ford Motor Company to a sustainable lean enterprise.
}

Kenneth A. Ryan 1968-

University of Louisville

Follow this and additional works at: https://ir.library.louisville.edu/etd

\section{Recommended Citation}

Ryan, Kenneth A. 1968-, "The re-innovation of Ford Motor Company to a sustainable lean enterprise." (2006). Electronic Theses and Dissertations. Paper 1243.

https://doi.org/10.18297/etd/1243

This Master's Thesis is brought to you for free and open access by ThinkIR: The University of Louisville's Institutional Repository. It has been accepted for inclusion in Electronic Theses and Dissertations by an authorized administrator of ThinkIR: The University of Louisville's Institutional Repository. This title appears here courtesy of the author, who has retained all other copyrights. For more information, please contact thinkir@louisville.edu. 
THE RE-INNOVATION OF FORD MOTOR COMPANY TO A SUSTAINABLE LEAN ENTERPRISE

\author{
By \\ Kenneth A. Ryan \\ B.S.A.E., St. Louis University, 1990 \\ B.S.M.E., University of Missouri, 1991
}

\begin{abstract}
A Thesis
Submitted to the Faculty of the

University of Louisville

J.B. Speed School of Engineering

in Partial Fulfillment of the Requirements

for the Professional Degree
\end{abstract}

Master of Engineering

in Engineering Management

July, 2006 
Copyright, 2006

Kenneth A. Ryan 
THE RE-INNOVATION OF FORD MOTOR COMPANY TO A SUSTAINABLE LEAN ENTERPRISE

Submitted by:

Kenneth A. Ryan

A Thesis Approved on

$6 / 19 / 06$

(Date)

by the following Reading and Examination Committee:

Surja Alexander, PhD., P.E., Thesis Director

William Biles, PhD., P.E., Faculty Advisor

John S. Usher PhD., P.E., Chair Industrial Engineering Department

Adel Elmagrabhy PhD., P.E., Chair Computer Science \& Engineering 


\section{ACKNOWLEDGMENTS}

I would like to thank my very beautiful wife, Holly, and our three children: Jacob, Nicholas, and Kate for putting up with all the anguish and time I spent away from home in class or studying. Holly's dedication and commitment to the family and exercising incredible leadership as CINCFAM (Commander-In-Chief of Family) was the biggest asset in helping me complete this thesis.

A very special thanks goes out to my curriculum advisor and class professor, Dr. Bill Biles, who taught me to think about a problem from a bigger more macro view than the discreet set of values that most cngincers strive to obtain. More special thanks to Dr. John Usher, who helped push me into going the thesis route. Let's see how Dr. Usher worded this (paraphrasing), 'You can take a three hour class and do a project worth three hours and it will take you about $\sim 150$ man hours to complete, or you can go the thesis route and you can get done with about $\sim 120$ man hours.' Now, that might not be the correct words, but the story is there - go the thesis route, it'll take you less time. It didn't quite work out that way, and I'm glad. I spent more time trying to understand the Big Picture of how the automotive industry works from industry leader, Toyota, and learned more than a class and project would have taught me.

Though I've regretted going this route at times and not taking what I perceived as the easier route (class and project), I was spurred on by endeavoring questions from my thesis advisor, Dr. Suraj Alexander. I greatly appreciated Dr. Alexander slogging through the readings of my thesis and keeping me grounded to using detailed examples and sound engineering principles. Without Dr. Alexander's perspective, this thesis would not have been as complete.

I greatly appreciated Dr. Hdel Elmagrabhy, for being a part of my thesis committee and bringing a very special point of view to never forget the environmental impact of manufacturing. Combined with Dr. Biles, they gave me the impetus for me to learn and understand Environmental Benign Manufacturing and how it applies to the auto industry.

In conclusion, I thank the University of Louisville for the outstanding Professors I've met along the way, and the great course curriculum assembled to achieve this master's degree. 


\section{ABSTRACT \\ THE RE-INNOVATION OF FORD MOTOR COMPANY TO A SUSTAINABLE LEAN ENTERPRISE}

For many years the concept of Lean Manufacturing has been applied in automotive development as a tool to refine the manufacturing practices to the greatest efficiency possible through waste reduction. Continuous Improvement is a quality innovation process that supports this objective, based on the manufacturing pillar - work processes and scientific experiments must be controlled and constantly modified and improved by the people who do, and are accountable for the work. Continuous Improvement implicitly implies the understanding and recognition of what is a problem and problem solving techniques used to formulate the best countermeasures to those problems.

The process of Lean Manufacturing embraces a philosophy of excellence, elimination of waste on value-added operations, employee involvement, and continuous improvement. It is a journey, an on-going process that results in improved customer satisfaction and hence corporate profits. Profit is the reward for customer satisfaction. Increase customer satisfaction and your rewards are higher profits. This is the best method to maintain or increase market share. Understanding the basic hierarchy and philosophy of how to increase profits is essential to creating a sustainable lean enterprise. The following structured process outlines the basic questions and answers for any company to ask itself: 
Questions:

\section{Why are we here?}

How do we improve our business bottom line?

\section{How do we give our customers what they want?}

\section{Every problem is a deviation from a standard!}

How do we and our suppliers achieve process stability and system standardization?
Answers:

To Make Money!

Give the customer the products they want with the quality they expect.

\section{To give the customers what they} want and expect, we must identify and understand variations in our processes and parts.

\section{Strict adherence to process} standards promotes structured problem solving and identification of variations.

\section{Level Scheduling "Heijunka"}

Level production schedule allows us and our suppliers to achieve production process stability.

This thesis is about Ford Motor Company getting back to its roots, the heritage it started with the development of the moving assembly line and the original concept of Lean Manufacturing. This paper will focus on the creative steps outlined in the Process to Sustained Success procedure toward the journey of Lean Manufacturing. In addition, the current state of production processes, and recommended specific corrective actions for the re-innovation of Ford Motor Company to a sustained lean enterprise in a modern era will be discussed. Questions will be asked and answered such as: Can Ford achieve sustained success implementing "The Way Forward" plan, or does "The Way Forward" [16] plan need to incorporate the Process to Sustained Success to meet Ford's long-term goals? The benchmark company for comparison is Toyota Motor Manufacturing Corporation. 


\section{TABLE OF CONTENTS}

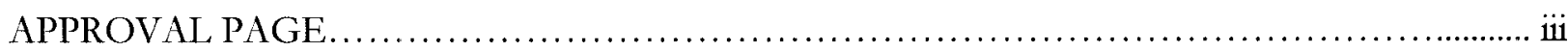

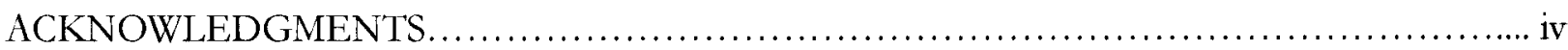

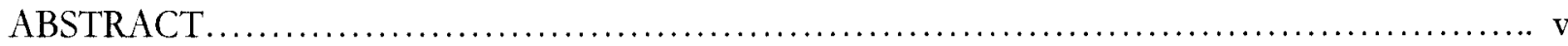

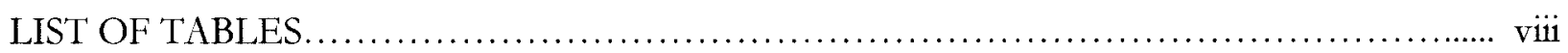

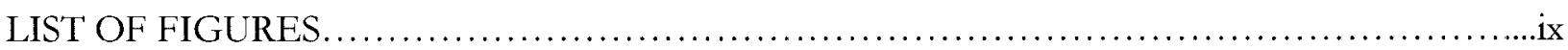

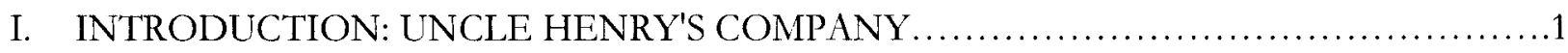

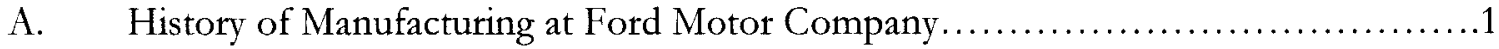

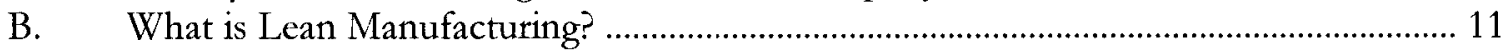

C. A New Vision for Ford Motor Company - The Way Forward Plan............. 15

D. Problem Statement................................................... 18

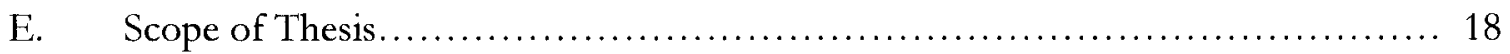

II. PROCESS TO SUSTAINED SUCCESS - CURRENT STATE OF FORD MOTOR

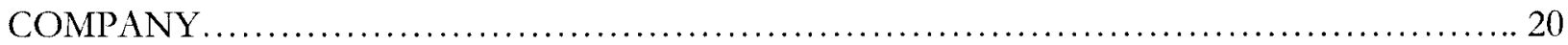
A. Level Scheduling.

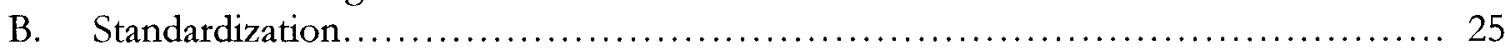
C. Structured Problem Solving .......................................... 32

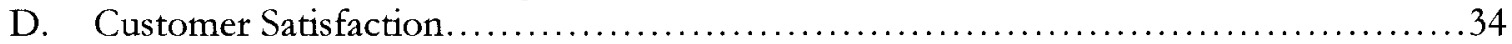

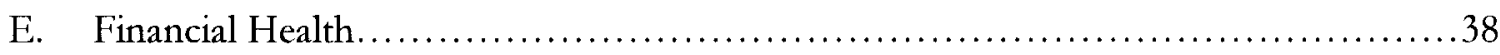

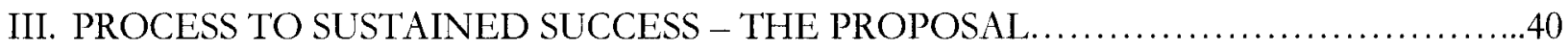

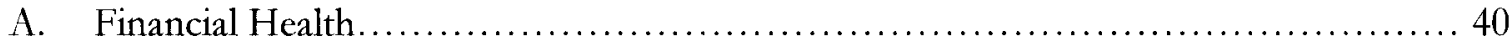

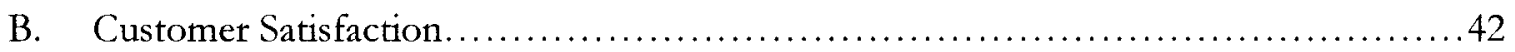
C. Structured Problem Solving ............................................. 44

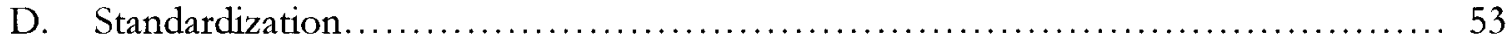

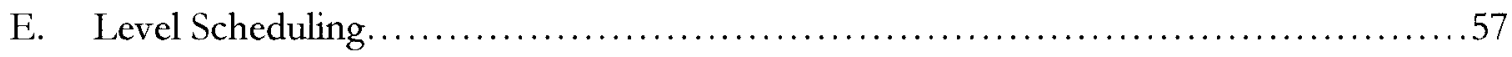

IV. LITERATURE REVIEW: LEADERSHIP \& PHILOSOPHY TO SUSTAINABLE

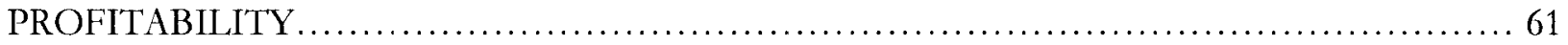

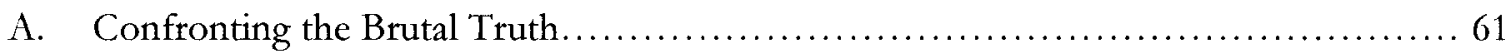

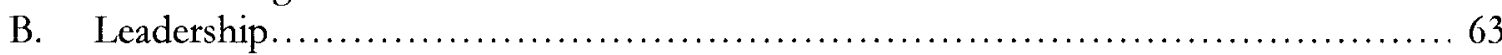

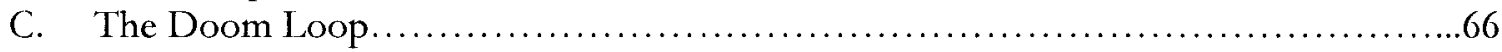

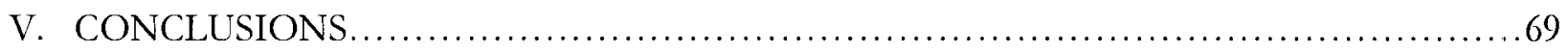

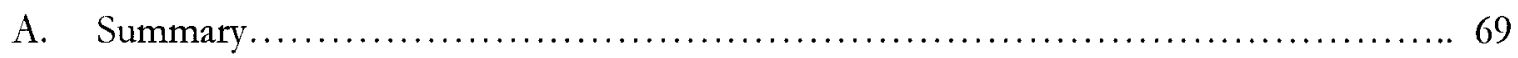

B. Areas for Further Work or Improvement.............................. 71 


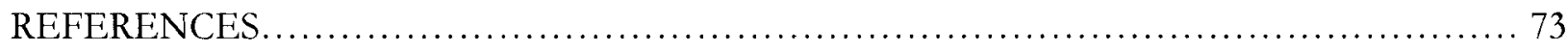

GLOSSARY OF LEAN MANUFACTURING TERMS $\ldots \ldots \ldots \ldots \ldots \ldots \ldots \ldots \ldots \ldots \ldots \ldots \ldots \ldots$

APPENDIX A - FORD MOTOR COMPANY HISTORICAL TIMELINE .................. 77

APPENDIX B - ANNOUNCEMENT OF THE THE WAY FORWARD PLAN ............. 78

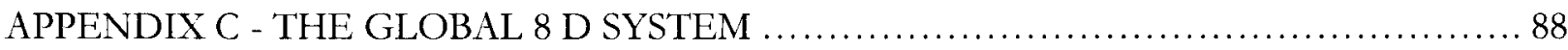

APPENDIX D - FORD MOTOR COMPANY 2005 FULL YEAR FINANCIALS.............91

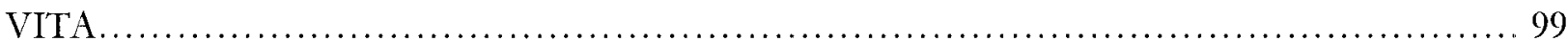




\section{LIST OF TABLES}

Table 1 - Example of typical LAP build schedule

Table 2 - Sample Hood Component Shipping Schedule

Table 3 - Standardized Work Combination Table

Table 4 - Louisville Assembly Plant with Level Schedule. 


\section{LIST OF FIGURES}

Figure 1 - The Way Forward Plan.

Figure 2 - Assembled Hoods in Racks Awaiting Installation.

Figure 3 - Assembler written Operator Instruction Sheet from Louisville Assembly Plant

Figure 4 - Current State Process Map

Figure 5 - GQRS TGW/1000 for new Launch Vehicle Performance 2005.

Figure 6 - GQRS TGW/1000 Five-Year Trend Chart.

Figure 7 - Ford Motor Company's 6 month Stock Valuation Trend Chart.

Figure 8 - Ford Motor Company's 30 year Stock Valuation Trend Chart.

Figure 9 - One Year Trend Stock Price Valuation Comparison - Ford to Toyota

Figure 10 - Ten Year Trend Stock Price Valuation Comparison - Ford to Toyota.

Figure 11 - DOE results for Pt a3 around 2006 Explorer hood

Figure 12 - DOE results for Pt a3 around 2006 Explorer hood.

Figure 13 - DOE results for Pt a3 around 2006 Explorer hood.

Figure 14 - DOE results for Pt a3 around 2006 Explorer hood.

Figure 15 - DOE results for Pt a3 around 2006 Explorer hood.

Figure 16 - Hood storage methodology in contrast with DOE recommendation

Figure 17 - Louisville Assembly Plant Laser System Schematic.

Figure 18 - Laser Welding vs. Resistance Welding Reduction of Flange...

Figure 19 - Laser Welding vs. Spot Welding Comparison.

Figure 20 - The Doom Loop. 


\section{Chapter I: Uncle Henty's Company}

\section{Introduction}

\section{A - History of Manufacturing at Ford Motor Company:}

"That line established the efficiency of the method," Henry Ford said regarding the moving automobile assembly line.[1] The idea of moving the work to the man reached its zenith on October 17, 1913 at the Highland Park final assembly line when the Ford rigged a chassis that was slowly pulled across the factory floor by rope and windlass. Parts, components, and 140 assemblers were stationed at different intervals along the 150 -foot line. As the winch literally dragged the chassis across the floor, workers attached parts to the vehicle. When the first car was finished, production men were amazed at the time saved. Rather than twelve and a half hours to build a single car, they had performed the feat in five hours and fifty minutes. [2]

Henry Ford first latched onto the concept that instead of bringing the man to the work, as cars were built in stationary cells at the time, work must be brought to the man. He initially used cradles that were pushed from one workstation to the next. A breakthrough came early in 1913 when a production engineer in the flywheel magneto assembly area tried a new way to put the component's parts together. The operation was divided into twenty-nine steps and workers were instructed to place only one part in the assembly line before pushing the flywheel down the line to the next assembler. The assembly time was reduced from about twenty minutes to five minutes per flywheel. This strategy was applied to the construction of the engine and finally the entire vehicle. [3]

The moving assembly line is only possible through the early inventions of luminaries such as 
Eli Whitney. In the early years of the USA, there was a severe shortage of skilled machinists. Whitney realized that by using a template, workers with little skill could not only operate machines, but also produce identical parts that were interchangeable.

Until then, under the English system invented during the Industrial Revolution, skilled machinists were required to produce parts from a design. But however skilled the machinist, parts were never identical, and each part had to be manufactured separately to fit its counterpart - almost always by one person who produced each completed item from start to finish.

Although there was still a requirement for the craftsmen to create prototypes of the design before production, they were no longer required in the actual manufacturing. Whitney first used the system to manufacture muskets. Such was his reputation that the U.S. government gave him a contract for 10,000 muskets, to be produced within two years, even though he had no factory or machines. It actually took eight years to deliver the order, as Whitney perfected and developed new techniques and machines, but he did go on to produce a further 15,000 muskets within the following two years.

Due to the concept of identical and interchangeable parts, Ford's constant revision and improvements to make a single car drove the build time to only ninety-three minutes in 1914 . The results were immediate and extraordinary allowing Ford Motor Company to produce more vehicles than all other automakers combined. Benefiting the customer the price for each Model T Ford dropped from $\$ 600$ in 1912 to $\$ 360$ in 1916 . "The perfection of the moving assembly line is Ford's greatest gift to history," says Don Werling, former historical director of the Henry 
Ford Estate, Fair Lane, at the University of Michigan - Dearborn, and founder of the Henry Ford Heritage Association. [4]

But the great gift Henry Ford gave the world was much more than a moving assembly line - it was the birth of Lean Manufacturing backed by the splendid notion of continuous improvement utilizing scientific testing and evaluations - hypotheses created to test the improved developments of the assembly line. Henry Ford's team investigated new ways to improve manufacturing techniques and flexibility. At the Rouge complex during the times after the stock market crash of 28 October 1929 Ford Motor Company survived through a mix of cost-cutting initiatives, price reductions, and higher wages, which Henry correctly surmised would sell more cars. In the process, he earmarked $\$ 25$ million for factory expansions and improvements making the plant flexible enough to manufacture tractors, automobiles, and a range of other vehicles using "vertical integration" manufacturing techniques. Henry Ford's spirit to improve efficiency and reduce production costs kept Ford Motor Company alive and well during the hard times of the Depression. Among the top manufacturing innovations during the Depression was the introduction of the one-piece cast V8 block by Ford. [5]

Business for Ford Motor Company trundled along during the 1930's until February 10, 1942 when by decree from the U.S. government that all civilian Ford automobile production cease and the company's immense manufacturing facilities in Michigan and other states were brought under the control of the War Production Board. "The same assembly line that made Ford automobiles is now to be used for jeeps and staff cars for army officers," the press reported. [6] Ford Motor Company poured its energies into the tools of war. Led by Henry Ford, seventyeight at the time, said to have "rolled up both sleeves" for the war effort. Henry took a track of 
land near Ypsilanti, MI called Willow Run, and ordered a mile long L-shaped plant built to produce B-24 Liberator bombers for the military. By 1945, Henry had his production line so efficient $70 \%$ of all B-24 bombers were made at Willow Run - no small feat given that Boeing Co. was a dedicated aircraft manufacturer. The company also excelled at producing M-4 tanks, parts, and engines; armored and reconnaissance cars; amphibious craft; swamp buggies; and a wealth of other war materiel.

Unfortunately during this time of war, Edsel, Henry's son and president of Ford Motor Company died on 26 May 1943. Henry, almost eighty years of age, resumed the title as president of the company. Edsel's eldest son, Henry Ford II - the "Deuce", a Naval Lieutenant, was released from service to go back to Ford Motor Company, learn the ropes, and eventually take over command. Henry made the "Deuce" president of the company on 21 September 1945 at only twenty-eight years old.

The company ran with the "Deuce" at the controls with Henry looking on every so often until Henry's death on 7 April 1947. By this time, Ford Motor Company was beleaguered by an inferior management system and other more serious problems, which Henry II tackled with fervor. The revitalized company met the postwar economic boom with a new Ford Division and a new car - the 1949 Ford, the first change in a Ford body since 1942 and the first change in a chassis since 1932 .

Times were changing for the United States with America's sudden postwar prosperity made a brand-new car an attainable dream for millions. Many middle-class families had the financial wherewithal to buy a second car. The 1950 s liberated the automobile from its early utilitarian 
bonds to soar into the futuristic visions mirroring the optimism of the nation. The people who grew up during the Depression, fought in WWII, and now figured they deserved the big twotone car with the huge V-8 engine, automatic transmission, and a boat load of chrome - big cars that reflected big dreams. Attentions of the automotive manufacturers turned to designing the cars people wanted - stylistic cars.

In 1955, Ford Motor Company explored an uncharted market and came up with a winner in the new Thunderbird. The company broke all previous sales records and the "Deuce" was named Time magazine's "Marketing Man of the Year." The next year President Dwight D. Eisenhower signed into legislation the Interstate Highway Act earmarking public funds to build a national grid of highways. Americans took to the roads in record numbers fueling an economic boom through the early 1960 s.

During the early 1960s, then President John F. Kennedy vowed America would be the first to the moon, and the spirit of the space age captured the automotive manufacturers' and consumers' imaginations. Ford led with three new cars, the 1959 Galaxie, the company's new top-line series; the 1960 Mercury Comet, its first principle upscale compact car; the 1960 Ford Falcon, and the 1962 Meteor. The car that took America's heart was introduced on 17 April 1964 at the New York World's Fair - the Mustang. More than a million Mustangs would be produced before its second birthday. [7]

The winds of change were blowing though. Fun and frivolity of the 1950 s and early 1960 s gave way to demands for stricter government controls on automobile hydrocarbon emissions. In 1964, California was the first state to mandate reduced amounts of nitrogen, carbon monoxide, and lead in car exhaust. The following year, the Motor Vehicle Air Pollution and Control Act 
of 1965 applied the California regulations to the entire country. More anti-smog rules were issued, such as the Federal Clean Air Act of 1970, which imposed a reduction of almost $90 \%$ in vehicle emissions. More challenges were on the way for the automotive manufacturers. In a speech to Ford's worldwide managers in February 1973, Henry II predicted the environment rules would become more restrictive as the public pressure increased. He also predicted another looming crisis - a major oil shortage. Later that year an embargo by OPEC proved him right. Ford quickly put its great might behind the small subcompact car introduced in 1971, the Pinto.

More governmental restrictions followed making the automobile industry responsible for energy conservation. The Energy Policy and Conservation Act of 1975 instituted Corporate Average Fuel Economy (CAFÉ) guidelines requiring automakers to consistently improve their vehicle's mpg metrics. Meeting these standards would not be easy for the American automotive manufacturers who are accustomed to building large vehicles. "American carmakers didn't want to make smallish Falcons and Valiants; they wanted to make full-size Buicks and Fords," says Robert Casey, Curator of Transportation at Henry Ford Museum and Greenfield Village. "It was pure economics: It didn't cost much more to make a full-size Ford than it did to make a Falcon, but you could sell the Ford for a lot more money." [8]

But in 1978 a second oil crisis occurred and this time Japanese companies were well positioned to take advantage of the consumer desire for smaller more fuel-efficient cars that were dependable and affordable. Complicating matters here in the United States was a favorable dollar-to-yen ratio, substantially lower labor costs in Japan, and soaring interest rates here in the U.S. 
The outlook for Ford was grim. The company's U.S. sales in 1980 were half the volume of 1978. Its market share fell from 23 percent in 1977 to 17.3 percent in 1980 , a year in which it lost a staggering $\$ 1.5$ billion. "Can Ford Keep Up?" was the headline on the 15 October 1979 cover of Forbes magazine. This decline eventually reached 16.6 percent market share in 1981 , lowest in history. Owner loyalty also deteriorated - to 35 percent in 1981 as well. Between 1980 and 1982 , the company lost $\$ 3.3$ billion - a staggering 43 percent of Ford's net worth.

A difficult task lay ahead of cost management. Red Poling was given this task and in short order he pulled one million units from production (getting back to a Lean Manufacturing principle - waste due to over-production), laid off some 60,000 Ford employees (reducing payroll expenses from $\$ 6.2$ billion to $\$ 5.2$ billion), and closed five plants (saving another $\$ 500$ million). At the same time and harking back to the days of Henry Ford in the early 1930 s, Ford spent $\$ 14$ billion between 1980 and 1984 on plant improvements, new products, processes, machinery, and equipment and another $\$ 9$ billion on research and development.

Red Poling explained that quality had to improve and only those plants that understood this objective would remain open. Poling also confided that the difference between Ford and its Japanese competitors was not the quality of workers but Ford's inferior management philosophy, which did not emphasize continuous improvements in product quality. This statement will become more prophetic in the next twenty years as Japanese manufacturers gain a majority of the world market share, and take over the leaders of market share in the U.S. with ever increasing profits.

"Quality is Job 1" now permeated the culture at Ford facilities all over the world. By the first 
quarter of 1983, Ford was profitable both at home and overseas for the first time in the past sixteen quarters; by the end of the year, Ford was the car sales leader in all of Europe for the first time in its history. The hard work and benefits were starting to pay off and a new ground breaking design was on the board, the new Ford Taurus and Mercury Sable. Ford had undertaken long-term planning of a kind never before seen in the automobile industry. The Taurus team contracted outside experts in ergonomics, insurance, and car repair to offer their specialized advice and criticism, of which many they implemented. Ford engineers literally tore apart hundreds of cars sold by competitors, a process called "reverse engineering," to learn others' best practices firsthand. The team brought the program in under budget realizing an impressive 11 percent return on investment. The company's pretax earnings in 1986 were better than GM's for the first time since 1924, and the next year, Ford's stock price climbed an astonishing 76 percent from its 1986 high.

In the mid-1980s, Ford continued to evolve, embarking on an ambitious agenda to acquire large financial services companies. Its objective was twofold: to offset the cyclical nature of the automotive business and to provide Ford's customer base with a broad range of financial services products. By the year 2000 , outside tiers of suppliers now contributed the lion's share of parts used in Ford vehicles. In 1995, the head of Ford Motor Company, Alex Trotman, adopted another endeavor, to cut costs, boost productivity, and grow the bottom line - Ford 2000.

The Ford 2000 strategy is to have global product teams create cars that would be sold around the world, thereby reducing waste and duplication of effort. A more efficient, leaner company would result and provide more autonomy to branch managers. The goal of a more nimble 
international company embracing teamwork, new technology, and a worldwide outlook - one far less bureaucratic and insular - remained the same. A new CEO of Ford, Jac Nasser, put the Ford 2000 initiative aside in favor of a new strategy, BLI - Business Leadership Initiative.

The latest initiative to make the rounds at Ford Motor Company is "Way Forward". "Way Forward" is an innovation initiative to set the direction of Ford Motor Company onto a profitable path. According to William Clay Ford, Jr., CEO of Ford Motor Company, "Innovation is going to be the compass by which this Company sets its direction. Innovative answers need to be found for every aspect of our business, from product development and manufacturing to human resources and finance. Not everyone will have the ideas that we need, but everyone can support and help implement needed innovation." [9]

Why such an exhausting description of Ford Motor Company's history? To point out the fact that since 1932, there has been no significant innovation or invention in manufacturing for Ford Motor Company. Henry Ford was the last true leader at Ford who fully understood manufacturing and the principles of efficiency that would later become known as, "Lean Manufacturing”. The following is an excerpt regarding Henry's amazing consciousness of manufacturing principles:

"Henry fought back with another new car, the pioneering Ford V-8, introduced in 1932. Other carmakers had made eight-cylinder engines before, but they were heavy and expensive, causing many to focus instead on six-cylinder engines. Henry disliked six-cylinder motors and always insisted that engines should be made only with four, eight, or sixteen cylinders. Once, upon hearing that his engineers had devised a six-cylinder engine without his knowledge, he was so 
infuriated that he took an axe to it.

Henry had a better idea - a one-piece V8 engine block that would be lighter in weight and less expensive to make. There was only one hitch: the casting technology to manufacture a single V8 engine didn't exist. That didn't stop Henry. He and a group of handpicked engineers set up shop in 1931 in Thomas Edison's old Fort Myers laboratory, which had been moved to the grounds of Greenfield Village in Dearborn, to find the solutions.

"Mr. Ford kept everybody away from [the project]," Emil Zoerlin, and electrical engineer on the project, said in his reminiscences. "As far as I know, Charlie Sorensen didn't know about it, [and] I don't know whether Edsel was aware. The original concept of the V8 was Mr. Ford's. $[\mathrm{He}]$ came in two or three times a day [and] was vitally interested in a one-piece casting of the cylinder block. It had to be one-piece, definitely." [10]

As Henry Ford was getting up in years, he started to turn control of Ford Motor Company over to his son, and later his grandson, Henry Ford II. But none of them could match Henry's prowess of manufacturing principles. In 1946 manufacturing gave way to "Modern Business Strategies" as the Deuce, Henry Ford II, hired 10 former USAAF officers, nick-named the "Whiz Kids", who would bring principles of modern management to the company. Thus was lost the emphasis on efficient manufacturing techniques and reduction of waste efforts.

General Ford Corporate 'Timeline: Appendix A 


\section{B - What is Lean Manufacturing?}

"Save ten steps a day for each of twelve thousand employees," Henry [Ford] said, "and you will have saved fifty miles of wasted motion and misspent energy." [11]

When you ask, "What is the Toyota Production System?" 80 percent of people will answer "A Kanban System", 15 percent will answer "A production system", and only 5 percent who understand the basic principle will answer "A system for the absolute elimination of waste." (Shingo, 1989) [12]

The Toyota Production System (TPS) is generally accepted as the basis for manufacturing principles known as Lean Manufacturing. Therefore, this thesis will concentrate most on TPS as a guide to Lean Manufacturing and a comparison to Ford Motor Company. However, understanding the basic philosophy of TPS is central to understanding what Lean Manufacturing is all about. This thesis uses TPS and Lean Manufacturing synonymously though there are some differences.

Lean manufacturing embraces a philosophy of excellence that includes the elimination of waste or non-value-added activities while adjusting the production flow of the product according to customer demand.

It uses the building blocks of: standardized work, workplace organization, visual controls, effective plant layout, and quality at the source, batch reduction, teams, customer demandbased manufacturing, point-of-use storage, quick changeover (SMED), one-piece flow, cellular 
manufacturing, and takt time.

Lean manufacturing also applies the modern elements and technologies of scrap reduction, process improvements in machining and tool selection as well as material selection, set-up reduction, Just-In-Time, Kaizan, world-class manufacturing, synchronous manufacturing, and inventory management.

In a paper prepared by The Kentucky Way partnership between the University of Kentucky and Toyota, the group outlines "The Lean Organization": [13]

\section{The lean organization...}

1 Designs its products and aligns every step in its operations to create the highest value for its customers.

2 Truly believes its people are its most important asset and creates a work environment that promotes respect, job satisfaction and meaningful contribution.

3 Is simultaneously stable and flexible.

4 Flows work so that problems are immediately visible and then has systems in place to fix them fast and permanently.

5 Assesses costs accurately, fully recognizing systems and lifecycle impacts of decisions.

6 Distributes power across the organization but maintains strategic focus and control through clear charters of responsibility, definition of organizational roles, and communication of appropriate organizational goals.

7 Relies on an evolutional use of standards to rapidly improve its methodologies, role 
definitions, and policy effectiveness while maintaining high levels of control.

8 Builds control into the system through structural simplification and does not succumb to the false promises of superimposed control through information systems.

9 Is skillful at using the key tools such as visual controls, standardized work, mistake proofing, and setup reduction, but knows that these exist simply to create the requisite structure and sustain control of lean operations; they are not at the heart of lean production.

10 Engages everyone as a knowledge worker and employs the lean work system -- a sophisticated system involving local work ownership and empowerment, strategic work focus, evolutionary standards, and learning-focused improvement strategies -- to rapidly kaizen methodologies for tremendous gains in efficiency, quality, and control.

11 Uses appropriate accounting and performance measurement systems that provide rapid feedback, motivates true system-level performance improvement, maintain appropriate focus on the long term, and take advantage of the control that exists through simplification of the system.

12 Relies on managers who know the work, who are in touch with the work through direct presence and keen observation, who get their hands dirty, who support the work, who develop their people, and have learned how to lead their teams.

13 Recognizes that competition occurs at the level of the extended-enterprise value stream and builds that value stream through strong partnerships with its suppliers and customers.

14 Is good, good to its customers, good to its people, and good to society. It ends up being very highly rewarded for that. 
The Toyota Production System evolved from the historic manufacturing system developed by Henry Ford. Among the distinguishing elements of Ford's system, all of which still can be seen today in any modern automobile plant:

1 A conveyor belt - work came to the workers.

2 Division of labor - workers handled only single steps in the assembly sequence.

3 Integrated supply chain - Ford kept each process in the production sequence supplied with all the parts and materials needed in the process.

A passage from the Toyota Motor Manufacturing employee's handbook, "The Toyota Production System":

"Henry Ford's manufacturing system thus provided the historical and technological foundations for the Toyota Production System. But circumstances in Japan provided the opportunity for some crucial improvements on Ford's system.

To begin with, production volumes in postwar Japan were miniscule compared with automotive output in the West. Those small production volumes did not allow Japanese automakers the luxury of using specialized equipment for each model. Nor did they allow for stocking huge inventories of parts.

Automakers in Japan thus needed to develop flexible methods for adapting the same machines to different vehicle models. And they needed to find ways to ensure reliable supplies of needed parts and materials without maintaining big inventories." [14]

What are the Toyota Production System's cornerstone ideologies?

1 Just-In-Time (JIT) production

o Doing it all for the Customer 
- Leveled production

o Pull system

- Continuous-flow processing

- Takt time

- Multi-skilled operators

2 Jidoka

O Building Quality into the production process

3 Standardized Work and Kaizen

- Standardized Work: the Basis for Kaizen

- Kaizen: the Lifeblood of Standardized Work

Within this thesis rhetoric of the Introduction, Lean Manufacturing is first and above all about the recognition and reduction of wastes typically viewed as - Over Production, Over Processing, Inventory, Waiting, Correction, Conveyance, and Motion. The starting line of Lean Manufacturing is not always obvious to most engineers and managers alike, but Lean principles start with the customer base.

\section{C - A New Vision for Ford Motor Company - The Way Forward Plan}

Announced on 23 January 2006, William Clay Ford, Jr. introduced the new President of the Americas, Mark Fields, and Mr. Fields' new direction to right the failing company. The plan Mr. Fields introduced: “The Way Forward”.

According to Mark Fields, the success of Ford Motor Company hinges on three priorities:

1 Creating a team that knows how to win 
2 Developing a Way Forward plan that shows us how to win

3 Developing with speed to help us win quickly

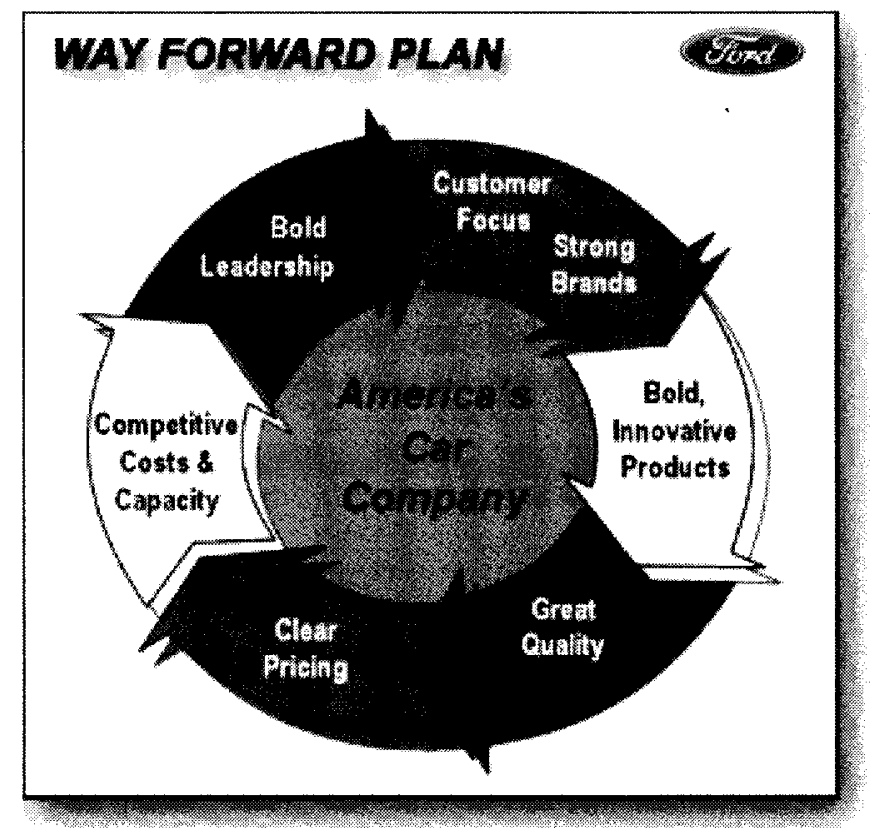

Figure 1 - The Way Forward Plan

The complete announcement is listed in Appendix B.

Summary of the Way Forward plan:

Comprehensive North American "Way Forward" plan focuses every part of the business on the customer - to build stronger Ford, Lincoln and Mercury brands, a strengthened product lineup and far greater quality, competitive costs and improved productivity.

- Product investments will result in new vehicles in new segments to reach more customers - including small cars and more crossovers - while maintaining Ford's truck leadership.

- Ford is committed to stabilizing its U.S. market share in the near term.

- Competitive cost structure includes net material cost reductions of at least $\$ 6$ billion by 
2010.

- Productivity improvements leverage the company's global product development scale and lean and flexible manufacturing system to introduce more products faster.

- Straight forward vehicle pricing will continue to be introduced with new models.

- North American capacity is realigned to match demand - with 14 manufacturing facilities to be idled - resulting in significant cost savings and reduced employment of $25,000-30,000$.

- Salary-related costs are being cut 10 percent in North America with the previously announced reduction of the equivalent of 4,000 salaried positions by the end of the first quarter. In addition, the company's officer ranks are being reduced 12 percent by the end of the first quarter.

- Ford is planning a new low-cost manufacturing site for the future.

- North American automotive profitability is achieved no later than 2008.

- Beginning in 2006, Ford Motor Company will no longer provide earnings guidance to keep the company and investors focused on one goal: sustainable profitability over time in all regions. 


\section{D - Problem Statement:}

The objective of this thesis is to provide a unique philosophy and structure as given in the

"Process to Sustained Success" diagram to form the basis for re-innovating Ford Motor

Company to continued profitability and continuous improvement.

This thesis doesn't intend to address every detail of Lean Manufacturing concepts and the application of specific techniques toward Ford Motor Company's manufacturing processes, but to develop the mindset and philosophy needed to confront the brutal reality that Ford's manufacturing and product development systems need to evolve from its heritage.

Through out the historical review of Ford Motor Company one thing became apparent in this research - Ford Motor Company lacks a structured and standardized approach to manufacturing continuous improvement prohibiting the re-innovation to a lean enterprise and direct competition with Toyota Motor Manufacturing Corporation. Can Ford achieve sustained success implementing "The Way Forward" plan, or does "The Way Forward" plan need to incorporate the "Process to Sustained Success" to meet Ford's long-term goals? The benchmark company for comparison is Toyota Motor Manufacturing Company.

\section{E - Scope of Thesis:}

The thesis is organized as follows. Chapter I gives an initial introduction to the history of Ford Motor Company, and Lean Manufacturing principles. Chapter II will focus on the current operations and structure at Ford Motor Company based on the steps of the "Process to Sustained Success". Chapter III, using the same steps of the "Process to Sustained Success", outlines proposed changes in the philosophy, management, engineering, and 
manufacturing structure to improve Ford Motor Company seeking long-term profitability.

Many comparisons and analogies will be made with Toyota Motor Manufacturing Company.

Chapter IV presents a literature review of great leadership and managerial philosophy and techniques, and how they should be applied to Ford Motor Company. Additionally, it will take us through the 5 Why's of how Ford came to be in the shape it's in. Chapter V provides conclusions and recommendations on potential areas for further study. 


\section{Chapter II: Process to Sustained Success - Current State of Ford Motor Company}

\section{A. Level Scheduling:}

A level schedule starts with the customer, and is an integral and important factor in deciding production rates and volumes for each vehicle line. The Japanese call Level Scheduling, Heijunka, which sequences orders in a repetitive pattern, and smoothing the day-to-day variations in total orders to correspond to long-term demand. The strategic implications are vast regarding vehicle inventory levels, raw material purchases, manufacturing tempo, and supplier daily production schedule.

Level Scheduling is accomplished by taking the total orders per product family for a time period (e.g. a month), and then create a schedule and build rate. At Ford Motor Company, this step is not properly accomplished and induces many wastes including the worst - Over Production, and forces Ford's manufacturing systems to "Push" instead of the customer demand "Pull System".

The frustration of Ford's Dealership network over this system is on a steady rise. The system works as such: A dealership receives vehicles based on vehicle line allocations; which are determined on the sales volume of a particular dealership. As an example, Stuatt Powell Ford in Danville, $\mathrm{KY}$ is allotted only one Mustang GT per month even though they have on average three customer orders per month. Ford Motor Company's Marketing group is reluctant to provide Stuart Powell's Ford Dealership with more Mustang GT allocations because Stuart Powell's vehicle sales on vehicle lines such as the Explorer, Freestar, and Freestyle are below Ford Motor Company's expectations. The compromises and dealings between Ford Motor Company and Stuart Powell Ford take place with Ford stating that if 
Stuart Powell takes delivery of three more Explorers then they will receive an extra Mustang GT allocation. This action of "packaging" in turn induces a response by Stuart Powell Ford to "push" vehicles onto the customers, and typically with Ford Motor Company having to provide costly incentives to move these products. Failure to sell more Explorers, Freestars, or Freestyles forces Ford Motor Company to idle manufacturing facilities due the Marketing and Sales down-weeks. Last year, Louisville Assembly Plant (LAP), was shut down for a total of seven weeks due to slumping sales. St. Louis Assembly Plant (SLAP, another plant that produced the Explorer and Mountaineer) ran at only 25\% capacity. And as of 8 March 2006, St. Louis Assembly Plant was permanently idled. [15]

Ford Motor Company's Marketing and Sales division attempts to balance customer desires for certain vehicle lines while keeping the manufacturing facilities operational at a given production rate. Due to the inflexibility of most of Ford's manufacturing facilities, the mentioned scenario induces a "push" system instead of a "pull" system where a manufacturer has the flexibility to produce to customer demand. Downtime in 2005 for LAP and SLAP are also attributed greatly in part to the inability to adjust Takt time, or production tempo to decrease or increase the rate of production based on customer demand. The ability to adjust Takt time starts with standardizing work elements and will be discussed in the next chapter dealing with a proposed system.

Again, Level Scheduling starts with the customer, but has profound affects on the manufacturing system and quality level of Ford Motor Company's supplier base. The current build complexity for the Ford Explorer/Mountaineer/Sport Trac built at LAP is over 14,000 different combinations. Most of the complexity is manageable, with only 25 parts brought into the plant ILVS. However, the main purpose of Level Scheduling is to smooth daily 
fluctuating production volume and mix requirements for the final manufacturing facility and the supplier base for a predetermined period of time to produce and deliver the same part number in the same volume and mix. Table 1 shows a snap shot of a typical production schedule at LAP (data taken 28 March 2006 at the Louisville Assembly Plant):

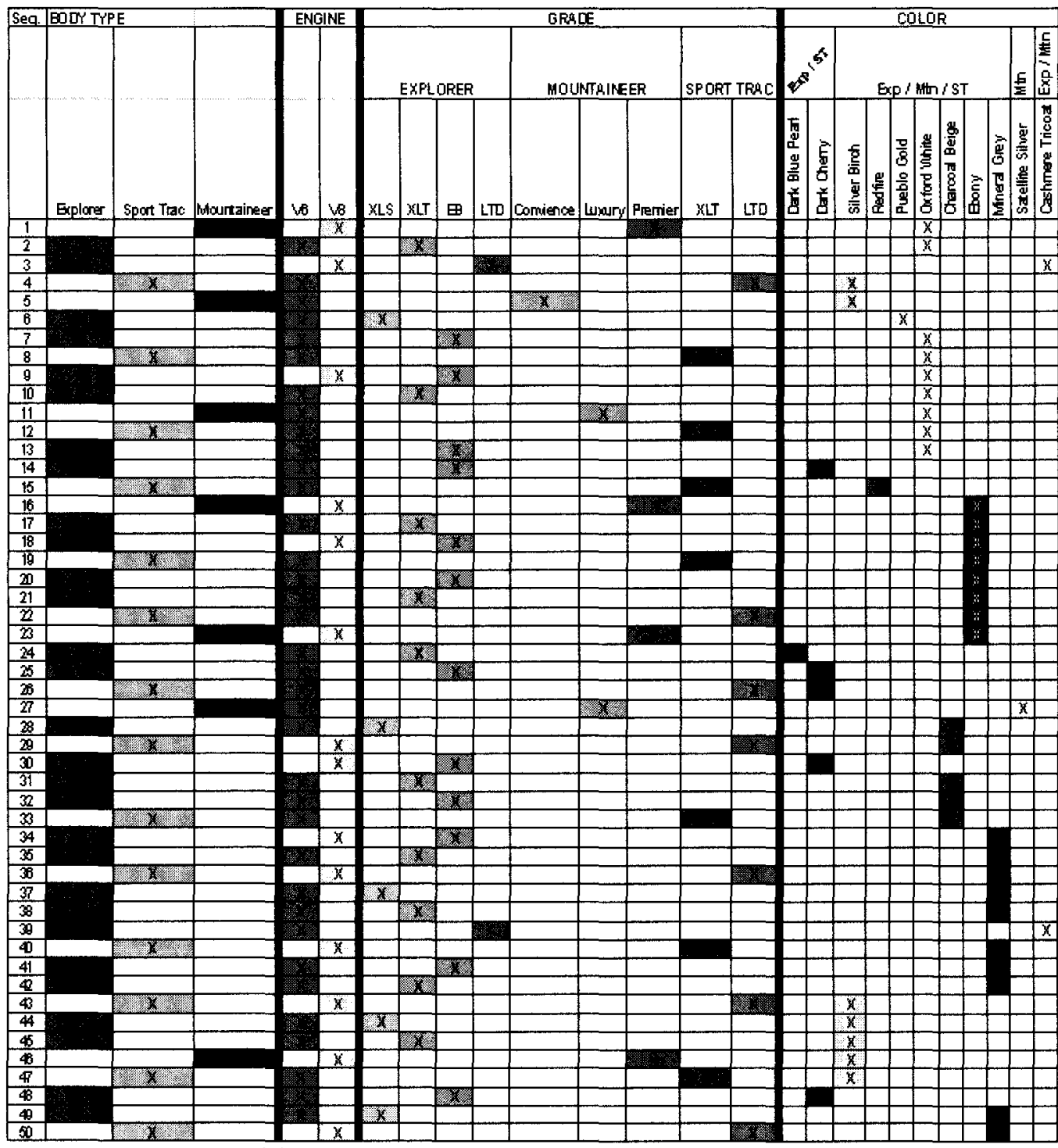

\section{Table 1 - Example of typical LAP build schedule}

Noticeable in the table above, neither the Body Type nor the engine, in order of precedence when determining build schedule, are completely balanced in a set pattern. Next in the order of precedence are trim level or Grade, and then color. 
From a supplier base perspective, the schedule of parts to ship to the manufacturing facility is critical for day-to-day scheduling of dies in a press and maintenance. The example below shows three weeks of shipping orders for hood components shipped from an outside supplier to the Louisville Assembly Plant. The hood inners and outers are for the Explorer, and are hemmed one-to-one at the assembly plant.

\begin{tabular}{|c|c|c|}
\hline $\begin{array}{c}\text { Date } \\
\text { Shipped }\end{array}$ & \# Hood Inners Shipped to LAP & \# Hood Outers Shipped to LAP \\
\hline 10-Apr-06 & 1040 & 640 \\
\hline 11-Apr-06 & 1560 & 1320 \\
\hline 12-Apr-06 & 520 & 1040 \\
\hline 13-Apr-06 & 520 & 680 \\
\hline 18-Apr-06 & 1040 & 1000 \\
\hline 19-Apr-06 & 1040 & 1000 \\
\hline 20-Apr-06 & 1040 & 1000 \\
\hline 21-Apr-06 & 1040 & 1320 \\
\hline 24-Apr-06 & 1040 & 1000 \\
\hline 25-Apr-06 & 1040 & 1000 \\
\hline 26-Apr-06 & 1040 & 1320 \\
\hline 27-Apr-06 & 1040 & 1000 \\
\hline 28-Apr-06 & 1040 & 1000 \\
\hline 1-May-06 & 1040 & 1720 \\
\hline 2-May-06 & 1560 & 1320 \\
\hline 3-May-06 & 1040 & 960 \\
\hline 4-May-06 & 520 & 714 \\
\hline 7-May-06 & 0 & 360 \\
\hline 8-May-06 & 1040 & 1360 \\
\hline 9-May-06 & 520 & 320 \\
\hline 10-May-06 & 1560 & 2000 \\
\hline 11-May-06 & 2080 & 1320 \\
\hline
\end{tabular}

Table 2 - Sample Hood Component Shipping Schedule

The hood components shipped in on a daily basis fluctuates from a day-to-day and component-to-component level, and don't meet the daily production schedule of 1138 units produced per day.

Level Scheduling an important factor in supplier quality. Ford provides suppliers with a confirmed production schedule for a set time period, but does not provide a level daily 
production schedule. Therefore, a supplier's production requirement in part volume and mix may vary dramatically from day to day. In the example above, hood inners and outers are paired one for one and assembled to create one complete hood. The daily volume rates are significantly different between hood components.

In order to meet Ford's fluctuating daily production volume and mix requirements, a typical supplier will adjust their manufacturing process in the following ways:

1 Increase/decrease production run time

2 Increase/decrease production cycle time

3 Add/subtract workers from process line

4 Increase/decrease scheduled changeovers

5 Cancel/delay scheduled tooling/equipment maintenance

6 Cancel/delay scheduled personnel training \& development

7 Bypass structured problem solving

8 Increase/decrease downstream supplier production requirements

All of these actions represent deviations from a standard and result in manufacturing process instability and inconsistent part quality.

Flexible manufacturing is difficult to obtained without practicing the first step of Heijunka; which leads to improving and developing standardization methods. 


\section{B. Standardization:}

Without a Standard - You don't have a problem! Additionally, a Problem is a Deviation from a Standard!

A level schedule provided by Ford Motor Company to its' own manufacturing facilities and suppliers alike allow the development and execution to sustain manufacturing processes based on Standardization. Achieving a level schedule doesn't make a lean system, but starts and promotes the reduction of waste enabling the manufacturing system with the mentality of lean concepts.

Taiichi Ohno was the man who did the most to structure the Toyota Production System (TPS) as an integrated framework. Mr. Ohno experimented with various ways of setting up equipment to produce items in a timely manner much like Ford Motor Company's founder, Henry Ford. But he got a whole new perspective on just-in-time production when he visited the United States in 1956. Ohno went to the United States to visit automotive plants, but his most important discovery was the U.S. supermarket. He marveled at the way customers chose exactly what they wanted and in the quantities they wanted. Ohno admired the way the supermarkets supplied merchandise in a simple, efficient, and timely manner.

Ohno describes TPS in terms of a supermarket. Each production line arrayed its diverse output for the following line to choose from, like merchandise on supermarket shelves. Each line became the customer for the preceding line, and a supermarket for the following line. The following line would choose those items needed and only those items, and the preceding 
line would produce only the replacement items for the ones the following line had selected.

This format is a Pull System, driven by the needs of the following lines. It contrasts with conventional Push Systems, which are driven by the output of the preceding lines. Going back to our level scheduling scenario with the dealerships, Ford Motor Company's current system is still the epitome of a Push System. Dealerships are often forced to push vehicles even though customer demand isn't there.

The beautiful supermarket concept also promotes standardization in marketing, packaging, shipping, and production of the product to affect the lowest costs and highest profits. Cost reductions are key and it starts with leaning the production system of wastes - the greatest being over-production.

A quick review of Ford's Louisville Assembly Plant's Body Shop illustrates a push system with much waste in over production, conveyance, and waiting. Illustrating this example again is the hood components after hemming into an assembled hood. The management at Louisville Assembly Plant chooses to hold around 1200 hoods in storage between the hood assembly line and hood install on the manufacturing line: 


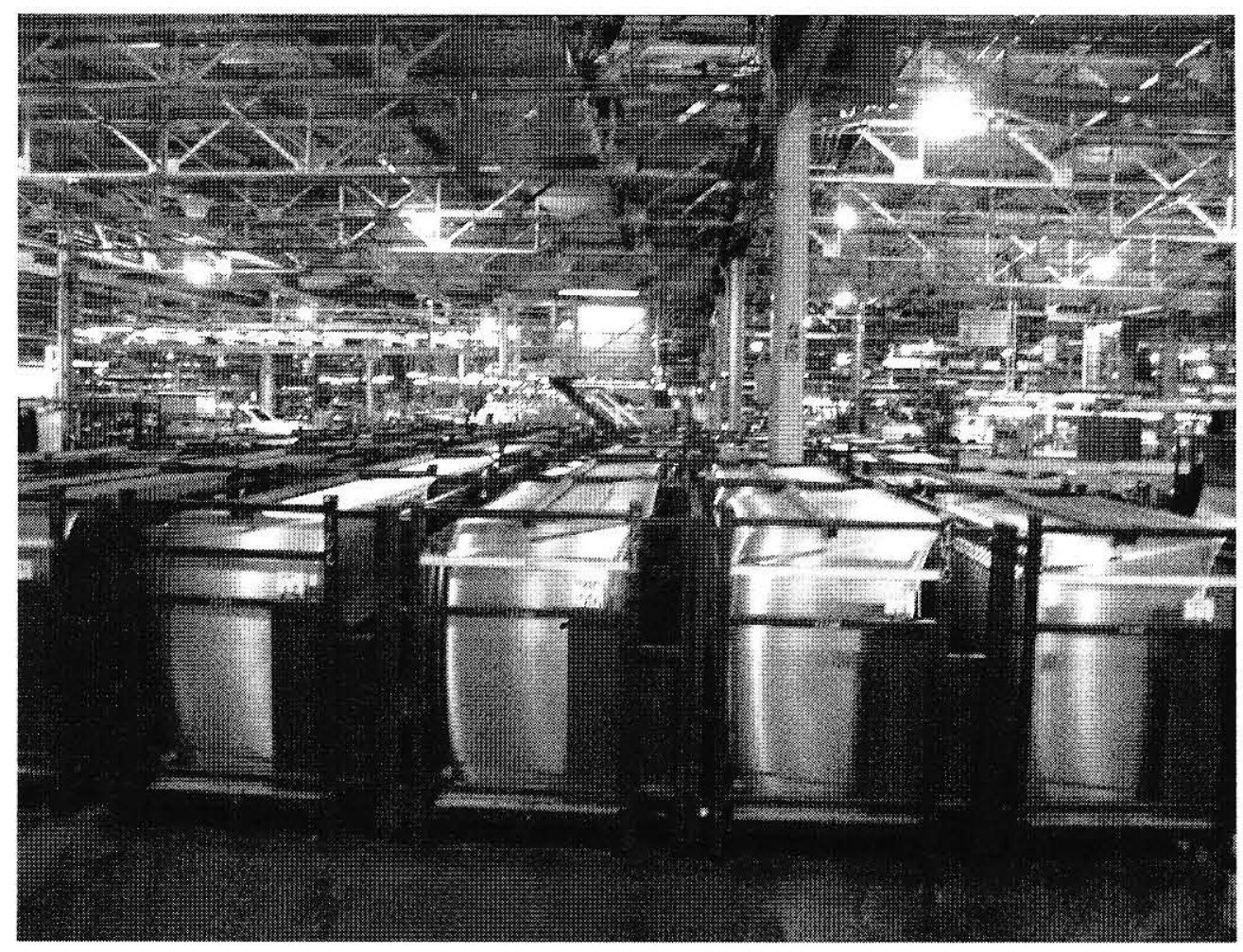

Figure 2 - Assembled Hoods in racks awaiting installation

The Hood Line is capable of running 110 hoods per hour compared with the vehicle assembly line of 80 jobs per hour. This over-speed of the Hood Line leads to the greatest waste noted in the picture above - Over-Production; which leads to the other wastes of Inventory and extra Material Conveyance to move to storage then to production. Keeping a balance of hoods near 1200 per day costs Louisville Assembly Plant around $\$ 81,600$ per week in additional inventory carrying costs, and jeopardizes the ability to move assembled hoods in a First in - First out, queue, fashion. If stock is not rotated in a standardized manner, the ability to problem solve a defect is very difficult if the team doesn't have the when, where, and why a defect occurred.

Understanding a defect and a defect definition starts with the process that an operator has to perform. Ford Motor Company attempts to standardize manufacturing processes as outlined 
in the process database, GSPAS, across the company globally. One of the failures of the system, though, is the lack of training and consistency among process sheet writers. An example of inconsistent process writing:

Element 010 - OBTAIN FENDER FROM RACK

Element 020 - OBTAIN FOUR SCREWS

Element 030 - HANDSTART FOUR SCREWS

Element 040 - TIGHTEN FOUR SCREWS

As compared to this incorrect version:

Element 010 - OBTAIN FENDER FROM RACK

Element 020 - OBTAIN FOUR SCREWS

Element 030 - HANDSTART FOUR SCREWS

Element 040 - OBTAIN NUT RUNNER

Element 050 - SECURE FOUR SCREWS

What's the importance of a verb? Ford's GSPAS system calculates MODAPTS , MODular Arrangement of Predetermined Time Standards, to utilize as a basis for operator work instructions. In the verb "TIGHTEN" MODAPTS calculates the time for an operator to retrieve nut-runner, position nut-runner to screw, trigger nut-runner till torque, and aside nutrunner. In the second series of instructions, Element 040 is redundant and inaccurate on two occasions. First, the verb "OBTAIN" is to procure a part not a tool. Secondly, MODAPTS calculates time from the verb "SECURE" to retrieve nut-runner, position screw to nut-runner, position nut-runner and screw to joint, trigger nut-runner till torque, and aside nut-runner. 
Basically, one of the most common mistakes in process writing is using incorrect verbs. In the example above, if the verb "HANDSTART" is used due to a cross-threading problem, then the verb "TIGHTEN" must be used - "SECURE" cannot be used in this example. The verb "SECURE" is used when a bolt, nut, or screw is placed to the driving implement of the nutrunner and shot in the joint without hand starting first (most operations are completed using "SECURE"). Therefore, a quick audit of many process sheets will show a lack of training and inconsistent process writing by the Manufacturing Engineering staff.

Standardization of process sheets are important in the creation of Operator Instruction Sheets (OIS); which were initially hand-written by operators themselves, but proved so unstandardized in execution and verbiage to the actual work performed as seen in Figure 3 . The new system in place is based directly off the GSPAS process sheets making standardization of language and format critical to quality. The problem: since work elements are not standardized within Ford, OIS sheets attempt to accomplish this without the philosophy to support a lean mentality and continuous improvement. 


\begin{tabular}{|c|c|c|c|c|c|c|c|c|c|c|c|c|c|c|c|c|}
\hline \multirow{2}{*}{\multicolumn{5}{|c|}{ Latisy lle A ssembly Piant }} & \multicolumn{3}{|c|}{ कि. . } & \multicolumn{7}{|c|}{ 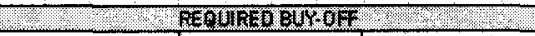 } & \multirow{2}{*}{\multicolumn{2}{|c|}{$\begin{array}{l}2 \\
1\end{array}$}} \\
\hline & & & & & \multicolumn{3}{|c|}{\begin{tabular}{|l|l|} 
a & B 2033 2033 \\
\end{tabular}} & \multicolumn{3}{|c|}{ Suppratior } & \multicolumn{2}{|c|}{ Hoaltis saret } & \multicolumn{2}{|c|}{ En fFonmental } & & \\
\hline & & & & & \multicolumn{3}{|c|}{$80.6 \times 4 \%$} & \multirow{2}{*}{\multicolumn{2}{|c|}{+}} & & \multicolumn{2}{|c|}{ 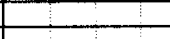 } & 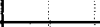 & & \multirow{2}{*}{$\begin{array}{l}1 \\
2 \\
3\end{array}$} & \multirow{8}{*}{ 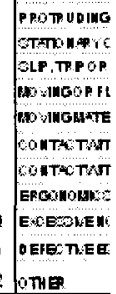 } \\
\hline \multirow{2}{*}{\multicolumn{5}{|c|}{ Operat or listruction Sheet }} & 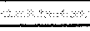 & 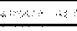 & $\because \cdots$ & & & & & & & & & \\
\hline & & & & & minbon & 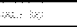 & & & & & & & $\vdots$ & & 1 & \\
\hline & Eop & artmant: is & & & s. & $898 ?: 3.8 \%$ & 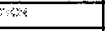 & & & & & & & & 5 & \\
\hline 3.0 & Eons & $16: 2-3030$ & & & & St 50 Loa & aad & & & & & & & & 5 & \\
\hline 5 & & M.pbacts: & \begin{tabular}{l|l} 
reck & sapte \\
\end{tabular} & wescichortics & DetTackm & & GLATITYCHDEK & oucke & Centhat & Sorta & MSLALPACTOA & EkBsterk & ot nic & PTOH & & \\
\hline & & & & Werph ore & & & & & 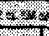 & (3) & $80 . \times 2$ & 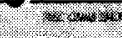 & 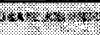 & 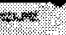 & & \\
\hline & 0 & $=$ & 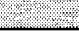 & 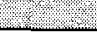 & & & 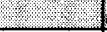 & axis & 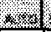 & 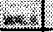 & 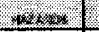 & & 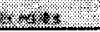 & & & \\
\hline$\frac{1}{30}$ & $\star$ & Start ing & xedirey & iifythet all & light saree & Sanefunc & cetioning & & & & 2 & Sharpedges. & & & & \\
\hline & & pongerty, & diffysenge & yisord arm & risgues im & rediataly. & & & & & & & & & & \\
\hline & & & & & & & & & & & & & & & & \\
\hline & 1 & Pick una & affle \& sn & Dinto the $\mathrm{D}$ & pillarboo & & & & & & & & & & & \\
\hline & & & & & & & & & & & & & & & & \\
\hline$\%$ & 2 & Gotostor & shelf $\& \mathrm{P}$ & ckupseat & belt slide 8 & einforcen & ment plate & & & & & & & & & \\
\hline & & & & & & & & & & & & & & & & \\
\hline & 3 & Take all $p$ & ts to fixtu & e Hi \& load & & & & & & & & & & & & \\
\hline & & & & & & & & & & & & & & & & \\
\hline & 4 & Stepouto & fixture $\&$ & ress the bla & ack palmb & thon to cy & ycle & & & & & & & & & \\
\hline & & & & & & & & & & & & & & & & \\
\hline & 5 & Gotothe & ck \& pick & upthe $D$ pill & Ntar irner & & & & & & & & & & & \\
\hline & & & & & & & & & & & & & & & & \\
\hline & 6 & Put Dpilla & irnerinto & fixtune \#2 & & & & & & & & & & & & \\
\hline & & & & & & & & & & & & & & & & \\
\hline & 7 & Stepout o & fixture \& & it runbutto & & & & & & & & & & & & \\
\hline & & & & & & & & & & & & & & & & \\
\hline & 8 & Repeat tro & $n+1$ & & & & & & & & & & & & & \\
\hline & & & & & & & & & & & & & & & & \\
\hline & 9 & Pushstoo & re-order & xtton wten & 1 st piece & remaved & d fornthe & & & & & & & & & \\
\hline & & container & or if stock & alls below & 30 mirute & supply. & & & & & & & & & & \\
\hline & & & & & & & & & & & & & & & & \\
\hline & 10 & Notifysu & avizor or & plitu leade & arif wrong & took is pli & acedonth & & & & & & & & & $=$ \\
\hline & & operation & & & & & & & & & & & & & & \\
\hline & & & & & & & & & & & & & & & & \\
\hline & & & & & & & & & & & & & & & & \\
\hline & & & & & & & & & & & & & & & & \\
\hline & & & & & & & & & & & & & & & & \\
\hline & & & & & & & & & & & & & & & & \\
\hline & & & & & & & & & & & & & & & & \\
\hline & & & & & & & & & & & & & & & & \\
\hline & & & & & & & & & & & & & & & & \\
\hline & & & & & & & & & & & & & & & & \\
\hline & & & & & & & & & & & & & & & ry & 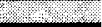 \\
\hline & & & & & & & & & & & & & & & as: & Artect \\
\hline & & & & & & & & & & & & & & & & Opora \\
\hline & & & & & & & & & & & & & & & $\infty$ & \\
\hline & 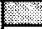 & (3) & \% & 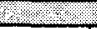 & 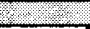 & (2) & Find & & & & & & & & $\%$ & \\
\hline (x) & & PERXOWA & IIIII) & - & 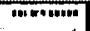 & situl & anoriminat & $=11$ & & min & onem & Paten & 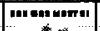 & ravese & का & \\
\hline (2) & & POTE:TIE & 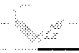 & $r^{2} x^{2}$ & 数: & & 1) & - & & 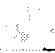 & & $\%$ & $8 \%$ & & & onent tie jeb \\
\hline
\end{tabular}

Figure 3 - Assembler written Operator Instruction Sheet from Louisville Assembly Plant 
Ensuring correct verbs within process sheets is an absolute must if improvements in "Standardized Work Elements" can ever happen at Ford Motor Company. The current system to "Balance a Line" is the old tried and true stopwatch. The problem of the stopwatch is that it doesn't take into account the level of effort of a particular element, but based on how fast one worker completes the designated tasks and then attempts to set a standard based this worker. The real problem comes into play when a "ringer" is positioned on a job to set up a job a fast rate, then pulled from the job after a period of time causing those positioned on the job afterward to struggle causing quality defects and through-put concerns. MODAPTS is not subjective and takes the stopwatch out of the calculation of production standards, improving employee relations while adding objectivity to standards. No longer will you discuss how fast a particular person is working during a time study, because MODAPTS requires no performance rating.

Unfortunately, the current system uses performance rated stopwatch evaluations to set up jobs making the job to standardize work elements a virtual impossibility. Without creating standardized work elements the results are manufacturing process instabilities and inconsistent part quality. Strict adherence to process standards promotes structured problem solving and allows operators and suppliers alike to readily identify variations in the process and parts. With a lack of standards, or a culture that commonly promotes deviations from a standard, a supplier cannot easily control process stability or part quality. 


\section{Structured Problem Solving:}

A problem is a deviation from a standard! Customer Satisfaction improvements mean the reduction or elimination of problems. To accomplish elimination of problems, Structured Problem Solving events must occur. The current methodologies to structured problem solving involve the use of specialized training with 6Sigma by certified Black Belts and Green Belts, and the Global 8D (eight disciplines) process. Louisville Assembly Plant employs four full-time Green Belts to assist in problem resolution. The Green Belt positions are an added job classification to the UAW-Ford agreement bringing the total number of unskilled classifications to fourteen. This is an important fact emphasizing UAW core values that an assembler's job is to assemble parts, not problem solve. Problem solving is then left to the classification of the Green Belts.

Personnel with the job classification of Inspector are charged to find problems as seen in Figure 4. However, there are many instances where Ford implements poka-yoke devices or systems into the process, especially if they are critical. Examples: correct door hinges, DC nut-runners with feedback tied to the manufacturing line, and vision systems inspecting for the correct part or attribute.

However, to be truly lean and employ good structured problem solving techniques, inspection must occur at the operation - called informative inspection. 


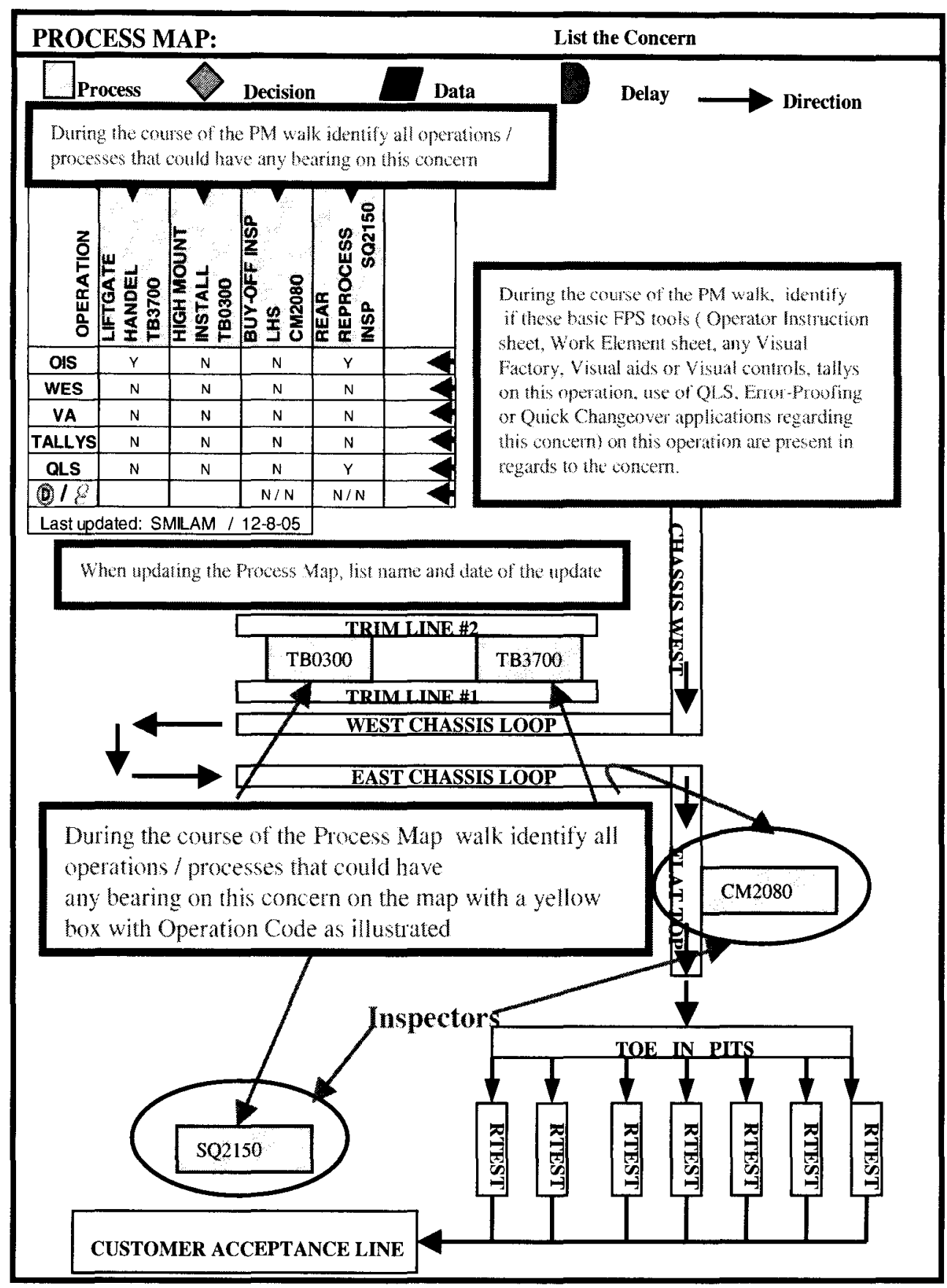

Figure 4 - Current State Process Map

In this process, installation of the Center High Mount Stop Light (CHMSL) is inspected at the end of the Chassis Line and in Pre-Delivery with the installation process occurring several hours prior in the Trim Area and far from the point of operation. 
This type of inspection is called Judgment Inspection and engages in the practice of statistical quality control (SQC) with inputs by the inspectors into a computerized tracking system.

Unfortunately, only the defect is tracked, but not what causes the defect. For this, a Black Belt or Green Belt is called in to assess and correct the problem. This system is hardly lean resulting in the wastes of motion, correction, and over processing. Again, this type of inspection does not occur at the operation where the defect can readily be seen and a corrective action or containment performed prior to advancing to the next operation. The end effect is quality defects that go unnoticed end up at the customer raising warranty costs and decreasing customer satisfaction.

Using the assembled hood example again, the biggest in-plant containment actions for LAP's Body Shop are hood fit problems. Hood fit issues are attributed to several factors: hood inner shape and hood outer trim flange lengths, assembled hood storage methodology and storage time. There are basically four distinct points around the hood at the four corners that are deemed critical to customer satisfaction. Understanding the factors through Structured Problem Solving techniques is essential in to improving customer satisfaction. The analysis is discussed in the next section.

\section{Customer Satisfaction:}

Customer satisfaction is critical to the end goal of increasing profits. Maintaining customer satisfaction is an absolute must in this competitive world market; which gives no advantages to new vehicles. The demanding consumer base expects world-class quality right from the gate. Unfortunately, Ford Motor Company lags far behind its competitors from an initial launch Global Quality Reporting System survey shown in Figure 5. 


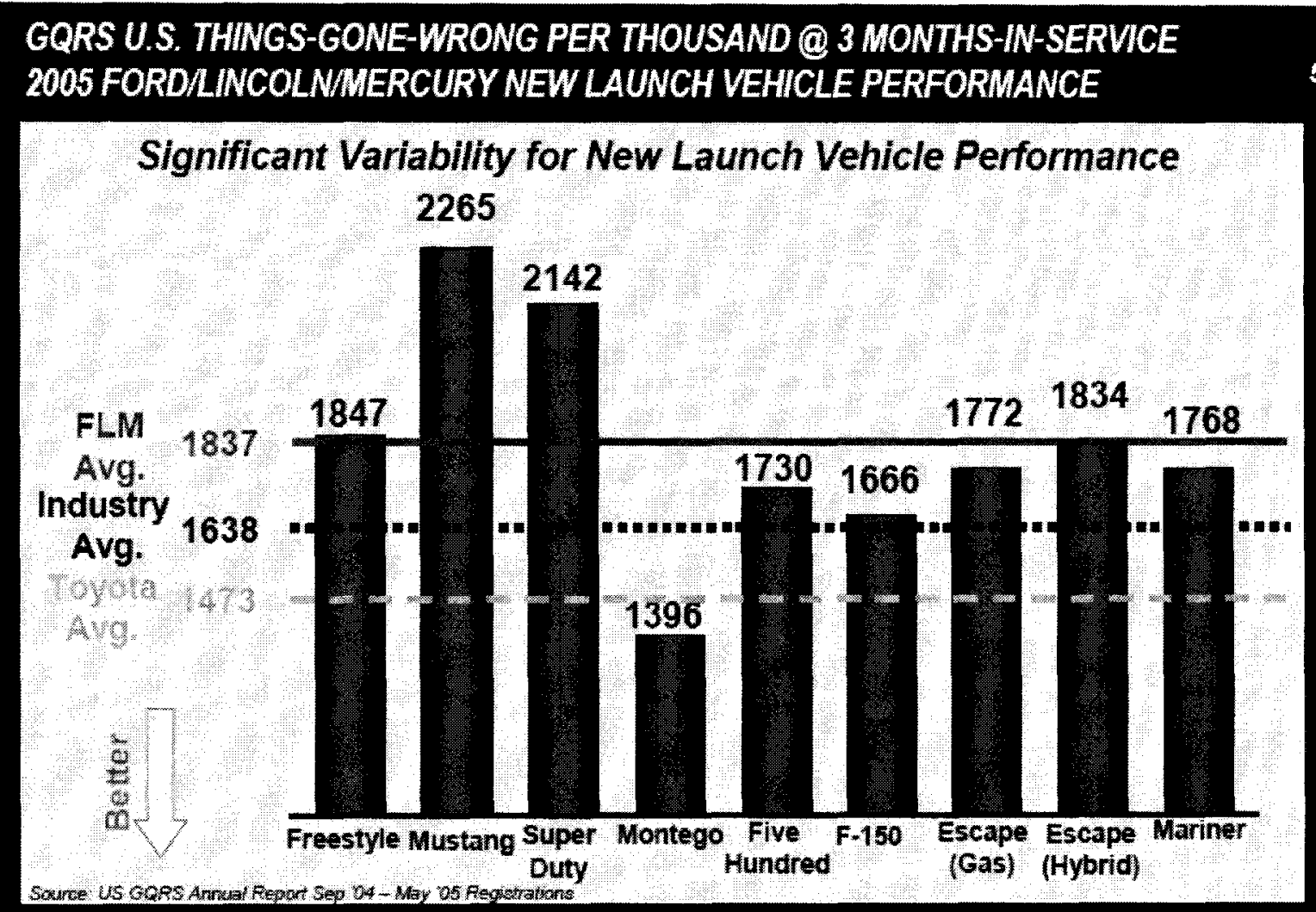

North Ameica Qualty Summit, January 31, 2006

Figure 5 - GQRS TGW/1000 for new Launch Vehicle Performance 2005

Ford Lincoln Mercury (FLM) is almost $400 \mathrm{TGW} / 1000$ worse than the class leaders Toyota and Honda. 


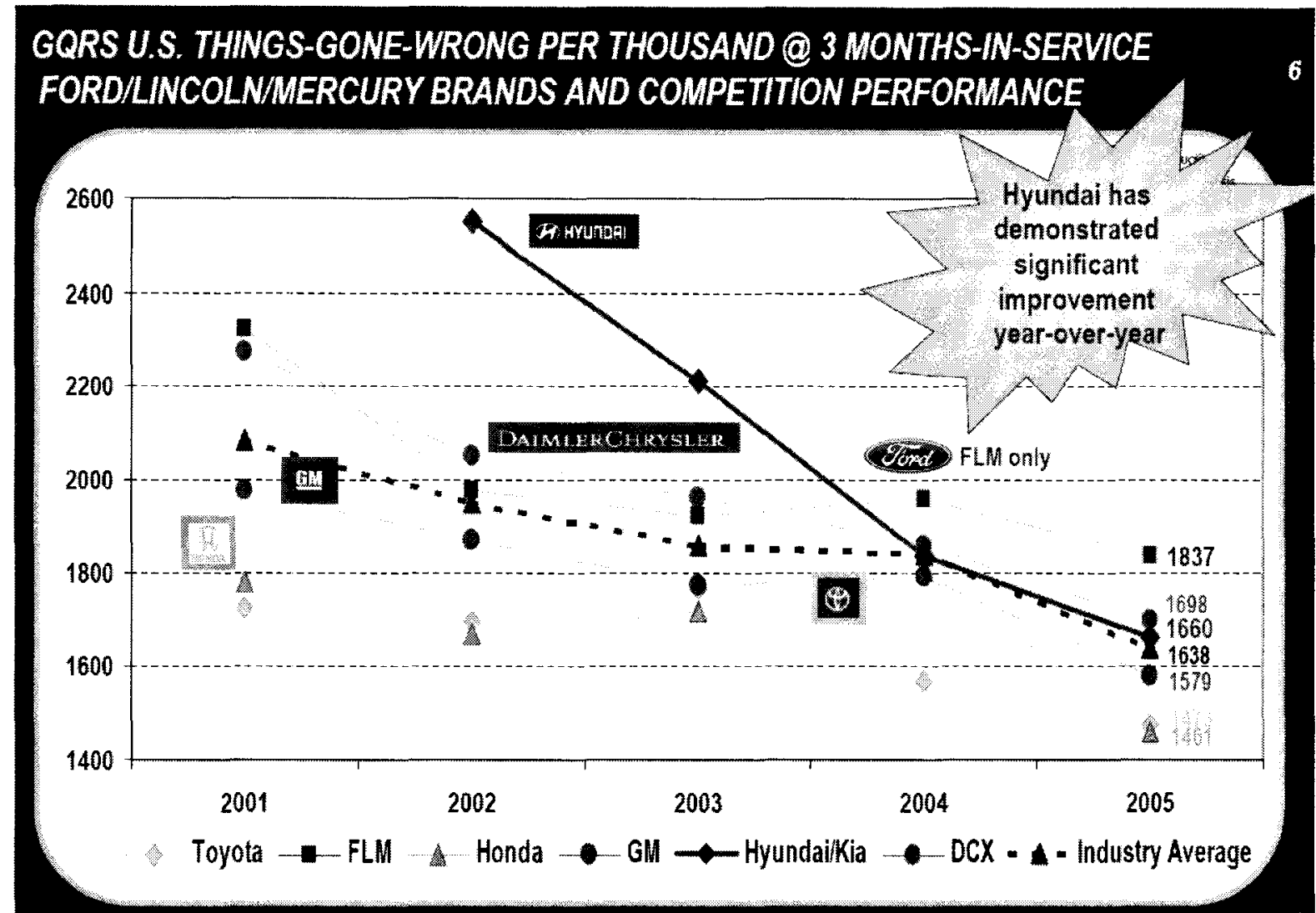

North America Quality Summit, January 31, 2006

Figure 6-GQRS TGW/1000 Five-Year Trend Chart

This figure shows that in the last five years, Ford Motor Company has made approximately $500 \mathrm{TGW} / 1000$ improvement, but still lags significantly behind its competitors.

The lack of significant improvement to keep pace with industry leaders Toyota and Honda, according to Anne Stevens, Executive VP, The Americas, Ford Motor Company [16]:

\section{Reality on Quality}

1 Key to our products' success in the marketplace is competitive quality:

- Some improvements have been made, but Ford still lags the competition 
- Our competitors have the same processes we do - the difference is their execution strategy

2 Execution is the key to our success

\section{Practices and Behaviors Resulting in our Current State}

1 Lack of focus on the containment of issues and the implementation of permanent corrective actions on things that matter most to the customer

2 Absence of cross-functional alignment on top customer driven concerns

3 Lack of process discipline, accountability, and enablers in place to deliver vehicles that are better than out-going models

4 We rely on customers to find issues - instead of utilizing less costly internal methods

The two most important bullet points from Anne Stevens are that our competitors' execution strategy is different, and a lack of process discipline. In the next chapter, a " 5 Why" drill down will help explain the lack of manufacturing continuous improvement, and highlight why the Japanese automakers are enjoying their current day advantage. 


\section{E. Profitability:}

Ford Motor Company is experiencing profitability problems in its North American

Automotive Operations for the last several years. For 2005, Ford's North America automotive operations reported a pre-tax loss of $\$ 1.6$ billion. The full report is outlined in Appendix D.

A quick review of last year's stock market value trend, Figure 7, shows an unsustainable trend or any form of improvement, and this can be attributed to lack of customer satisfaction and consumer confidence in the real or perceived quality of Ford Motor Company's products.

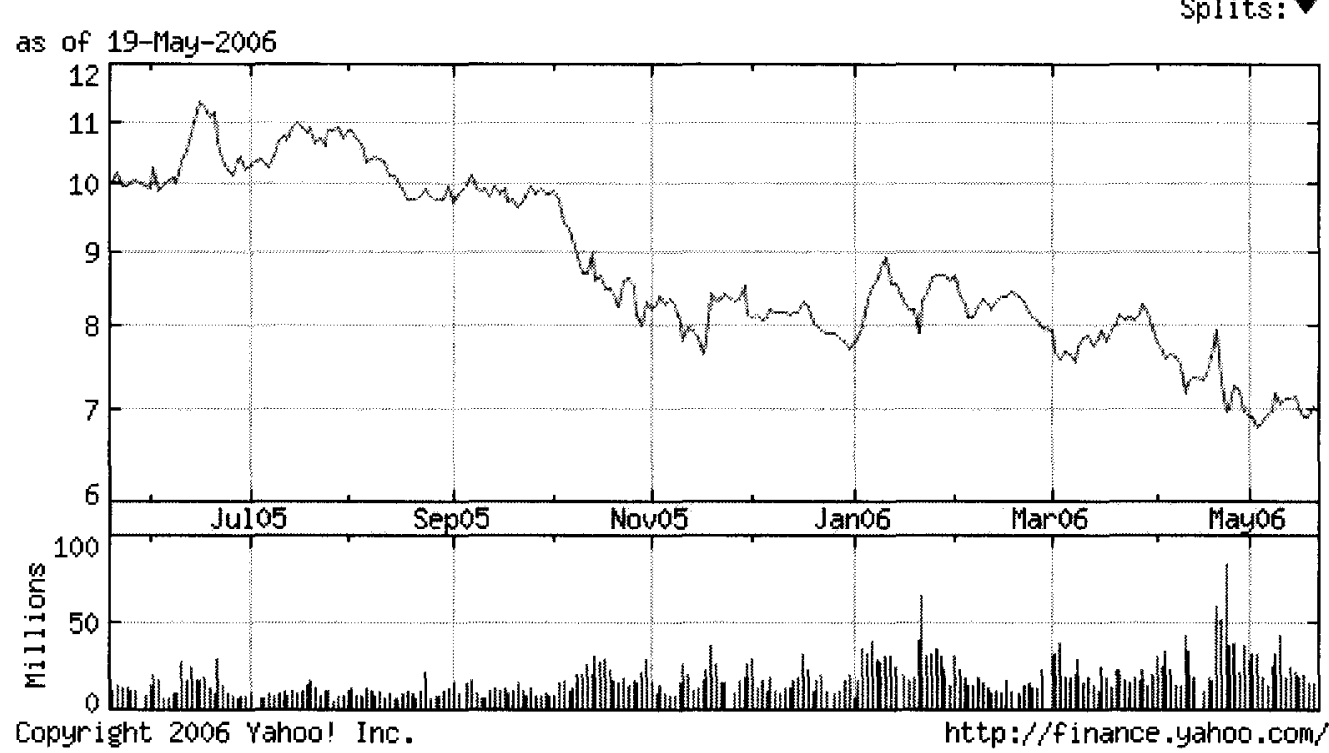

Market Cap (intraday):

$\$ 13.19 \mathrm{~B}$

Total Cash (mrq):

$\$ 19.15 \mathrm{~B}$

Total Debt (mrq):

$\$ 151.10 \mathrm{~B}$

Operating Cash Flow (ttm):

Shares Outstanding:

$\$ 10.60 \mathrm{~B}$

$1.88 \mathrm{~B}$

Figure 7 - Ford Motor Company's 6 Month Stock Valuation Trend Chart 


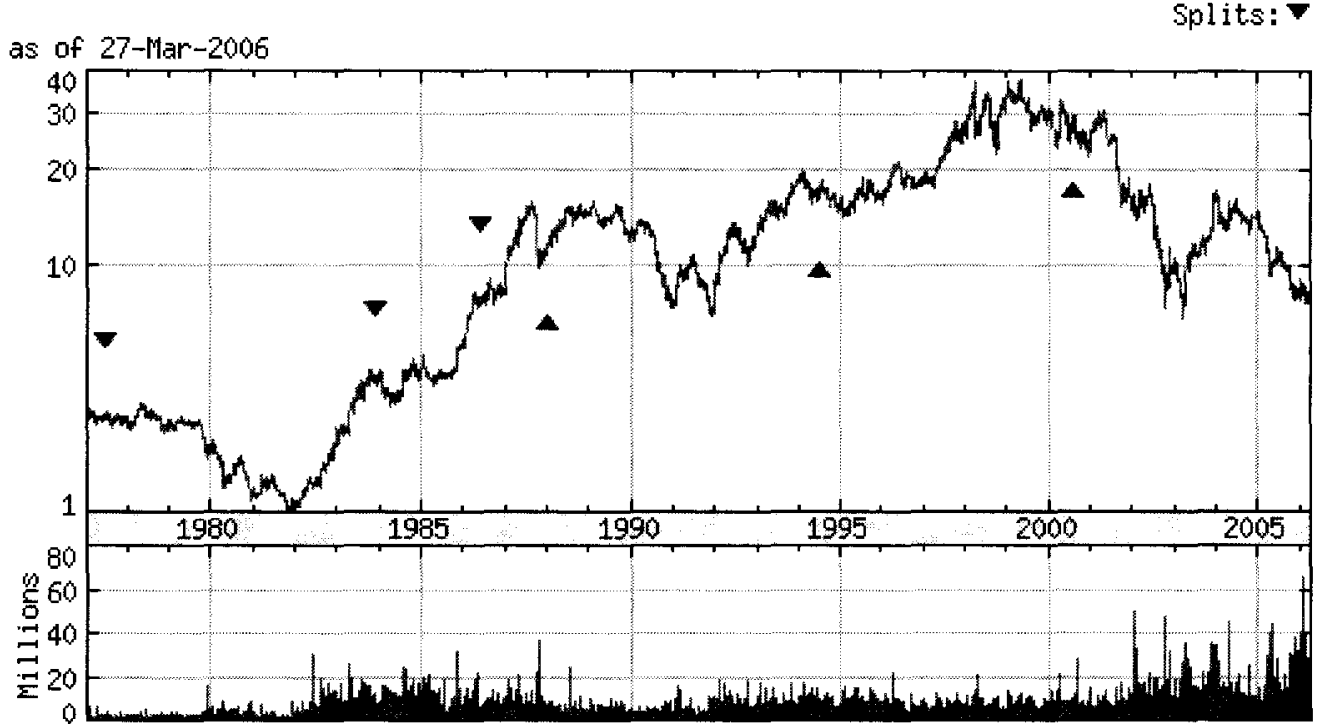

Copyright 2006 Yahoo! Inc.

http://finance .yahoo.com/

Figure 8 - Ford Motor Company's 30 year Stock Valuation Trend Chart

Higher stock price allows a company more capital to work with to invest in research and development, new products, or improving manufacturing facilities to a leaner system. Most of Ford's assembly plants are in need of significant capital investments to update the manufacturing equipment to truly flexible systems. Current manufacturing systems are capable of only building one basic model with brand variations, i.e. Explorer and Mountaineer. 


\section{Chapter III: Process to Sustained Success - The Proposal}

\section{A. Profitability:}

Why are we here? Only one answer exists - To Make Money. There is no other altruistic point being in business. Understanding how an enterprise becomes more profitable a review of the industry leader's financial performance as a comparison to Ford Motor Company's performance is the first step.

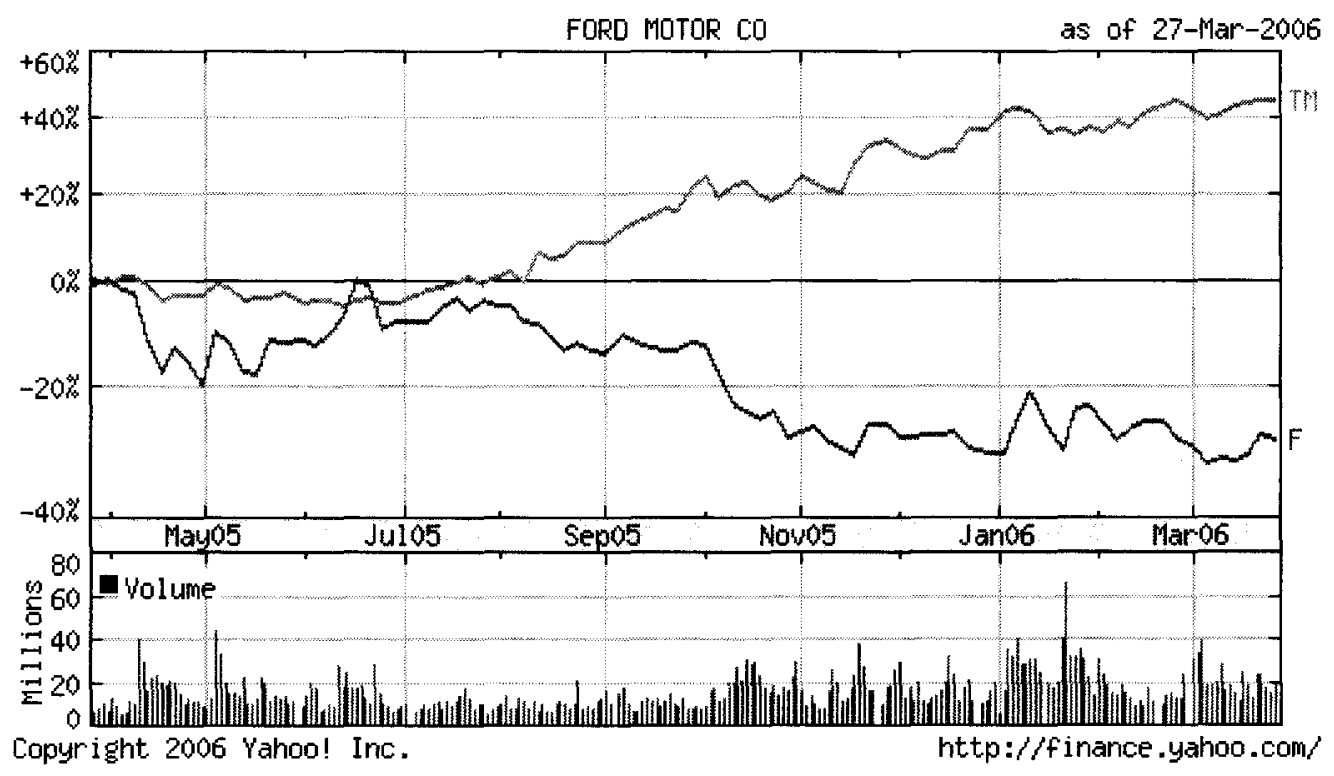

$\begin{array}{lcc} & \text { Ford Motor Company } & \text { Toyota Motor Manufacturing } \\ \text { Last Trade: } & \$ 7.03 & \$ 109.91 \\ \text { Market Cap (intraday): } & \$ 13.19 \mathrm{~B} & \$ 178.15 \mathrm{~B} \\ \text { Total Cash (mrq): } & \$ 19.15 \mathrm{~B} & \$ 20.19 \mathrm{~B} \\ \text { Total Debt (mrq): } & \$ 151.10 \mathrm{~B} & \$ 93.12 \mathrm{~B} \\ \text { Operating Cash Flow (ttm): } & \$ 10.60 \mathrm{~B} & \$ 22.53 \mathrm{~B} \\ \text { Shares Outstanding: } & 1.88 \mathrm{~B} & 1.62 \mathrm{~B}\end{array}$

Figure 9 - One Year Trend Stock Price Valuation Comparison - Ford to Toyota 


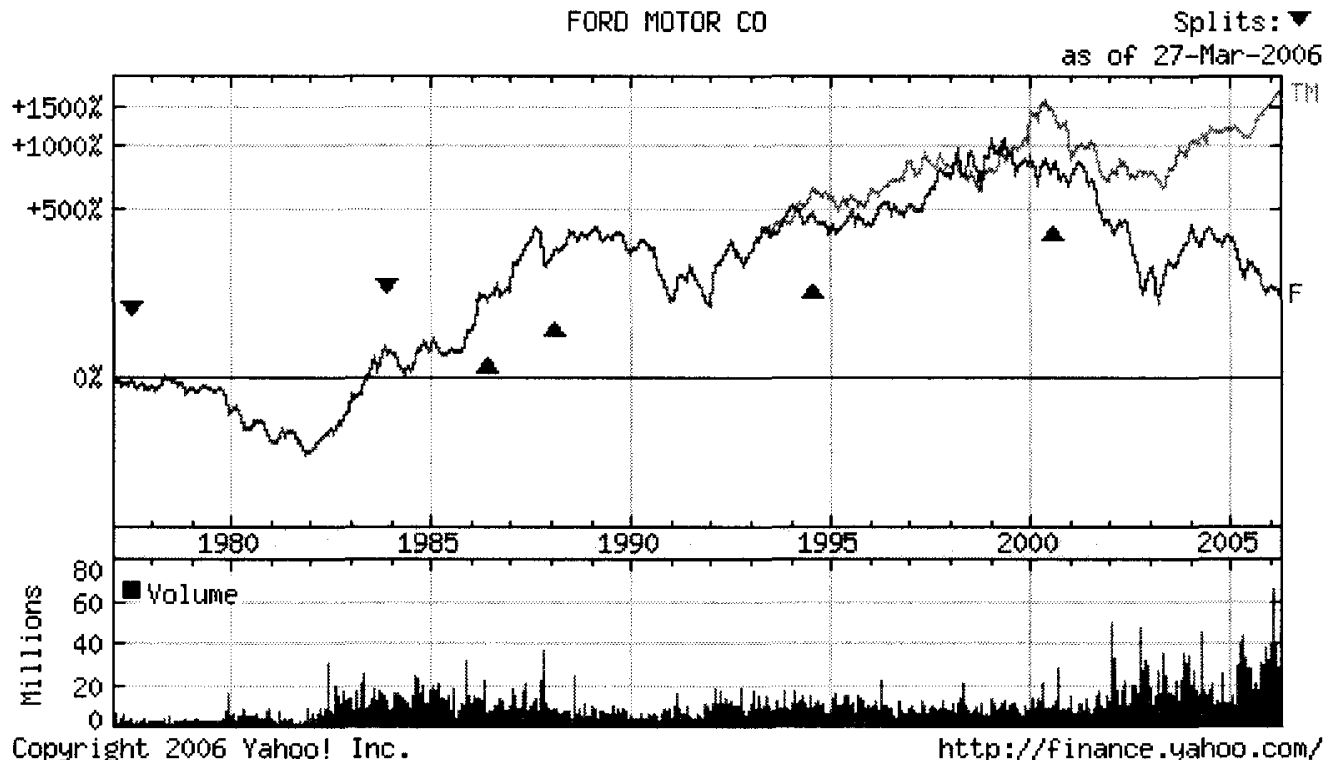

Figure 10 - Ten Year Trend Stock Price Valuation Comparison - Ford to Toyota

The stock price gap between Ford and Toyota increased dramatically in the last five years because of 'Toyota's adoption of TPS or lean manufacturing principles through necessity over 50 years ago. Over the last 50 years, Toyota has nurtured its Toyota Production System in the elimination of waste and thereby raising quality. Improving quality and keeping costs down through waste elimination produces greater customer satisfaction and profits. The stock price trend chart in Figure 10 is an outcome and reward the illustrates Toyota's continuous improvements, while at the same time demonstrating Ford's lack of continuous improvement and sustainability in customer satisfaction measured by lost stock price.

The best way to accomplish this is by implementing a total cost accounting strategy and getting away from the "Task" based strategy that doesn't promote continuous improvements in quality. The philosophy that elimination of all wastes is essential to all business and manufacturing decisions is imperative to increasing customer satisfaction and greater profit returns. 


\section{B. Customer Satisfaction:}

To improve the business bottom line give customers the products they want with the quality they expect at reasonable costs delivered on time. Companies that are more efficient than their competitors in providing customers with high-quality goods and services will thrive. Those that are less efficient than their competitors will parish. The globalization of markets means customers don't have to accept anything less.

Toyota has been able to sustain its increasing trend in share value, customer satisfaction, and automotive market share. By fostering TPS over the last 50 years, "Management and labor have developed an intrinsic trust between each other, which has only deepened over the years. Management has rewarded employees for productivity gains with improved compensation and working conditions. Employees have taken the initiative in activities for raising efficiency and otherwise enhancing the company's competitiveness." [17] In addition, Toyota understands the fundamental principle for reliability is to avoid changing the conditions of a good design. Example: my wife's 1993 Toyota Camry has the exact same steering wheel, cruise control system, window and door lock controls, door handles, and park brake lever to name a few items as Toyota's 2006 4Runner. Take a good design, keep it, and apply kairen along the way.

Ford has not been able to make that leap in improvements to keep up with the competition. According to Anne Stevens' point shared in the last chapter, "Our competitors have the same processes we do - the difference is their execution strategy." To understand how Ford must improve look at Ford's history and ask the Five Why's.

Why was Ford dominant in the early 1900's? Henry Ford's emphasis was on manufacturing 
efficiency.

Why the lack of continuous improvement? Focus shift to product development and lost emphasis on manufacturing continuous improvements.

Why the shift to product development? The adoption of Modern Business Principles

by Ford's management team focused the philosophy to product development.

Why adopt "Modern Business Principles"? At the time, Ford's accounting system was in shambles and needed a shake up with good cost accounting. Fortunately, the government made this an easier task by controlling the price of steel. In addition, after WWII, attention turned to designing the cars people wanted - stylistic cars and in large quantities.

Why develop stylistic cars in large quantities? At the time, American's demand was over-whelming for vehicles as new interstates were built, and the United States expanded to sub-division life styles. At the same time, there was no outside competition since WWII decimated most of Germany and Japan's manufacturing facilities.

Japan in contrast after WWII had miniscule production volumes per model, which did not allow Japanese automakers the luxury of using specialized equipment for each model. Nor did they allow stocking huge inventories of parts. In essence, Japanese automakers had to be lean to survive. To survive, Toyota developed its' Toyota Production System and implemented it across all functions in its company starting with its manufacturing system over to product development good design reviews that emphasize discovery of undetected problems caused by intentional or incidental changes. 
The Toyota Production System supports productivity gains by highlighting waste and engenders quality gains by illuminating problems when and where they occur. In other words, by moving from Judgment Inspection to Informative Inspection - inspection at the process quality and customer satisfaction gains are made.

Ford concentrated more on mass production of stylistic vehicle that were more works of art at times, but lacked manufacturing techniques to continuously improve a design or manufacturing process. This attitude still exists today at Ford Motor Company.

\section{Structured Problem Solving:}

To give customers what they want and expect, we must identify and understand variations in our processes and parts and use structured problem solving events to eliminate problems and waste.

At Ford and Toyota alike, machines are equipped to detect production problems and shut down immediately when one occurs, indicating where and what type of problem it is on a marquee board or other display. According to Shingo Shigeo, "At Toyota, however, the most important issue is not how quickly personnel are alerted to a problem, but what solutions are implemented." [18]

Revisiting the hood fit problem at Ford's Louisville Assembly Plant, four factors contribute to the degradation of hood quality during the process: Hood inner shape, hood outer flange length, storage method, and storage time. Using these factors in a Structured Problem Solving technique called Design of Experiments (DOE), we are able to find which factors are critical, and the interactions between the factors given the response variable of hood deflection at 
customer defined specific points around the hood:

$\Delta \mathrm{Y}($ Hood Deflcction $)=F(X)=$ function of $(A=$ Inner Shape, $B=$ Outer lilange, $C=$ Storage Time, \& $D=$ Storage Mcthod $)$

Factors:

- A - Inner Panel Shape at rear corners (current vs. $1 \mathrm{~mm}$ above nominal)

- B - Outer Panel Flange Length (current vs. 3mm short)

- $\mathrm{C}$ - Storage Time (Panels measured within $15 \mathrm{~min}$ of hemming vs. $24 \mathrm{hr}$ hold)

- D - Storage Method (Panels stored Vertically vs. Horizontally)

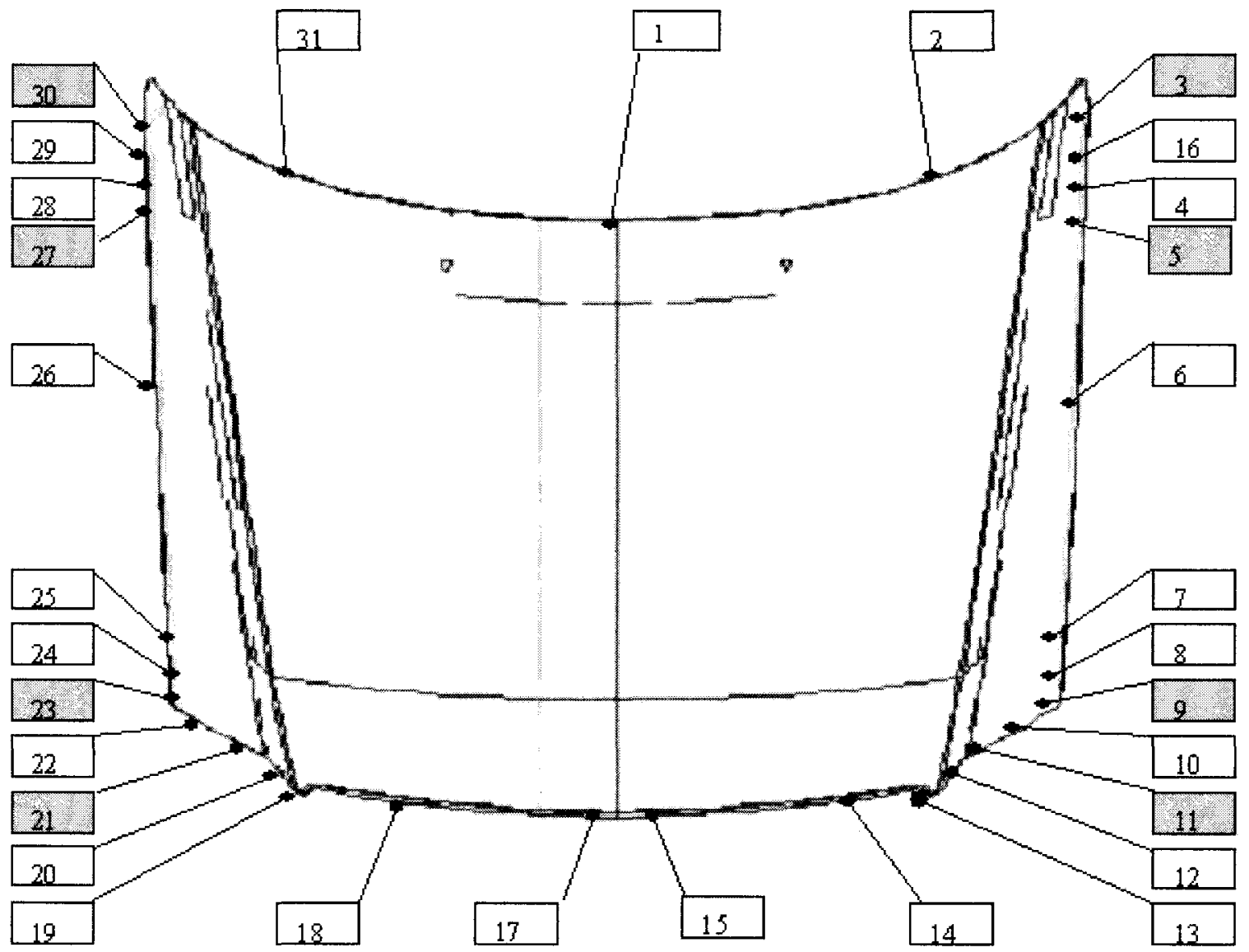

Figure 11: 2006 Explorer Hood Significant Characteristics for Quality

In Figure 11, points 3, 9, 23, and 30 around the hood are deemed the most critical to customer satisfaction based on warranty analysis and other quality indicators such as JD Powers report and Global Quality Reporting System (GQRS) for craftsmanship. Evaluating around points 3, 
9, 23, and 30 for this exercise and using a 4 factor, 2 level DOE the results are computed using

Minitab:

Response is sheet metal deflection from nominal on hood Pt a3:

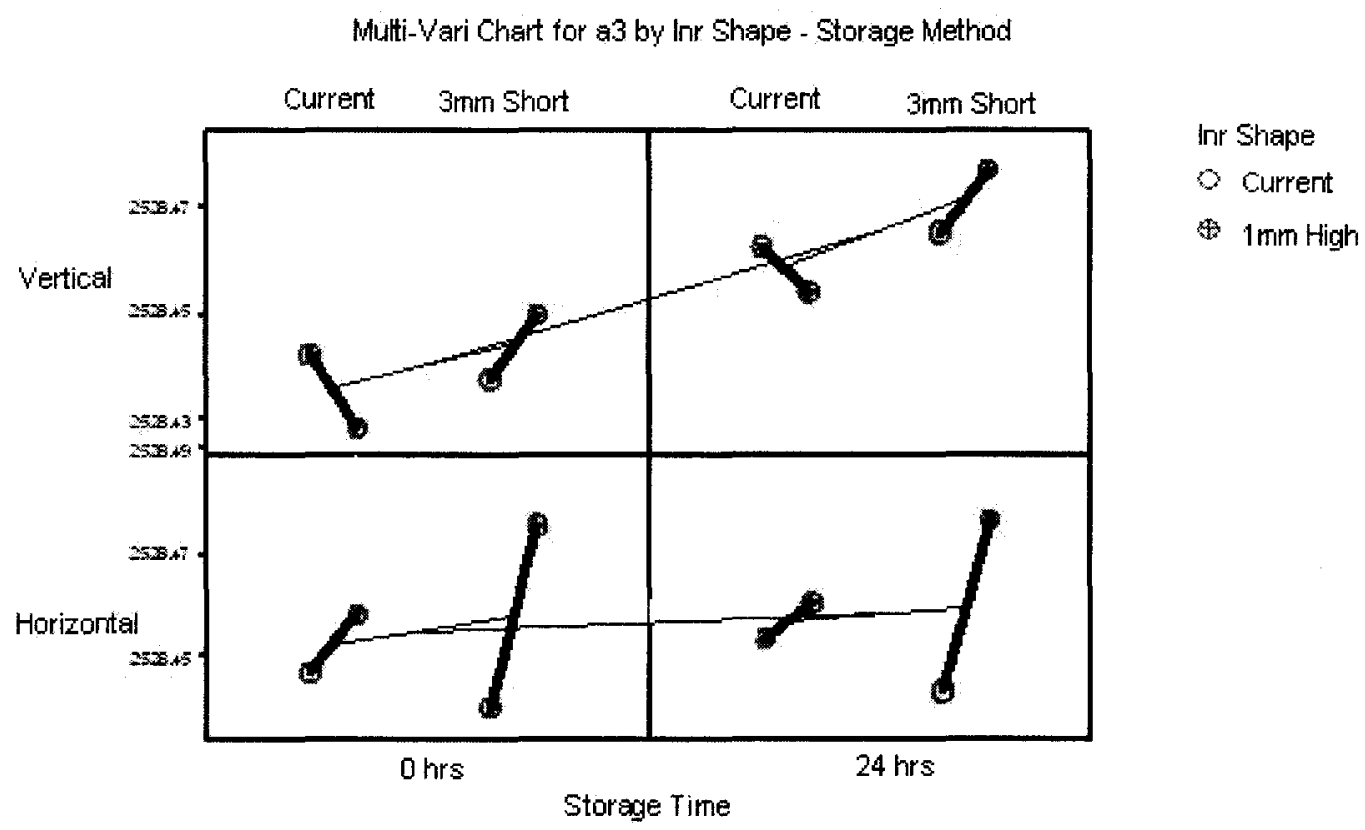

Main Effeots Plot - Data Means tor a3

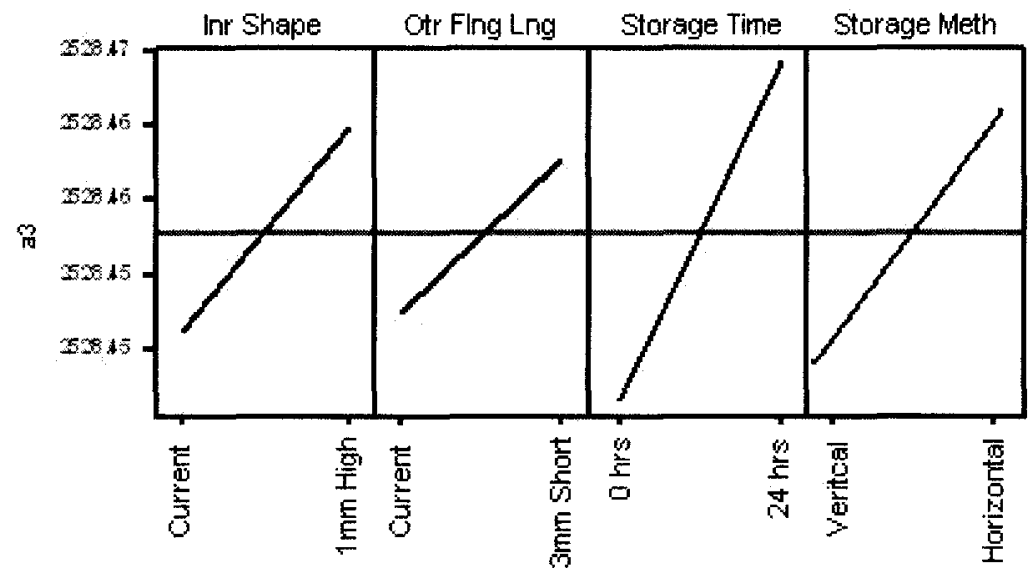

Figure 12: DOE results for Pt a3 around 2006 Explorer Hood 
Response is sheet metal deflection from nominal on hood Pt a9

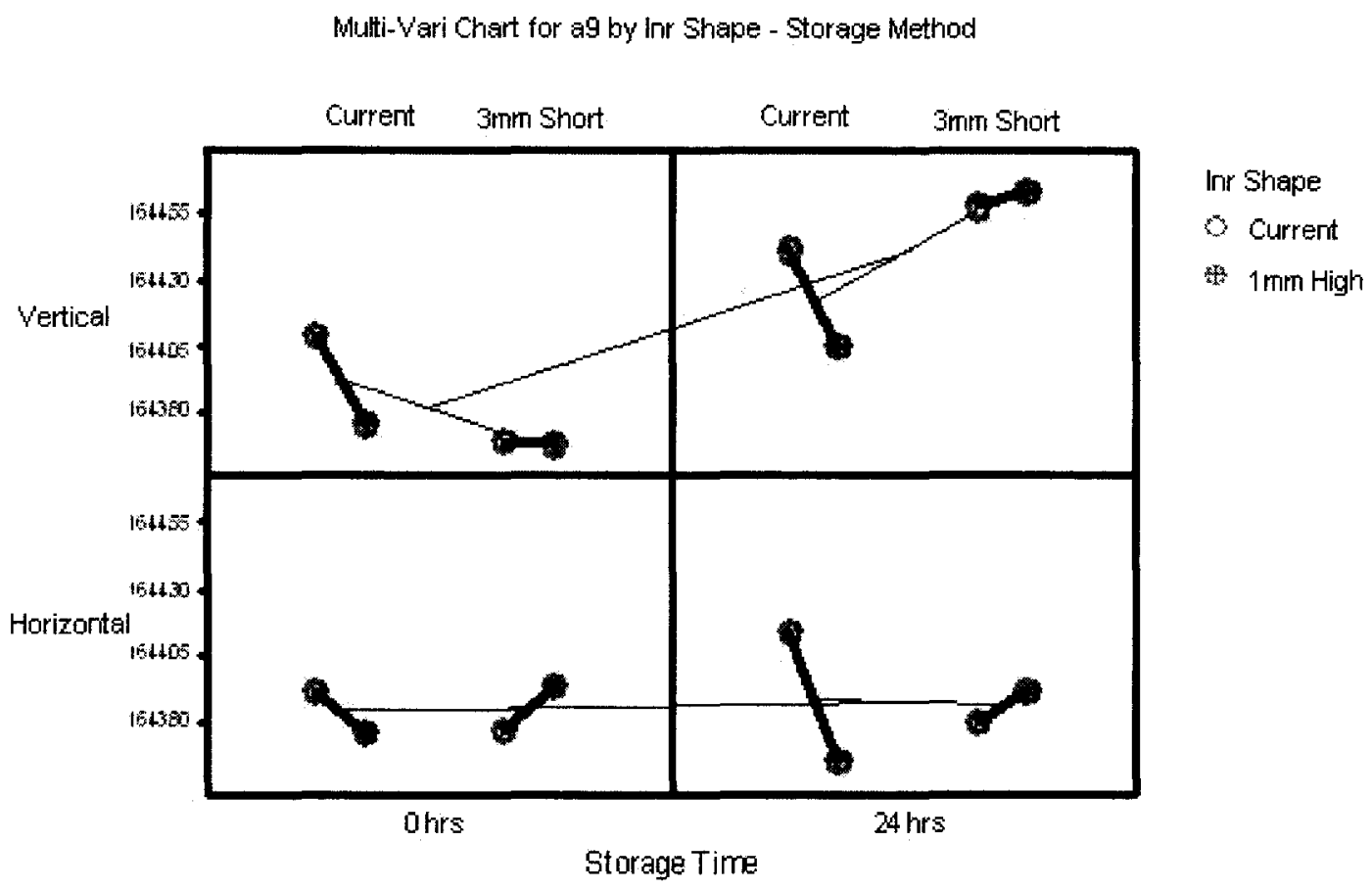

Viain Effects Plot - Data Means for ag

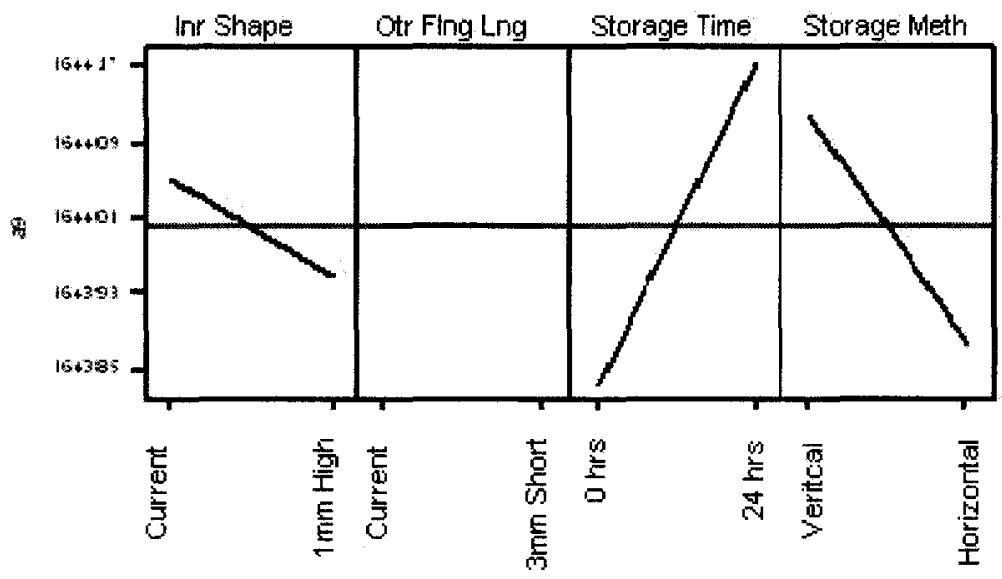

Figure 13: DOE results for $\mathrm{Pt}$ a 9 around 2006 Explorer Hood 
Response is sheet metal deflection from nominal on hood Pt a 23
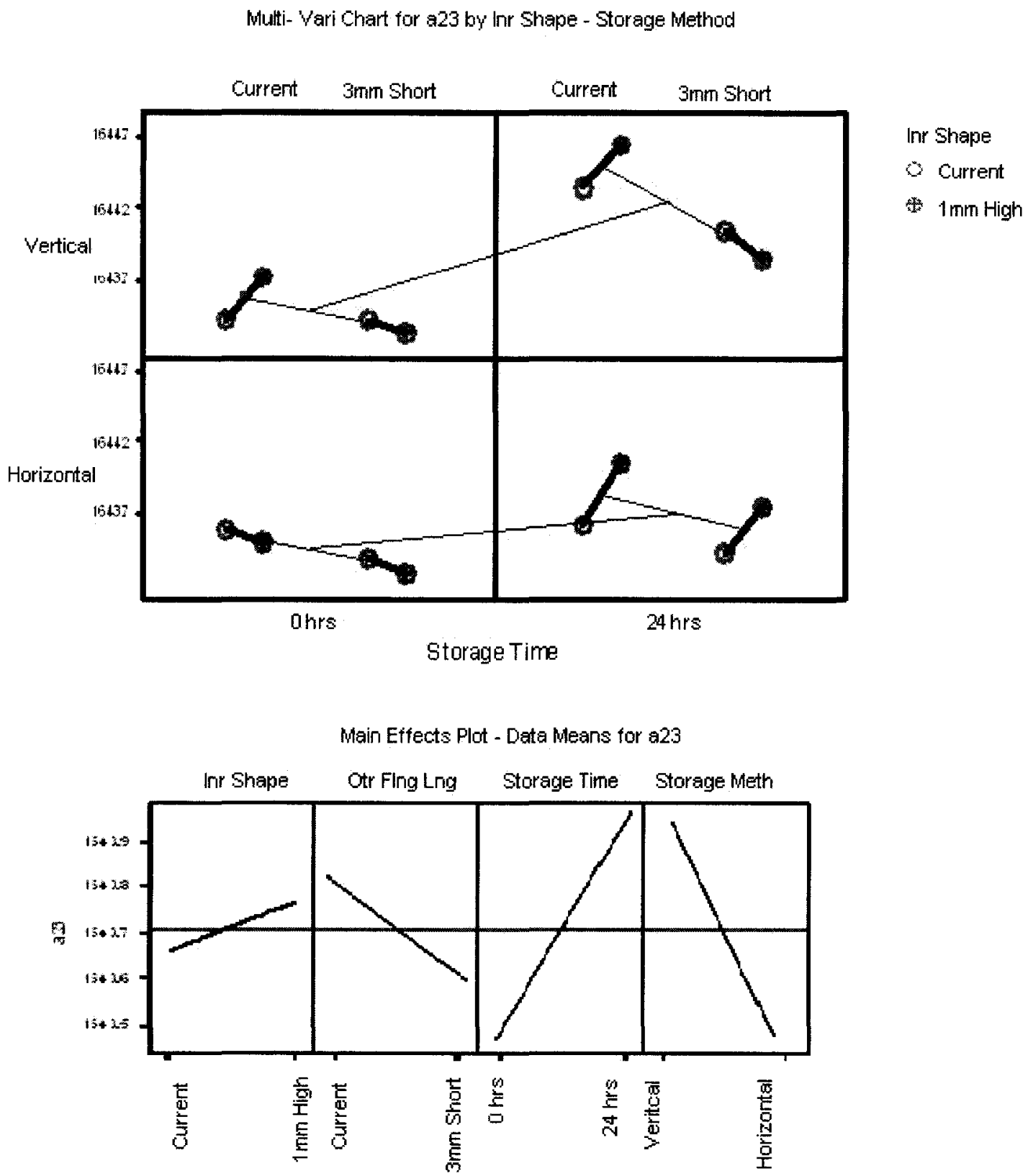

Figure 14: DOE results for Pt a23 around 2006 Explorer Hood 
Response is sheet metal deflection from nominal on hood Pt a30

Multi-Vari Chart for a30 by inr Shape - Storage Method

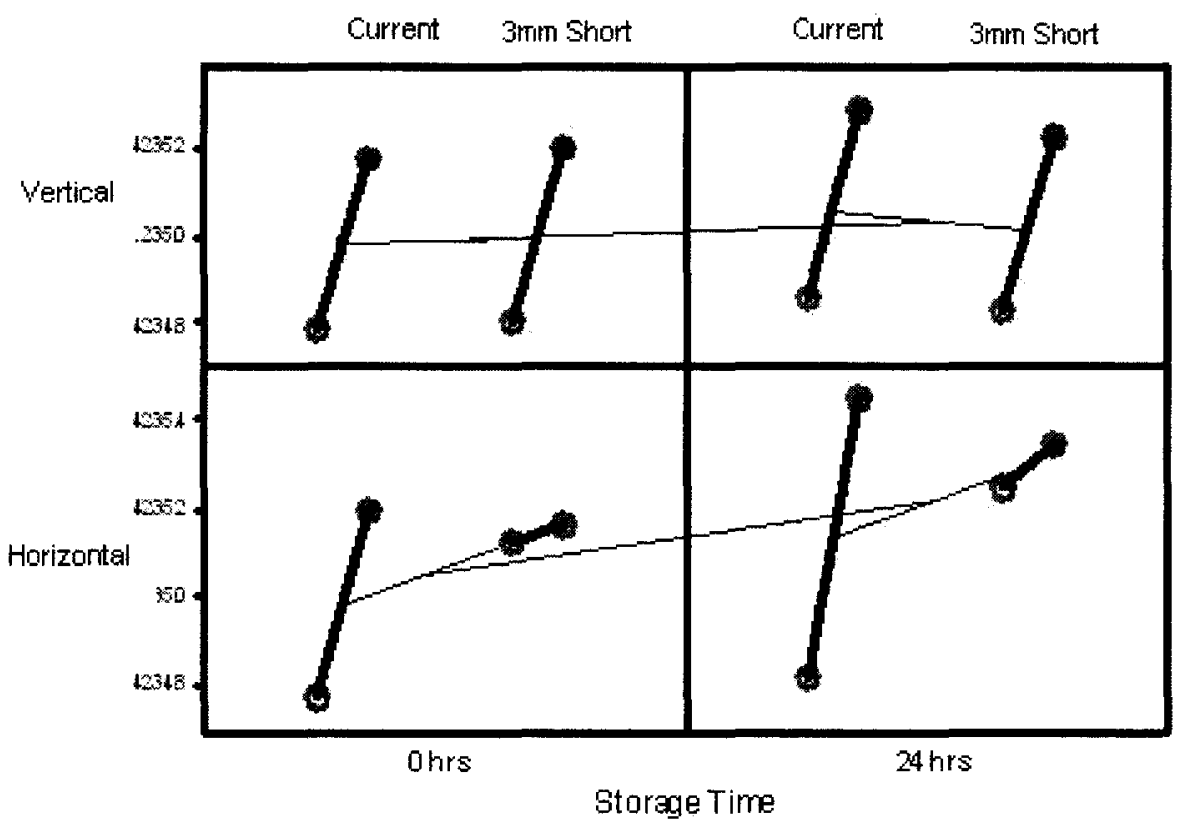

Inr Shape

$a$ Current

$1 \mathrm{~mm}$ High

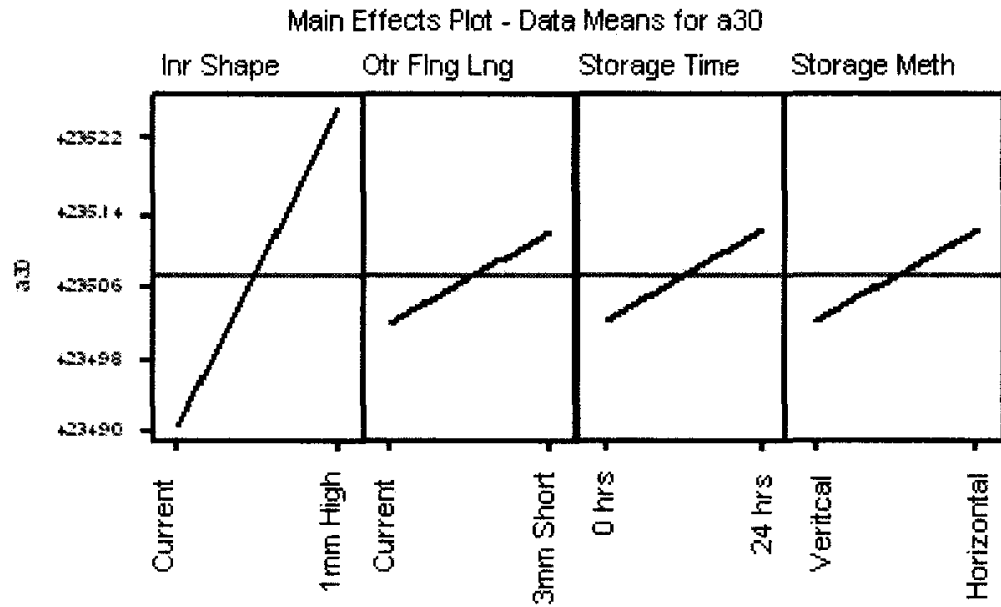

Figure 30: DOE results for Pt a30 around 2006 Explorer Hood 
- Chose 8 CTQ's - pts 3,5,9,11,21,23,27,30

- Analyzing the data shows -

- A - Inr Shape (5)

- B - Flange Length (4)

- C - Storage Time (5)

- D - Storage Method (8)

Significant Interactions:

- AB (6)

- $\mathrm{CD}(5)$

-Which Factors have highest cost implications?

- Validation Study: Run 5 panels with the same x1, x2, x3, and x4

Next Steps:

- Define critical few " $x$ 's"

- Find mathematical relationship: $y=f(x)$

- Identify operating window of critical x's to achieve desired "Y"

DOE results analyzed and optimized to define the mathematical model:

$\Delta \mathrm{Y}(\operatorname{Hood}$ Deflection $)=F(X)=$ function of $(\Lambda=\operatorname{Inner}$ Shapc, $B=$ Outer Flange, \& $C=$ Storage Timc $)$

Mathematical Models:

Pt 3: $\Delta y=-0.007+0.005 \mathrm{~A}+0.004 \mathrm{~B}+0.009 \mathrm{C}+0.007 \mathrm{AB}$

Pt 9: $\Delta \mathrm{y}=0.659+0.17 \mathrm{C}$

Pt 23: $\Delta y=0.379-0.15 \mathrm{~B}+0.25 \mathrm{C}$

Pt 30: $\Delta y=-0.037+0.004 \mathrm{C}$

Most Important Factor $=$ Storage Method: Horizontal - Recommended by DOE

Recommendations for hood quality improvements are:

- Maintain current Hood Inner Shape

- Maintain current Hood Outer Flange length

- Store completed hoods horizontally for 24 hours for epoxy cure if not cured during e-coat oven process.

However, in keeping with Lean Manufacturing principles, recommend hood conveyor from Hood Hemming Line to Hood Installation station (70 ft distance) keeping hoods in the horizontal position during the short conveyance. The completed bodies then go through 
Paint's e-coat system and ovens; which, fully cures the two-part epoxy in the hood hem.

Contrasted with the LAP management direction for hood storage as shown in the following picture:

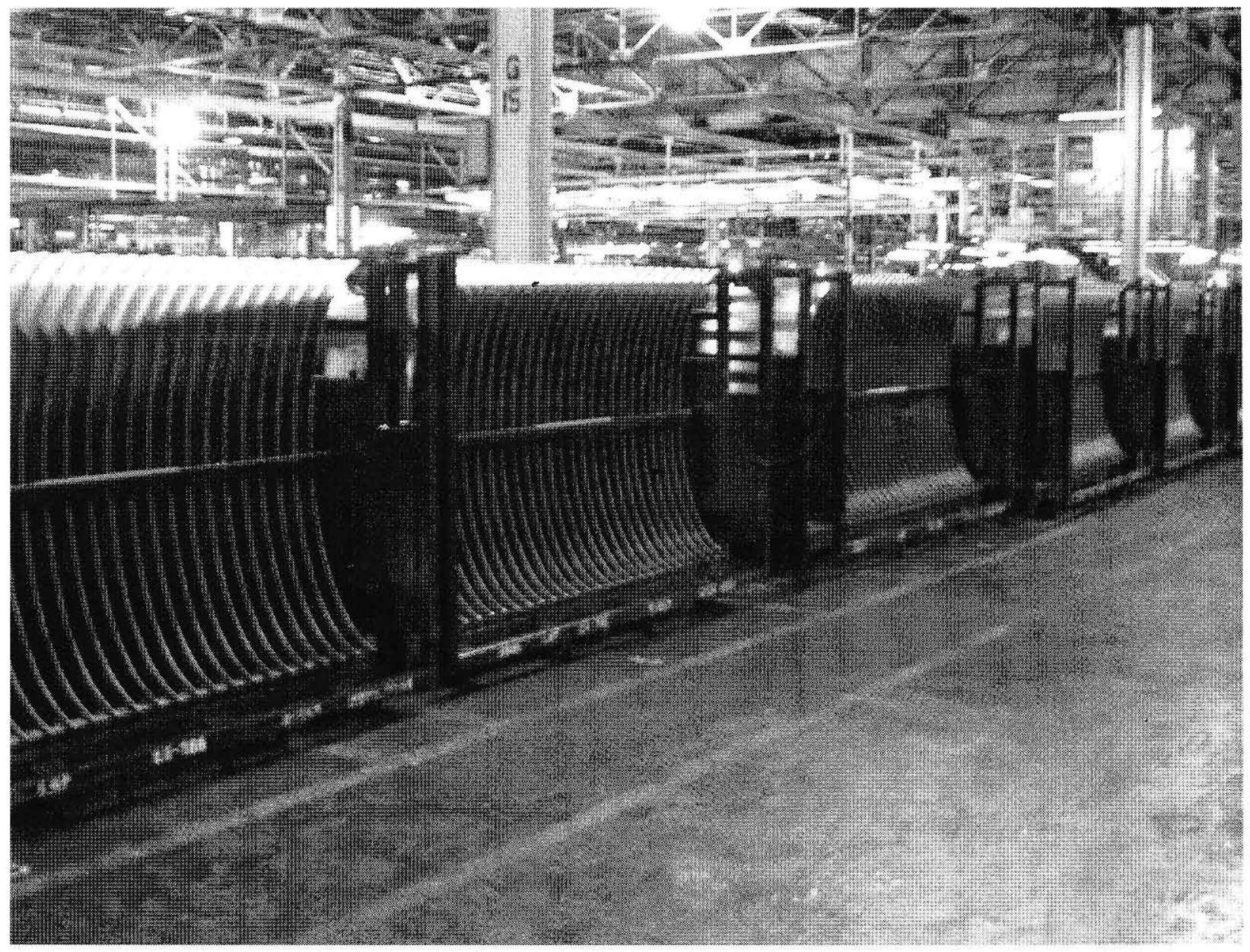

Figure 16 - Hood Storage Methodology in Contrast with DOE Recommendations 
Understanding the problem is vital to developing solutions that permanently reduce the error state. This requires what the Japanese call: Genchi Genbutso - Go Look and See. Using Structured Problem Solving in the form of a DOE, the best methodology for manufacturing the Explorer hood was determined. Missing from this manufacturing scene is the implementation of the DOE recommendations by management adding wastes and costs to the Ford enterprise - the greatest being over production which leads to most of the other types of wastes.

From a broad perspective, to accomplish Structured Problem Solving effectively, as stated in the previous section on customer satisfaction, Ford Motor Company and the UAW need to restructure the negotiated contract eliminating many lines of demarcation and job classifications leaving only several to manage - Quality Leader, Team Member, and Material Handling for instance. This action will effectively promote the ability to reduce or eliminate Judgment Inspection in favor of Informative Inspection by allowing inspection to be part of the process and operation. During an informative inspection, you check for abnormalities and perform feedback and action; this allows you to eliminate the cause of the problem at the source and reduce defects. In Figure 4, the two inspectors at the end of the line would be unnecessary, and non-value added to the process since the detection of errors they catch don't give an indication of the root cause. We might be able to infer to the root cause, but without seeing defect occur an inference is all it is, which requires more investigation by dedicated Black Belts or Green Belts.

"Instead of looking for defects that have already occurred, informative or source inspections check for errors that may cause defects. Feedback is then carried out and immediate action 
taken to prevent the error from generating a defect.

Thus, there are two types of quality control:

1 Quality control to reduce defects by judgment inspection

2 Quality control to eliminate defects by informative inspection" [19]

Therefore, the reduction of job classifications would allow Ford Motor Company to insert manual inspection methods into the process as part of standardized work elements reducing the potential for defects.

\section{Standardization:}

Every problem is a deviation from a standard! Strict adherence to process standards promotes structured problem solving and identification of variations and waste. Starting with the operators and using MODAPTS to standardize every element of work to its basic form allows each operation to be balanced based on Takt time with the ability to add informative inspection into the process where needed. MODAPTS standardizes every motion including steps or walks to discreet amounts of time. This method eliminates performance rated stopwatch evaluations, and the mistrust formed between management and labor.

The Lean benefits of standardizing work elements allow the creation of "Standardized Work Combination Tables", shown in Table 2, not only prescribes operator instructions in a standardized format, it also allows the operators, supervisors, and engineers alike to see unnecessary non-valued added wastes in the process. Knowing the unnecessary non-valued added wastes provides a basis for continuous improvement in efficiency and quality of the products. 


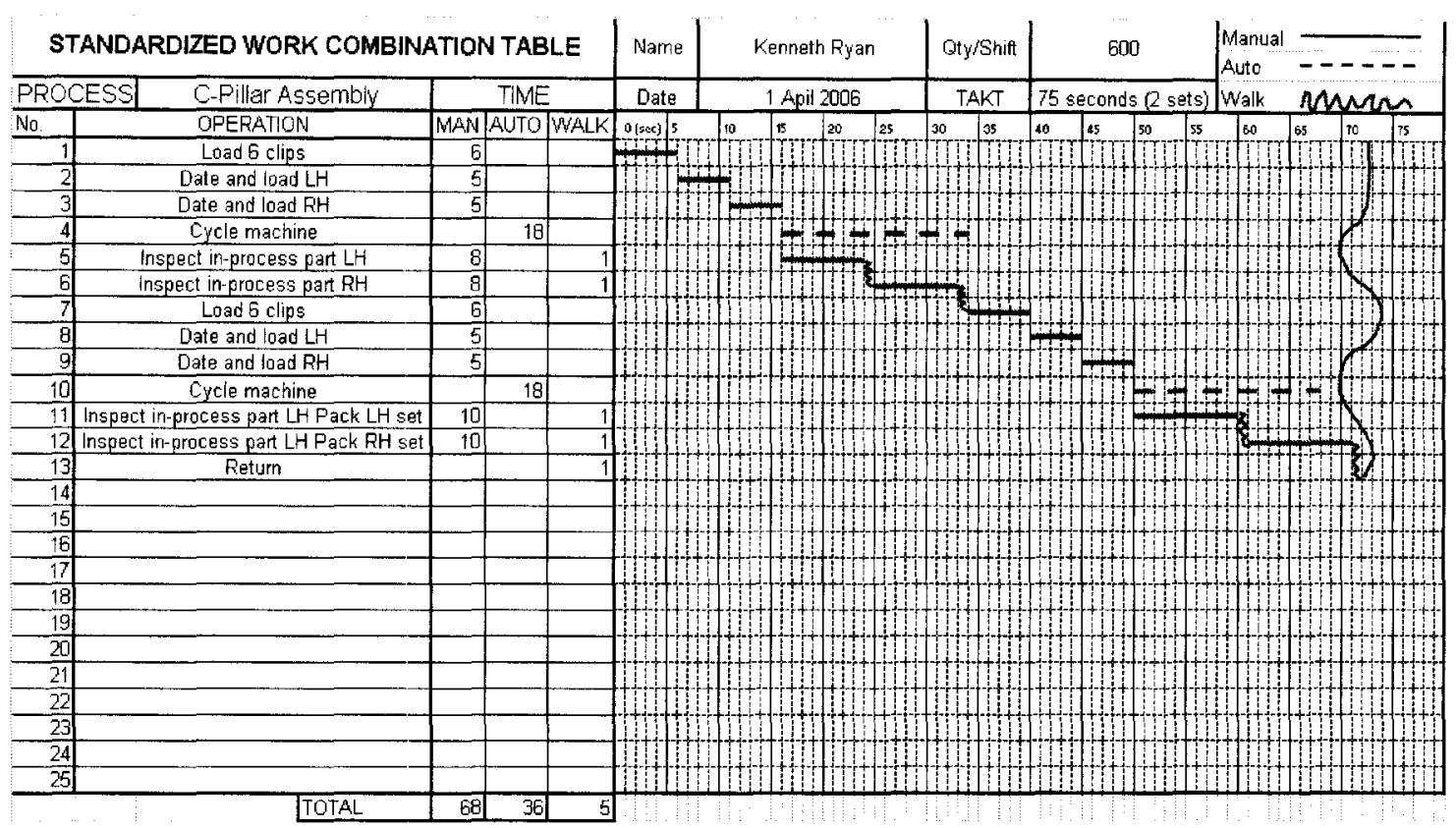

Table 3 - Standardized Work Combination Table

Standardizing work elements can only happen with better training and strict adherence to process writing standards by the engineering community. As discussed in the previous chapter, inconsistently written process sheets lead to inaccurate MODAPTS, which in turn affect standardizing work elements.

Standardizing work elements also gives engineering an understanding of labor impacts and process methodologies of a new system helping to avoid troublesome spots far ahead of implementation. To illustrate this point, a quick summary of Louisville Assembly Plant's hood line showed over 1200 hoods waiting for value-added work (installation to a vehicle) increasing inventory costs, material handling costs for extra conveyance of parts in racks, and two extra operators to transfer hoods from assembly line to racks.

Standardization of work through virtual manufacturing techniques and structured problem solving enhances manufacturing innovation into lean production systems. One of those 
systems being investigated to re-innovate Ford Motor Company to a lean manufacturing system is laser welding.

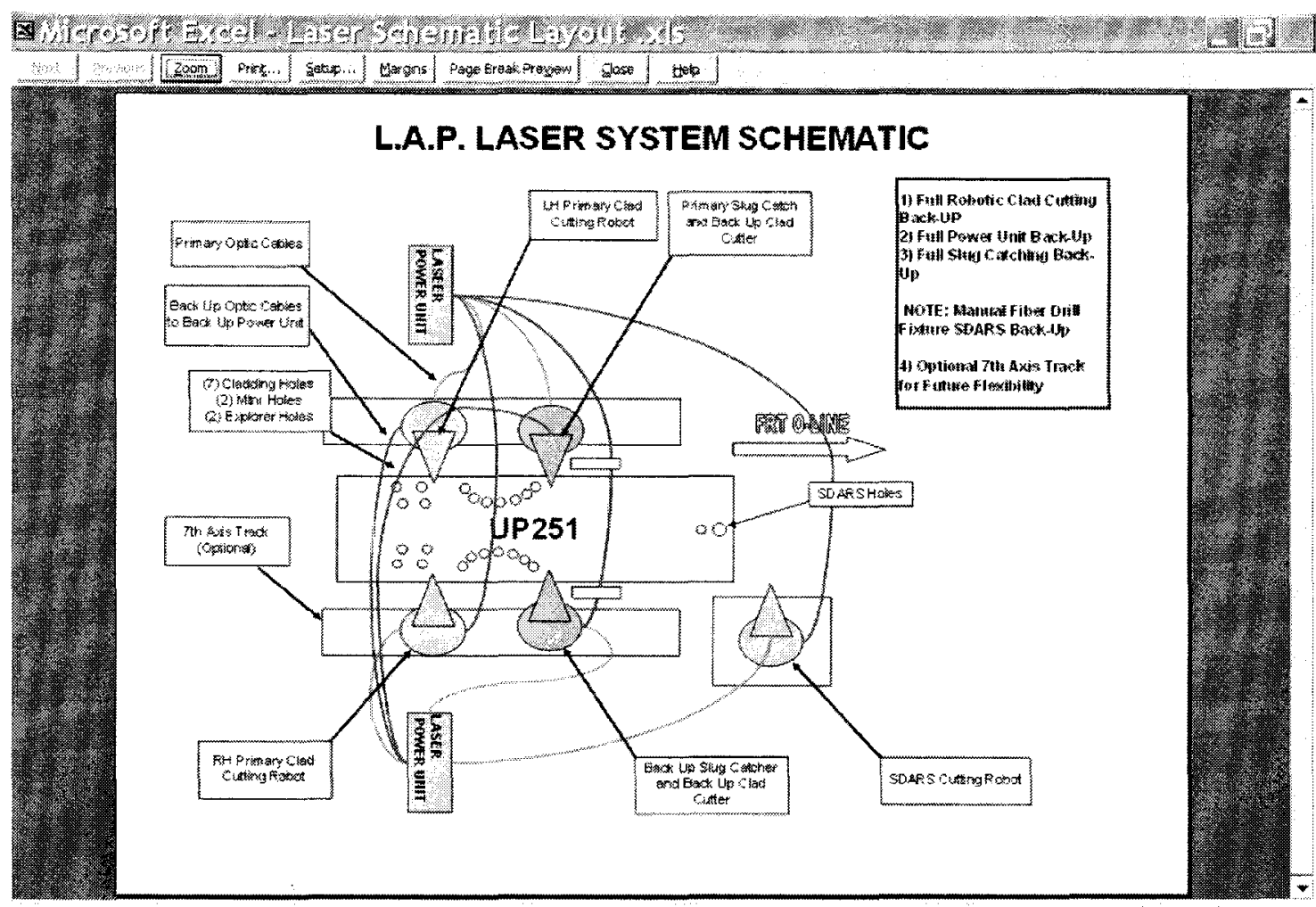

Figure 17 - Louisville Assembly Plant Laser System Schematic

This one laser cell will cut holes and weld the roof panel onto Explorers, Mountaineers, and Sport Tracs replacing six different welding stations performing the tasks in 23 seconds compared to conventional resistance welding's 2 minutes and 33 seconds. Both time and space are saved along with the great waste of over production by reducing the numbers of vehicles in the system from six to one.

This manufacturing technological innovation also allows greater flexibility in product development advances in materials and weight as demonstrated in the next figure. 


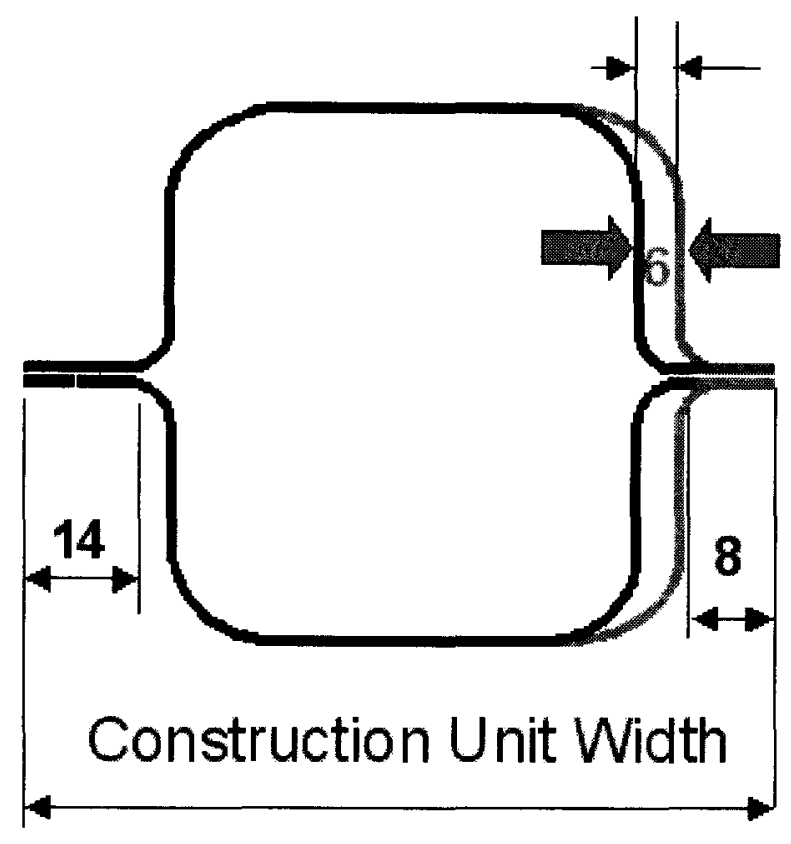

Figure 18 - Laser Welding vs. Resistance Welding Reduction of Flange

\section{Laser Welding vs. Spot Welding Comparison}

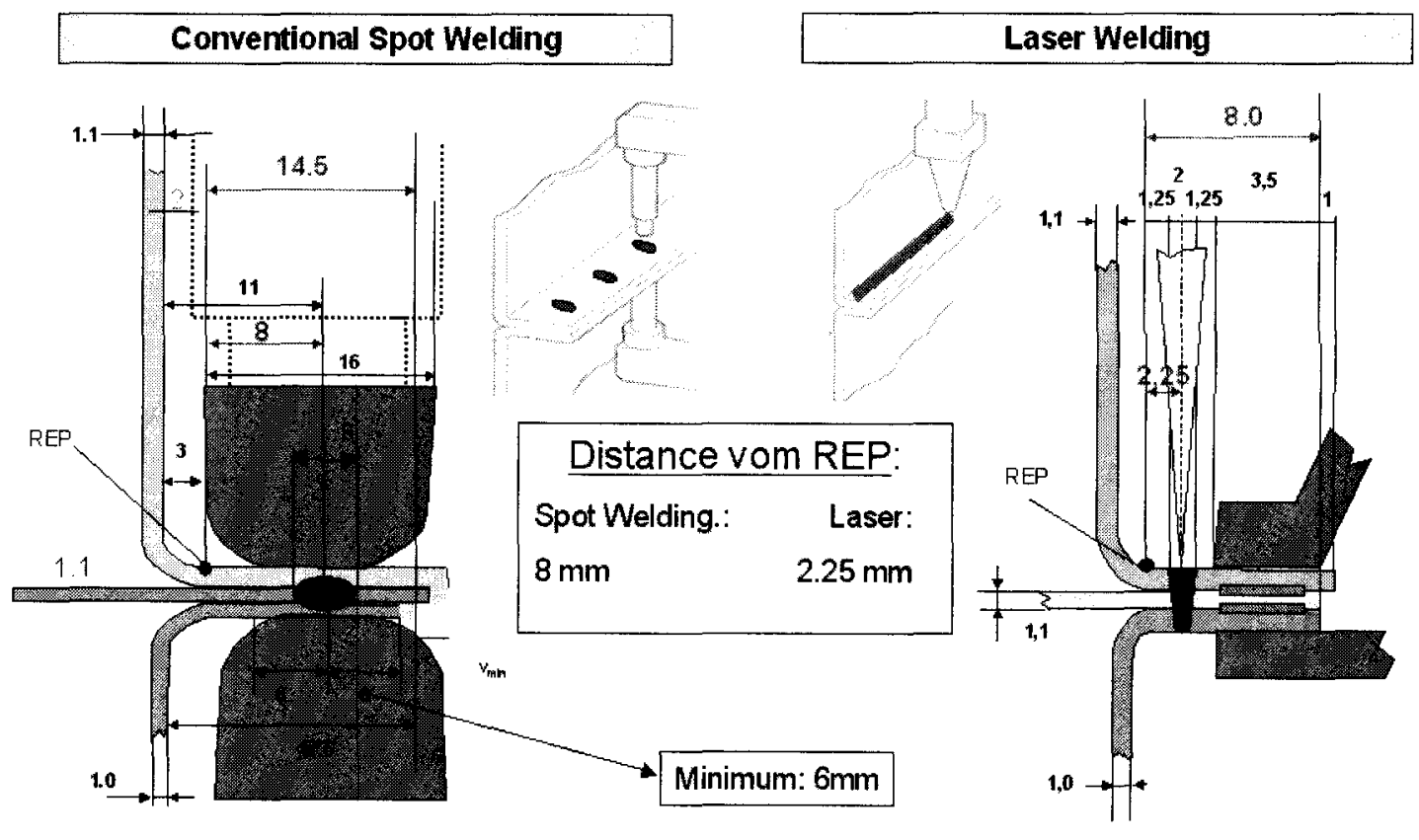

With metal sheet thickness more than $3.5 \mathrm{~mm}$ a diam eter of the spot torch of $20 \mathrm{~mm}$ is required!

Figure 19 - Laser Welding vs. Spot Welding Comparison 
Advantages of reduced flange widths follow a lean system in manufacturing and design by producing sections that:

1 Higher profile section at same work piece width

2 Less weight

3 Higher stiffness in seams in comparison to conventional welding techniques

4 High process speed

By implementing these engineering innovations and standardizing these systems actoss Ford's manufacturing arena, Ford can realize waste reductions in the design and manufacturing systems allowing the assembly plants more flexibility to meet customer demand of the products desired.

\section{E. Level Scheduling:}

To achieve process stability and system standardization it is recommended that Ford Motor Company and its supplier base practice Level Scheduling. A level production schedule allows suppliers and the company to achieve production process stability. The purpose is to meet customer demand by adjusting a manufacturing facility's build schedule to stable volumes and mix rates over a set period of time. This keeps inventories from varying dramatically day-today allowing better control over materials and reducing the burden of over-production.

A level schedule allows a supplier to develop, execute, and sustain a manufacturing process based on Standardization and incorporated in the following processes:

1 Delivery schedule - reduce inventory to what is needed by the customer

2 Production schedule based on a consistent cycle time, process layout, \& number of workers - increase efficiencies thus reducing non-value added work, and fully utilizing each worker 
3 Tooling \& Equipment Preventative Maintenance schedule - allows scheduled time to perform critical PM work on necessary tools and equipment.

4 Structured Problem Solving - level scheduling promotes standardization from which a problem is a deviation from a standard and forces inspection back to the process to understand and root cause the concern.

5 Scheduled continuous improvement - allows for Ford's 6Sigma kaizen events to occur to make enhancements in the design or process.

6 Downstream supplier production/delivery schedule - it all starts with the customer and a level schedule allows for deliveries meeting customer demand for the products they want.

Earlier shown was a typical Ford build schedule in Table 1. Table 3 takes that same schedule and levels it based on Body Type and Engine. You can go even further in detail by leveling on items of greater complexity such as vehicle Grade and Color. 


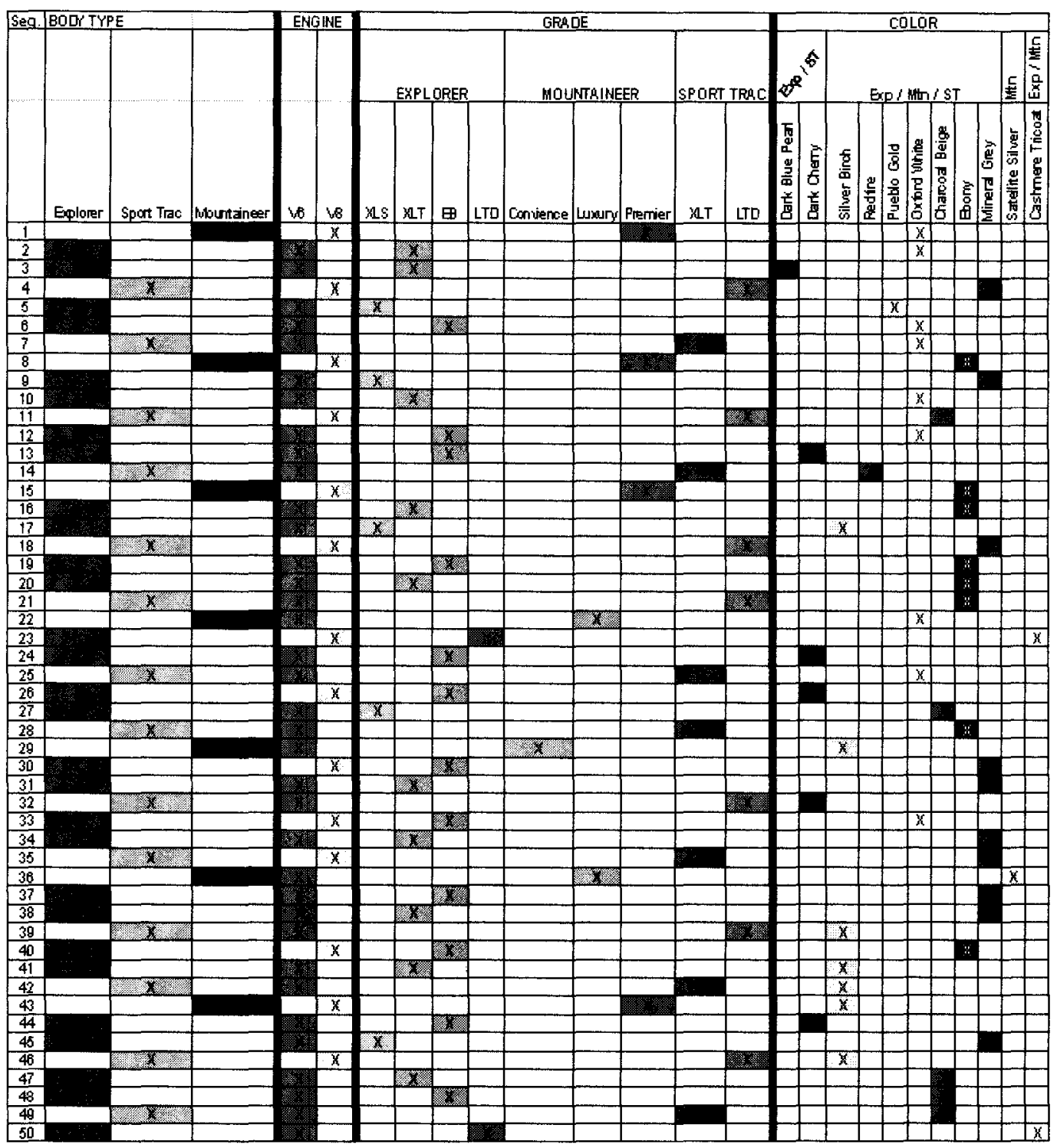

Table 4 - Louisville Assembly Plant with Level Schedule

Compared to Table 1, Table 3 illustrates a more repetitive pattern for Body Type and Engine level production schedule so that for a set period of time a supplier is required to produce and deliver the same part number, in the same volume and mix (generally with a maximum fluctuation of $\pm 5 \%$ ). Again, a level schedule allows the downstream supplier to standardize its production/delivery schedule, which in turn affects a positive outcome in quality and ultimately customer satisfaction.

Shigeo Shingo best describes Toyota's level scheduling system, "While some argue that the 
most important benefit of the Toyota production system is that it prevents surplus capacity disparities from influencing upstream processes, its real superiority lies in its ability to minimize stocks of finished products." [20]

Louisville Assembly Plant needs improved understanding of Lean techniques to improve its competitiveness as demonstrated by one simple system - the hood assembly and storage line. As shown in Table 2, hood inners and outers should be scheduled in the same quantity supplied on a daily basis to meet manufacturing demands based on customer orders; which improves the quality of parts from special cause damages, thus improving customer satisfaction.

With increased customer satisfaction, demand for the vehicle could stabilize or rise allowing better marketing and sales forecasting. The ultimate goal is the ability to give the customers the vehicles they want without having to create "dealer packages" in order to push product onto the customer base, again "minimizing stocks of finished products" and thus creating a leaner system in inventory, or over production. But the whole manufacturing and product development systems behind it must be standardized and structured to provide for this "customer driven Pull system", resolving problems in a structured format, increase quality and customer satisfaction, ultimately increasing profits. After all, aren't we here for the money? 


\section{A. Confronting the brutal truth:}

3 April 2006: Toyota Motor Manufacturing stock price closed at $\$ 110.35$; Ford Motor Company - \$7.77! How do you explain Toyota's stock price valued at 14.2 times the value of Ford's?

According to the Chicago 'I'ribune [21], "The easy explanation is that U.S. carmakers start at a clear disadvantage: They are plagued by "legacy costs," the sky-high pension and health-care expenses brought on by union contracts and generations of retired employees." The article points out, "But interviews with current and former Ford executives indicate that there are other, less obvious legacy costs as well. Ford, they say, suffers from years of short-term thinking and billions in questionable investments. While it tried to adopt the highly-efficient management strategies pioneered by Toyota, those efforts have been hobbled by a lack of firm, consistent leadership at the top and a divisive, feudalistic corporate culture that has grown up over the years. 'The result is a high-cost, inflexible operation that leaves Ford trailing even GM when it comes to efficiency. David Cole, chairman of the Center for Automotive Research, a non-profit think tank based in Ann Arbor, Mich., estimates that excluding labor expenses, Ford's operating costs are as much as $\$ 1,000$ per vehicle higher than GM's - a major competitive disadvantage. Former Ford executives say the gap between Ford and Toyota on the cost of materials has trended as high as $\$ 1,600$ a vehicle. "If GM had Ford's (operating) costs it would be gone," Cole said."

"What's most striking - and telling - about this period of management turmoil is how different it is from the way Toyota operates. Consistent leadership, teamwork and investment in the future are the hallmarks of the Toyota system. "It requires leadership behavior that is long 
term and contemplative," said University of Michigan professor Jeffrey Liker, author of the "lhe Toyota Way." "It requires a way of working together and reaching a degrce of consensus. This is a set of things that don't come naturally to a traditional U.S. manufacturer like Ford."” $[2.1]$

Mark Fields calls the problem "chimneys" as illustrated by another Ford executive's account in the same Chicago Tribune article, "As executives sought to protect their empires, meetings of the Americas group often devolved into blame fests, not problem-solving sessions, said one former member of the group. Worse, a lack of firm leadership meant the company was often run by committee where everyone had a vote. This led to slow decision-making and a dysfunctional lack of accountability." $|21|$

The lack of accountability is a failure of management to recognize the overall importance of the endgame - sustainable profitability. But how do you deal with these adverse financial times when you don't know how the story will prevail?

In the Stockdale Paradox, Admiral James Stockdale, Congressional Medal of Honor recipient for shouldering the burden of command as a prisoner of war in Vietnam's Hannoi Hilton from 1965-1973 keeping high the number American prisoners that survived, said of that adverse time, "I never lost faith in the end of the story," he said, when I asked him. "I never doubted not only that I would get out, but also that I would prevail in the end and turn the experience into the defining event of my life, which, in retrospect, I would not trade."

When asked, "who didn't make it out?" "Oh, that's easy," Admiral Stockdale responded, "the optimists!"

Continuing his lesson, Admiral Stockdale made one of the most crucial points that Ford executives need to fully understand and appreciate, "I Ihis is a very important lesson. You must 
never confuse faith that you will prevail in the end-which you can never afford to lose - with the discipline to confront the most brutal facts of your current reality, whatever they might be." $[22]$

\section{B. Leadership:}

Has the Way Forward Plan confronted the brutal reality that Ford Motor Company needs to change? Absolutely. Is the Way Forward Plan realistic about achieving sustainable success by 2008? Probably not is the answer. Where do you start? You start naturally at the top with leadership.

Let's look at a different industry comparing Bethlehem Steel to Nucor Steel. Both companies faced the competitive challenge of cheap imported steel. "Bethlehem Steel's CEO summed up the company's problems in 1983 by blaming imports: "Our first, second, and third problems are imports." Ken Iverson and his crew at Nucor considered the same challenge from imports a blessing, a stroke of good fortune ("Aren't we lucky; steel is heavy, and they have to ship it all the way across the ocean, giving us a huge advantage!"). Iverson saw the first, second, and third problems facing the American steel industry not to be imports, but management...telling a stunned gathering of fellow steel executives in 1977 that the real problems facing the American steel industry lay in the fact that management had failed to keep pace with innovation." $[23]$

Innovation is the key to Bill Ford's vision as he introduced the Way Forward Plan, "Bill Ford: "Ford Motor Company was solidly profitable in 2005 and growing around the world. The next chapter in our history will be remembered for a renewed commitment to innovation and as the time we moved boldly to prepare Ford's North American business for global competition." [9] 
But as the previous example of the steel industry exemplifies, it takes leadership able understand what needs to happen to build, create, and contribute to sustained success. It takes a "T.evel 5 Leader".

The lack of Level 5 Leaders as Jim Collins, author of "Good to Great" puts it, is probably the most oppressive factor in Ford's current situation. According to Jim Collins, "I.evel 5 leaders want to see the company even more successful in the next generation, comfortable with the idea that most people won't even know that the roots of that success trace back to their efforts. As one I evel 5 leader said, "I want to look out from my porch at one of the great companies in the world someday and be able to say, 'I used to work there.' " [24]

At Ford, the situation is more akin to the Chicago Tribune article, "But former executives say the question isn't intent - it's execution. Because Ford has so many engineering ficfdoms and a lack of strong leaders to force them to cooperate, agreeing on a shared design or dividing up development responsibilities can turn into a dogfight. One former executive, for instance, said because of turf battles, the percentage of common parts on the Mazda6-Fusion platform is only 30 percent, well behind the Japanese. This means Ford isn't getting the full benefit of economies of scale in parts buying. Instead, it is forced to hammer on supplicrs for lower costs, creating financial problems for them." [21]

Creating financial problems for your supplier base has profound effects on the assembler's end cost and quality of parts. In a lean system, the assembler and the supplier must establish the most important part of a business relationship - Respect and trust. As James Womack states in "The Machine That Changed 'The World", "the assembler must respect the supplier's need to make a reasonable profit... well aware of the learning curve that exists for producing practically any item. So they realize that costs should fall in subsequent years, even though 
raw-materials costs and wages increase somewhat. Improvements in lean-production companies should, in fact, come much faster - that is, learning curves should be much steeper - than in mass-production companies because of kaizen." [25]

These improvements in cost and quality at the suppliers and the assembler, Ford Motor Company, alike don't happen just because you implement Lean techniques and methodologies. So what does make the difference between the comparison company Toyota, and Ford? The difference is trust and the realization that improving actual operations are not the job of management - it's the job of the workers themselves.

Toyota's philosophy in leadership is not merely the creation and use of lean toolsets, but in making all its work a series of nested, ongoing experiments. Their leadership views standardization as the explicit specification of how work is accomplished coupled with testing work as it is being done. As Steven Spear states in the Harvard Business Review, May 2004, "The end result is that gaps between what is expected and what actually occurs become immediately evident. Not only are problems contained, prevented from propagating and compromising someone else's work, but the gaps between expectations and reality are investigated; a deeper understanding of the product, process, and people is gained; and that understanding is incorporated into a new specification, which becomes a temporary "best practice" until a new problem is discovered." [26]

In Toyota's training system, creating Level 5 leaders starts with Genchi Genbutso - Go Look and See. There is no substitute for direct observation. Leaders are trained to lead by example, and foster an atmosphere committed to resolving problems. Toyota accomplishes this by training their leaders to directly observe problem letting the failures tell him what he needed to know. The leaders then learn how to propose changes that should always be structured as 
experiments - in structured problem solving events. They are encouraged to experiment as frequently as possible, making small incremental changes rather than large system-design changes. And last and most important, their leaders coach, not fix! But without getting down to the lowest point and understanding how to observe, propose structured experiments, and make small changes they cannot lead at 'loyota. And without this leadership, the Toyota Production System starts to fail.

\section{The Doom Loop:}

Leadership is definitely the key to recovery and building a process to sustain success. Any Level 5 l,cader will recognize that when righting a ship, and new initiative must be well thought out and planned accordingly to keep from entering Jim Collins" "Doom Loop".

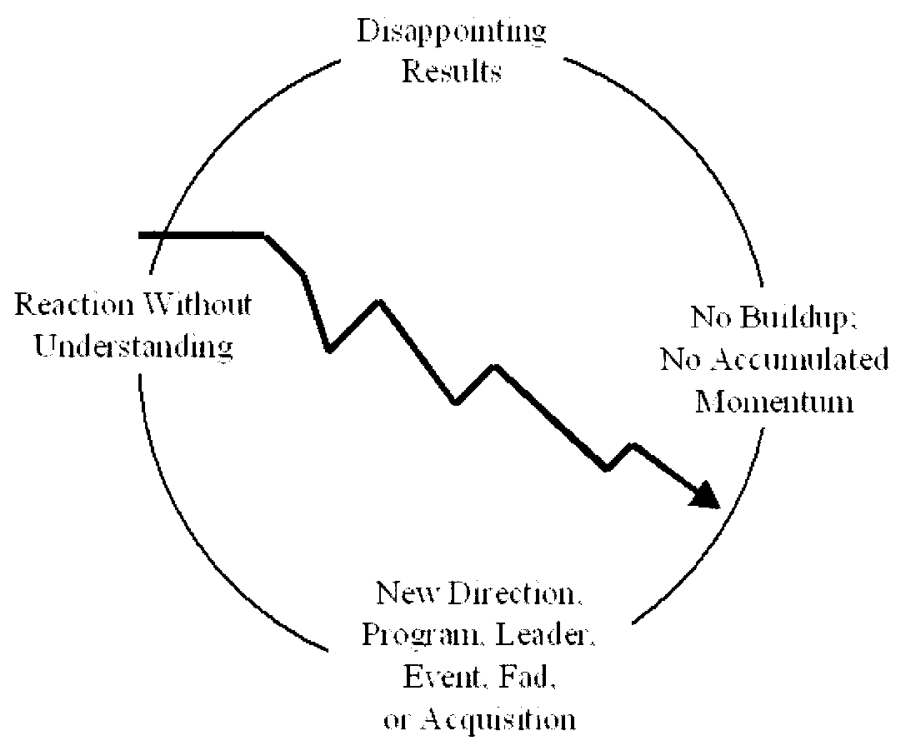

Figure 20 - The Doom Loop

One of the symptoms that you're in the Doom Loop is that you're so overwhelmed by crisis you feel there's no time to learn your way out - that's not really true. Fveryone acts as if there is no time to do tasks that don't appear to contribute to results. Of course, this belief 
runs counter to what we all know from real life. Improved results come from better decisions and more effective follow-up, learning, and practice, and not from obsessive focus on the outcome. You simply do not get better without practice, and the practice required of most of us in the Doom I.oop is to engage in ruthlessly honest reflection on what's happening in our business. Toyota was in the same situation around 1950, but had a plan called the Toyota Production System (TPS) that they would nurture and foster an environment between management and labor to provide for continuous improvement and future sustainable success. TPS was well thought out and executed that a whole new industry of experts and consultants evolved to what is now known as I cean Manufacturing.

But to get out of the Doom Loop, Mark Fields is trying to point this company in the right direction by following one of 'Toyota's most basic ideas.

"He [Mark Fields] is also working on another Japanese idea. At Toyota, according to James Womack, president of the Lean Enterprise Institute, "what managers do is ask questions - they don't give answers." Fields hopes to instill the same management style at Ford.

"Our culture is that the senior guys on top have all the answers and those below must justify the thoughts of the higher-ups," Fields said. "But those on top don't have all the answers. I don't have all the answers."

Whether Fields is the man to bring order to the maclstrom at Ford remains an open question. But Womack said his best strategy is to use the crisis atmosphere for all it's worth. People forget, he said, that 'oyota nearly went bankrupt in 1950 and only afterwards developed its world-beating system. Paraphrasing Taiichi Ohno, an early advocate of the Toyota Production System, Womack said, "No one does this stuff unless they're desperate." [21]

After an intensive study of the Way Forward plan, I find myself questioning what the "Plan" 
really is, and how it's going to meet Ford Motor Company's financial goals and allow sustainable success. Ford Motor Company has all the tool sets in its inventory, but just needs to get back to the history that Henry Ford created - uncompromising improvements in manufacturing efficiency and quality. Henry demonstrated his leadership by looking for himself, experimenting for himself, and teaching and expecting the same from the people around him. These are the philosophies that Ford was built on, and Toyota vastly improved.

'Therefore, I conclude that "lhe Way Forward" plan needs to adopt "The Process for Sustained Success" to fully utilize its I ean Manufacturing toolsets and achieve Ford Motor Company's long-term goals to be successful many years in the future. 


\section{Chapter V: Conclusions}

\section{A. Summary:}

This thesis introduced a unique high-level perspective on the implementation of Lean Manufacturing to Ford Motor Company. The Process to Sustained Success leads Ford on a journey to adopt and use lean manufacturing in every aspect of its business from marketing and sales to the manufacturing centers, accounting, material handling and scheduling, product development, and Ford's supplier base.

The concept that continuous improvement through waste reduction in the automotive industry lay with the achievements of Henry Ford putting all the pieces together to create a complete system of mass production starting with the moving conveyor belt and division of labor. Toyota's creation out of necessity, the 'loyota Production System, invented the new concepts of lean production extending from product planning through all the steps of manufacture and supply system coordination onto the customer. Toyota's almost fanatical adherence to the Toyota Production System and waste reduction has led them to become the most profitable automotive maker in the world.

The Process to Sustained Success really did nothing more than assimilate lean manufacturing techniques into a simple management process tool to help drive waste reduction and increase profitability. But it asks certain hard things of the leadership at Ford Motor Company:

1 Change the way you think about your role at Ford from a manager to a teacher and coach by learning the simple techniques of observation and expcrimentation to reduce waste. Teaching and fostering an environment that promotes waste reduction has the positive effect of improving the company's profitability through the 
elimination of direct and indirect costs. The simple attitude of looking for and obscrving the best way to reduce wastes and defects will have an enormous benefit in customer satisfaction by eliminating problems before they occur.

2 Align your organization not around the fiefdoms you've built, but around what's best for the enterprise of Ford Motor Company. Standardizing organizations around design, processes and disciplines, then simplifying and communizing components that customers don't regard as high impact to vehicle desire, i.e. window switches, creates the basis for standardization in the manufacturing arenas. Through standardization of designs, manufacturing wastes can be observed and eliminated. In addition to standardizing designs and processes, practicing J evel Scheduling starts the process of flexible manufacturing allowing Materials, Planning, \& Logistics (MP\&L) to optimize packaging of parts, and routes of delivery to every assembly plant. When organizations align themselves with the common goal of reducing wastes, the company profits.

3 Management and labor need to implicitly trust each other and give the opportunity to succeed to the operators on the floor coached by management on waste reduction techniques.

This last point allows true empowerment of the operator to improve quality of the vehicle, and of their working conditions. A good thing about trust is that is grows, and once this system is put in place it gives people the chance to become as good as they can. It also encourages then to find better ways to get their work done while improving quality and costs to Ford Motor Company. Basically, people don't want to fail, so why not give them the opportunity to succeed? 
The main key points to gain from The Process to Sustain Success are to provide a level schedule for production and supplicrs, standardized work elements, continuous improvement through observation and experimentation (structured problem solving), which will improve customer satisfaction, and hence increase profits.

Lnfortunately, the Way Forward Plan with its circular loop (please refer to Figure 1) doesn't point to an objective, which, in this case is Profitability. 'The Way Forward rests on the ptinciples of Bold Leadership, Compctitive Cost and Capacity, Clear Pricing, Great Quality, Bold Innovative Products, Customer Focus and Strong Brands. These principles are all necessary points, but not targeting the core objective - profitability.

\section{B. Areas of Future Study:}

The Process to Sustained Success focused on the high-level application of setting up or revising a complete enterprise such as Ford Motor Company into a lean production system. Future research into the specific lean manufacturing tools for each process step should be pursued to give better operational direction and standardization.

Management and labor relations play a major role on the impact to a manufacturing facility and the development of a lean enterprise. I abor is critical to the success of implementing lean principles. How labor accepts accountability for efficiency and quality improvements in a union shop is determined on the level of trust. 'This trust must be given and fostered in a learning environment. 
Supplier relations concerning their quality and cost improvements would be a great area for further study. Again, there must be a trust between assembler and supplier to understand each other's businesses making sure that one or the other isn't going to get into financial or quality difficulties. One cannot survive without the other. Reducing wastes and controlling costs are vital for both to survive, and the assembler can't forget that point.

Lastly, the study and improvement of the interaction between Marketing and Sales and the dealership networks to provide a better understanding of customer needs and wants versus manufacturing capabilities to further improve a "Pull" system and challenge the production system in flexibility and level schedule. Again, it all starts with the customer, and by trying to meet customer demand without producing excessive inventories for dealers allows both the dealership and automotive company to thrive. 


\section{References:}

1. Russ Banham, The lord Century, Centennial Idition, San Diego, Cl: 'lehabi Books, pp. $38(2003)$

2. Ford Notor Company - llistong

3. Russ Banham, The Ford Century, Centennial Ldition, San Diego, CA: 'Tehabi Books, pp. $37(2003)$

4. Russ Banham, The lard Century, Centennial Fdition, San Diego, C. I: 'l'chabi Books, pp. $39(2003)$

5. Russ Banham, The Ford Century, Centennial Idition, San Diego, CA: 'lchabi Books, pp. $202(2003)$

6. Russ Banham, The Iord Century, Centennial Ldition, San Dicgo, CA: Tehabi Books, pp. $62(2003)$

7. Lewis, David and the Luto Editors of Consumer Guide, 100 Years of lORD, 1 Centennial Celebration of the Ford Molor Company, I incolnwood, IL: PII, pp. 217, 223 $(2003)$

8. Russ Banham, The I'ord Century, Centennial Edition, San Diego, CA: 'Tehabi Books, pp. $71(2003)$

9. William Clay Ford, Jr., Speech given 23 Jan 06, to Jiord Motor Company employees

10. Russ Banham, The liord Century, Centennial Ldition, San Diego, CA: 'l'chabi Books, pp. 202-203 (2003)

11. Russ Banham, The Ford Century, Centennial Ldition, San Diego, CA: Tehabi Books, pp. $38(2003)$

12. Shigeo Shingo, 1 Study of the Toyola Prodution System From an Industrial Engineering l'ieupoint, Cambridge, MA: Productivity Press, pp. 67 (1989)

\section{3. http://www.mfg.uky.edu/lean/kyway.html}

14. 'loyota Motor Manufacturing, The Toyota Produition System, Japan, pp. 3-4 (1995)

15. Intcrview with Stuart Powcll Ford, Danville, KY, 17 March 2006.

16. F'ord Motor Company, North Imerican Quality Summit, January 31, 2006

17. Ioyota Motor Manufacturing, The Toyota Prodution System, Japan, pp. 3-4 (1995) 
18. Shigeo Shingo, A Study of the Toyota Production System From an Industrial Engineering I iewpoint, Cambridge, MA: Productivity Press, pp. 74 (1989)

19. Mlan Robinson, Modern Approaibes to Mamufacturing Improvement, Cambridge, MA: Productivity Press, pp. $60(1990)$

20. Shigeo Shingo, A Study of the Toyota Production System From an Industrial Eingineering V iewpoint, Cambridge, MA: Productivity Press, pp. 135 (1989)

21. Chicago Tribune, At Ford, staying alive is Job 1, Knight Ridder/Tribune News Service, Mar 10, 2006

22. Jim Collins, Good to Great, New York, NY: HarperCollins Publishers, pp. 83-85, The Stockdale Paradox

23. Jim Collins, Good to Graat, New York, NY: HarperCollins Publishers, pp. 34, I.cvel 5 Leadership

24. Jim Collins, Grood to Great, New York, NY: HarperCollins Publishers, pp. 17-38, Level 5 Leadership

25. James P. Womack, The Maibine That Changed The World, New York, NY: HarperCollins Publishers, pp. 149

26. Steven Spear, Learning to Lead at Toyota, Harvard Business Review, May 2004 


\section{Glossary of Lean Manufacturing Terms}

Following is a short list of terms often used in explaining lean manufacturing techniques.

Cellular Manufacturing - linking of manual and machine operations into the most efficient combination to maximize value-added activities while minimizing wastc. $A$ cell layout is typically $\mathrm{U}$-shaped and utilizes one-piece flow.

Kanban System - a pull system that uses color-coded cards attached to parts or part containers to regulate the upstream production and delivery flow.

Lean Manufacturing - the process of analyzing the flow of information and matcrials in a manufacturing environment and continuously improving the process to achieve enhanced value to the customer.

Non-Value Added - Any activity that does not add market form or function or is not necessary. (I'hese activities should be eliminated, simplified, reduced or integrated.)

Pull System - method of controlling the flow of resources by replacing only what has been consumed. A pull system relies on customer demand.

Push System - resources are provided to the consumer based on forecasts or schedules. (Lean manufacturing encourages the climination of push systems.)

Takt Time - customer demand rate. Takt time sets the pace of production to match the rate of customer demand and becomes the heartbeat of any lean system. It is calculated by taking the work time available and dividing it by the number of units sold.

Value Added - Any activity that increases the market form or function of the product or service. (These are things the customer is willing to pay for.)

Value Engineering - Improves the product by designing or redesigning to maintain quality while reducing manufacturing costs.

Judgment Inspection - Inspection based on a "post-mortem" of quality defects discovered at final inspection distinguishing defective from non-defective products.

Informative Inspection - Informs processing whenever a defect is discovered at the point of origin so that steps can be taken to correct the processing method or condition and prevent recurrence.

ILVS (In Line Vehicle Sequencing) - Sequential Part Delivery or SPD is the process of delivering automotive parts to an assembly plant in the exact order or sequence in which the vehicles that need them are coming down the production line.

MODAPTS - MODular Arrangement of Predetermined Time Standards is a predetermined time system used for: 
- Calculating reliable production standards,

- Improving an organization's productivity,

- Analyzing departmental efficiency, and

- Improving employee relations.

KAIZEN - Continuous incremental improvement in the production process. 


\section{Appendix A}

Ford Motor Company Historical Timeline:

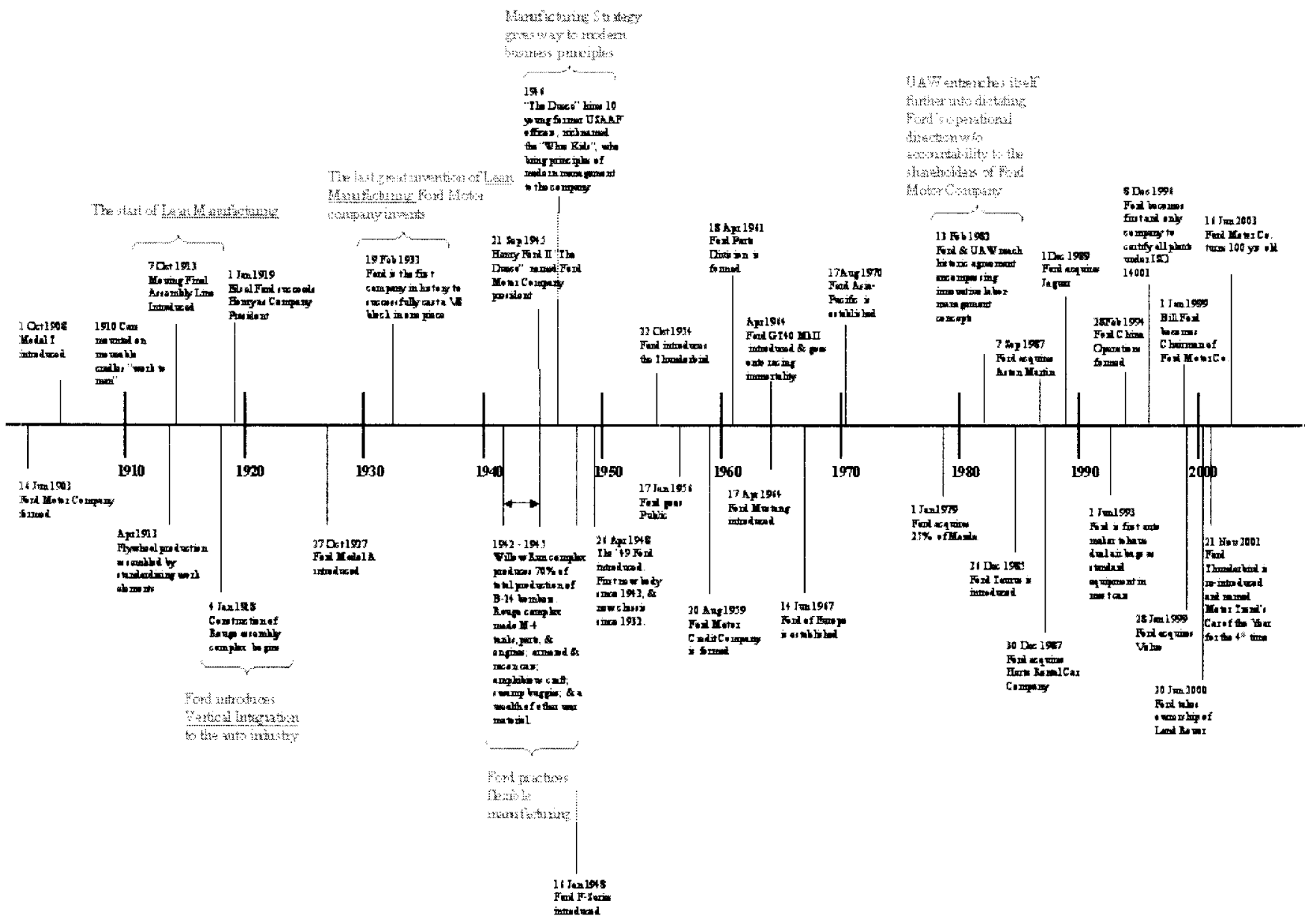

Referemoe: Ford Motar Company media 


\section{Appendix B}

\section{Announcement of the The Way Forward Plan:}

DEARBORN, Mich., Jan. 23, 2006 - Ford Motor Company [NYSE: F] today announced details of a comprehensive plan to restore profitability to its automotive business in North America no later than 2008. Ford will apply lessons learned from consumers and the company's successes around the world to strengthen its Ford, Lincoln and Mercury brands and deliver more innovative products while simultaneously reducing costs and improving quality and productivity.

"The automotive market in North America is rapidly becoming as crowded and fragmented as other global markets," said Bill Ford, chairman and CEO. "To meet this challenge, we are acting with speed to strengthen the Ford, I incoln and Mercury brands, deliver the innovation customers demand and create a business structure for us to compete - and win - in this era of global competition.

"We will be making painful sacrifices to protect Ford's heritage and secure our future," he added. "Going forward, we will be able to deliver more innovative products, better returns for our sharcholders and stability in the communities where we operate."

\section{Ford Around the World - 2006 Outlook}

For 2006 , the company is expecting another year of profitability from automotive operations outside of North America. Pre-tax profits, excluding special items, are expected from automotive operations in South America, Europe (Ford of Europe and Premier Automotive Group), Asia-Pacific and $\Lambda$ frica, and from Mazda and Associated Operations. North American automotive operations are expected to be unprofitable. Overall, Ford's global automotive operations are expected to have pre-tax losses in 2006, while Ford Motor Credit is expected to achieve pre-tax profits.

The underlying assumptions behind this outlook include: full-year industry volumes of 17 million units in the U.S. and 17.3 million units in Europe; industry net pricing that is expected to be down slightly in the L.S. and Europe. Also, the company's quality performance is 
expected to improve, market share is expected to stabilize or improve in all regions, and cost performance is expected to be favorable. Capital expenditures of approximately $\$ 7$ billion are expected during 2006 , while the company expects its year-end cash balance to be more than $\$ 20$ billion.

Beyond the above expectations, the company is providing no other guidance about its financial performance for 2006 - to keep employees and investors focused on one goal: sustainable profitability over time in all regions.

"We must be guided by our long-term goals of building our brands, satisfying customers, developing strong products, accelcrating innovation, and, most importantly, producing a sustainable profit from our automotive business," said Bill Ford.

\section{Ford in North America - the Way Forward}

Ford's automotive business in North America was profitable in 2003 and 2004, thanks to the product investments and cost reductions driven by the company's Revitalization Plan, announced in 2002 .

Since that time, more and stronger competition in all segments, a faster-than-expected customer shift from traditional SUVs into other segments, significantly higher material and energy costs and other factors have resulted in lower market share and higher costs for the company.

"The team in North America, led by Mark Fields and supported by Anne Stevens, developed the plan for North America, drawing on their extensive global experience in Asia, Europe and 'The Americas. 'They have reenergized the Ford team to make it work, and they have the full support of the ford Motor Company behind them," said Jim Padilla, president and chief operating officer.

Ficlds, executive vice president and president, The Americas, calls the plan the "Way Forward." It touches every piece of the North American business to make it more customerfocused, product-driven and efficient, including:

1 More clarity for the Irord, J incoln and Mercury brands - with a sharper focus on the 
customer and a clear point of view that will appeal to more buyers than today.

$2 \Lambda$ renewed commitment to design, safety and technology innovation to differentiate Ford Motor Company and its products in the marketplace.

3 New product investments - utilizing Ford's global architectures and scale - to deliver more new products faster, including more crossovers, hybrid vchicles, new small cars, increased spending on Ford's truck leadership and new "white space" products.

4 Material cost reductions of at least $\$ 6$ billion by 2010 .

5 Continued straightforward pricing that is clear, credible and simple, which will further improve residual values.

$6 \quad A$ lean and flexible manufacturing system combined with capacity matched to demand. Capacity will be reduced by 1.2 million units or 26 percent by 2008 , representing the majority of actions within the plan's 2006-2012 period.

7 Plant-related employment is reduced by 25,000-30,000 people in the 2006-2012 time period, in addition to salaried personnel reductions and a reduction in the company's officer ranks.

\section{Stronger Ford, Lincoln and Mercury Brands}

Ford kicked off the Way Forward plan in October with a comprehensive analysis of consumer attitudes and values in the U.S. automotive market. Ihe goal was to develop a laser-like focus on different customer targets for I'ord, Lincoln and Mercury to guide each brand's design, engineering and marketing decisions.

"One of the most important findings from this research is that Americans really do want to buy American brands, as long as they are competitive with the imports," said Fields. "We know this, because it's already working in some segments today, such as the success of the new Ford Fusion in the import-dominated midsize car market.

"Of all the leading automakers, we believe Ford is America's Car Company because of where we've been. In terms of economic and social influence, there is no other company that's had a greater impact on the lives of people in the U.S. and in the 20)th century than Ford." 
Customers identify with Ford and its uniquely American story, the research also revealed.

"The challenge going forward is to give our customers, employees, retirees, dealers, suppliers and investors a reason to believe in Ford. That is going to be our focus," Fields said. "Our Way Forward is not a retreat into smaller markets, but a retaking of the American marketplace. It's time to play offense. It's time to fight back.

"We will compete vigorously to be America's Car Company, winning the hearts and minds of even more customers," he added. "We will maintain our commitment to our loyal truck customers, while delivering innovative and boldly styled cars, crossovers, SUVs and other allnew products that will appeal to people who are still inspired by the American dream."

With that clear point of view in the marketplace, Ford is investing in new products for Ford, Lincoln and Mercury.

'I 'he investment includes moving forward with the company's plan to offer hybrid technology on half of the company's Ford, Mercury and I incoln nameplates in the U.S.

Today, the company is announcing that hybrid versions of the Ford Five Hundred, Mercury Montego, Ford Edge and Lincoln MKX will debut in the 2008-2010 timeframe. The new hybrids will join the Ford Escape and Mercury Mariner hybrids, which are on sale today, as well as the Ford Fusion and Mercury Milan hybrids, which will debut in 2008. Overall, Ford Motor Company plans to build 250,000 hybrids a year by 2010 .

Ford also is announcing that it will introduce new "white space" products to reach customers in new segments, and accelerate plans to bring even more crossover vehicles and new small cars to market. At the same time, the company announced that it is increasing its product investment in Ford F-Series truck leadership; increasing momentum on its blockbuster cars today, such as the Ford Fusion and Ford Mustang; introducing more design innovations - for more "at a glance" sheet metal changes - and introducing more safety innovations throughout its North American lineup.

"With more focused brands, new product investment and innovation, Ford will slow the rate 
of loss and then stabilize our U.S. market share in the near term, even as competitors add new models," Ficlds said. "From there, we can set our sights on the future."

The Ford Brand: In the past, the Ford brand has demonstrated a clear customer focus in many - but not all - segments. Going forward, the Ford brand will build upon the success of hits, such as the Ford F-Series, Explorer, Expedition, Mustang, Escape and Fusion, and enter new segments with a clear, consistent and distinct point of vicw - one driven by bold, American design and innovation. 'The 2007 fiotd lidge, which goes on sale later this year, embodies that spirit.

"We know how to play offense and play to win," Fields said. "Our plan will deliver more products - from small cars to our largest trucks - that are unmistakably Fords."

Ford remains committed to maintaining leadership in full-size pickup trucks with the FSeries. The company also plans to continue its momentum in midsize cars - with all-whecldrive and hybrid derivatives coming for the ford Fusion - and developing new small cars and even more crossovers for the Ford brand.

Mercury: Ford is recommitting itself to Mercury and has developed more focused positioning that is a refinement of the work already done to revitalize the brand.

The newest Mercury products - the Milan, the Mariner and the Mariner Hybrid - are attracting younger customers to the brand and more women than Ford-brand products in the same segments, Fields said. In addition, they are bringing new customers to Ford Motor Company - at conquest rates as high as 50 percent.

"The attraction of Mercury is modern, expressive design - one that is differentiated from Ford vehicles. Our Mercury target customer is not looking for product functionality that is substantially different from Iiord vehicles. But they do have different attitudes and values, and they want a product that visually communicates that distinctiveness.

"Going forward, we will be more aggressive in appealing to these customers with clear, 
modern differentiation in the design of Mercurys, a unique purchase experience and marketing that is targeted, personalized and interactive," Fields said.

Lincoln: Ford's vision for the Lincoln brand is to make Lincoln the reward for consumers who are living the American dream. The company sees Lincoln becoming the largest volume contributor to the Lincoln Mercury business.

"Lincoln customers don't need to shout about success. They are self-made people with enough confidence to be elegant and understated," Fields said. "That understanding of the Lincoln customers will drive our brand and product decisions going forward."

The 2006 Lincoln Zephyr, the brand's first entry-luxury car, and the 2007 Lincoln MKX, the brand's first crossover, are significant first steps. Going forward, the company plans to give Lincoln vehicles an even clearer point of view through their powertrains, unique comfort and convenience features and unique designs.

"Lincoln is about American luxury. There are many customers in this country living the American dream and who would prefer to drive America's luxury car. That is where we are headed," he added.

Straightforward Pricing: Ford is accelerating the clear-and-simple pricing strategy that began with the introduction of the Ford Fusion and Ford Mustang. Ford plans to reduce the MSRP of its products and dramatically reduce and cap rebates as it introduces new products.

"We started introducing clear pricing two years ago. 'The success of Mustang and Fusion proves that it works," Fields said. "We will bring sticker prices more in line with actual transaction prices and cap 'cash on the hood' rebates as we introduce new cars and trucks into the marketplace. It will protect our margins and consumers, too, through higher resale values."

Ford also will increase its product advertising, focusing on brand characteristics based on innovative designs, features and customer benefits. 


\section{Investment-Efficient Product Creation}

Ford has committed to return its North American automotive business to profitability no later than 2008. Over time, the Way Forward plan should deliver profitability throughout the lineup - including new small cars - by achieving significant matcrial cost savings as well as quality and productivity improvements.

Several new initiatives will bolster ongoing work that already is yielding significant operating improvements. Specifically:

1 Ford will use more global vehicle architectures in North America, particularly for cars and crossovers, to reduce investment spending and improve quality.

2 The company will share more parts and systems that are invisible to the customer, such as brakes, suspension and underbody components, across its North American, European and Asian brands to leverage its global purchasing power for lower costs and better quality.

3 Ford will continue to implement its Global Product Development System - which is based, in part, on Mazda's highly successful and efficient model - to reduce product development times by six to 12 months, depending on the size of the program.

4 Ford will continue to invest in lean and flexible manufacturing, with 75 percent of its North American assembly capacity being "flexible" by the end of 2008 .

Improved quality will be achieved, in part, through the "Aligned Business Framework" agreements with select strategic suppliers. The agreements are designed to strengthen collaboration and create a more sustainable business model for both Ford and its key suppliers to improve mutual profitability.

The Aligned Business Framework - coupled with Ford's "Commodity Business Plan" process and a new single-team approach to product development and purchasing - will deliver improved quality and drive technology innovations to Ford, while lowering costs.

"We are committed to developing strong relationships with a select group of more capable, more financially stable strategic suppliers on a long-term basis," said Anne Stevens, executive 
vice president and chief operating officer, The Americas. "Strong suppliers and proven processes that everyone sticks to religiously go hand in hand with delivering innovation, quality and lower costs."

\section{Smaller, Nimbler Organization}

Achieving a lean fixed-cost structure and significantly improving Ford's North American assembly capacity utilization are critical components of the Way Forward plan.

"We're now well past the point in which one or two hit products can correct the overcapacity we have or justify the staffing levels we maintain - even with the significant actions we've taken during the past couple of years," Stevens said. "Sadly, this isn't just a Ford issuc. It's an issue for our domestic competitors, as well.

"As hard and painful as it is to idle plants and reduce our work force, we know these sacrifices are critical to set the stage for a stronger future," she added.

Ford is taking the following new actions to align its capacity with expected demand and to reduce fixed costs:

114 manufacturing facilities will be idled and cease production by 2012 , including a total of seven rehicle assembly plants.

2 Assembly capacity will be reduced by 1.2 million units or 26 percent by the end of 2008.

3 A new low-cost manufacturing site is planned for the future.

Ford will idle the following facilities through 2008:

1 St. Louis Assembly

2 Atlanta Assembly

3 Wixom Assembly

4 Batavia Transmission

5 Windsor Casting (announced following CAW contract negotiations in 2005)

6 I'wo additional assembly plants, which will be determined later this year

In addition, production at St. 'Thomas Assembly will be reduced to one shift. Facilities 
operated by Automotive Components Holding LLC are not included in the new announcement.

All of these actions will reduce total North American employment by 25,000-30,000 people in the 2006-2012 time period. 'This is in addition to the previously announced reduction of the equivalent of 4,000 salaried positions in the first quarter of 2006 - or 10 percent of salaryrelated costs - and a reduction in the company's officer ranks by 12 percent by the end of the first quarter.

Ford has briefed the leadership of the UNW and CAW about these plans.

\section{Financial Impact}

2006 will be a year of transition as Ford moves from its old North American business model to a new customer-focused strategy that is designed to restore automotive operations in the region to profitability no later than 2008 . The estimated pre-tax financial impact of the North American plan in 2006 includes:

$\$ 250$ million for hourly personncl separations - excluding ACH actions.

$\$ 220$ million for fixed asset write-offs.

"Our cost structure will improve as we progress through 2006 and increasingly thereafter, and we'll return to profitability in our North American automotive business no later than 2008," said Don I.cclair, executive vice president and chief financial officer. "We're confident in our plan and optimistic we can achieve our goals."

\section{Summary}

Ford begins a new era in its North American automotive business with a realistic view of the challenges facing the company but also building on several important competitive strengths, including:

$1 \Lambda$ corporate commitment to design, safety and technology innovation.

2 Leadership in full-size pickup trucks, where the Ford F-Series has been No. 1 for 29 
years.

3 A resurgent car business, paced by the Ford Mustang and Fusion, the Mercury Milan and the Lincoln 7 ephyr.

4 A strong and growing presence in crossover utility vehicles, today's fastest-growing segment.

5 Ford Credit, which continues to be closely linked to Ford's automotive business, delivering solid profitability.

6 More than 4,300 Ford and I incoln Mercury dealerships.

"Ford's strengths were built over 100 years, and we are taking the tough but necessary steps to address our issues with candor, speed and compassion for the people affected by our work force reductions," said Bill Ford. "This next chapter in Ford's history will be remembered for our renewed commitment to innovation and as the time we moved boldly to prepare Ford's North American business to face global competition." 


\section{Appendix C}

\section{The Global 8 D System:}

\section{Background}

In February, 1995, a cross-organizational steering committee was formed to develop a best practice problem solving process and computerized system that merged differences between organizational approaches to solving problems (TOPS, EQUIP TOPS, Prevent Recurrence and others). The corporate-wide process and supporting system was to be made available to Ford employees and suppliers and provide a common source of lessons learned. The original Global 8D software system that came of this effort was a Windows-based client/server program. In late 1998, a companion web application was created to be run over the Ford intranet. With the continued focus on web technologies, the client/server system was decomissioned at the end of 2000 and the Global 8D on the Web application is now the single-source for working with 8Ds within Ford.

\section{Our Vision}

The vision of Global 8D is to implement a common, enhanced, worldwide $8 \mathrm{D}$ problemsolving process for Ford Motor Company and its suppliers.

\section{Our Mission}

'The mission of Global 8D is to provide a common process; which effectively defines and resolves concerns and prevents their recurrence. Also:

1 Increase management understanding

2 Improve concern resolution and prevention

3 Improve performance to Quality/Cost/'Timing

4 Promote frank and open problem solving

5 Provide automated computer support

\section{D0 - Prepare for the Ford Global 8D Process}

\section{Purpose:}

In response to a symptom, evaluate the need for the G8D process. If necessary, provide an Emergency Response Action to protect the customer and initiate the G8D process.

\section{G8D Application Criteria:}

1 The symptom(s) has been defined and quantificd.

2 The G8D customer(s) who experienced the symptom(s), and the affected parties, 
when appropriate, have been identified.

3 Measurements taken to quantify the symptom(s) demonstrate that a performance gap exists AND/OR priority (severity, urgency, growth) of the symptom warrants initiation of the process.

4 The cause is unknown.

5 Management is committed to dedicate necessary resources to fix the problem at the root cause level and to prevent recurrence.

6 Symptom complexity exceeds the ability of one person to resolve

\section{D1 - Establish Team}

\section{Purpose:}

Establish a small group of people with the process and/or product knowledge, allocated time, authority, and skill in the required technical disciplines to solve the problem and implement corrective actions. 'The group must have a designated Champion and 'Team Leader. 'The group begins the team building process.

\section{D2 - Describe the Problem}

\section{Purpose:}

Describe the internal/external customer Problem by identifying "what is wrong with what" and detail the Problem in quantifiable terms.

\section{D3 - Develop Interim Containment Action (ICA)}

\section{Purpose:}

Define, verify, and implement the Interim Containment Action (ICA) to isolate effects of the problem from any internal/external customer until Pcrmanent Corrective $\Lambda$ ctions (PCAs) are implemented. Validate the effectiveness of the containment actions.

\section{D4 - Define and Verify Root Cause and Escape Point}

\section{Purpose:}

Isolate and verify the Root Cause by testing cach possible cause against the problem description and test data. Also isolate and verify the place in the process where the effect of the Root Cause should have been detected and contained (Liscape Point). 
D5 - Choose and Verify Permanent Corrective Actions (PCAs) for Root Cause and Escape Point

\section{Purpose:}

Select the best Permanent Corrective Action to remove the Root Cause. Mlso select the best Permanent Corrective Action to eliminate Escape. Verify that both decisions will be successful when implemented without causing undesirable effects.

\section{D6 - Implement and Validate Permanent Corrective Actions (PCAs)}

\section{Purpose:}

Plan and implement selected Permanent Corrective Actions. Remove the Interim Containment Action. Monitor the long-term results.

\section{D7 - Prevent Recurrence}

\section{Purpose:}

Modify the necessary systems including policies, practices, and procedures to Prevent Recurrence of this problem and similar ones. Make Recommendations for systemic improvements, as necessary.

\section{D8 - Recognize Team and Individual Contributions}

\section{Purpose:}

Complete the team experience, sinecrely recognize both Team and Individual Contributions, and celebrate. 


\section{Appendix D}

\section{Ford Motor Company 2005 Full Year Financials}

Today Ford Motor Company is announcing its third consecutive year of profitability. Fullyear 2005 net income was $\$ 2$ billion, or $\$ 1.04$ per share, and fourth-quarter net income was $\$ 1.24$ million, or 8 cents per share.

Full-year pre-tax profits, from continuing operations, excluding special items, totaled $\$ 3.4$ billion. On the same basis, the Automotive sector lost $\$ 1$ billion. Within this, South America, Europe and Asia Pacific were profitable. These profits were more than offset by losses in North America. Premier Automotive Group lost $\$ 100$ million, sharply improved from 2004. Financial Services reported a pre-tax profit of $\$ 4.4$ billion.

A press release containing more details about our fourth-quarter and full-year results is attached.

\section{\# \# \#}

\section{FORD MOTOR COMPANY REPORTS 2005 NET INCOME OF \$2 BILLION, PROFITABLE FOR THIRD CONSECUTIVE YEAR}

Third consecutive year of profitability. Full-year net income of $\$ 2$ billion, or $\$ 1.04$ per share.

Full-year earnings from continuing operations of $\$ 1.28$ per share or $\$ 2.5$ billion after tax, excluding special items.

Excluding special items, South America, Europe and Asia Pacific were all profitable, but these profits were more than offset by losses in North America. Premier Automotive Group continued to incur losses, but these were substantially reduced from 2004 levels.

Fïnancial Services, including Ford Motor Credit, reported strong results. 
DEARBORN, Mich., Jan. 23, 2006 - Ford Motor Company [NYSE: F] today reported 2005 full-year net income of $\$ 2$ billion, or $\$ 1.04$ per share. In 2004 , the company reported net income of $\$ 3.5$ billion, or $\$ 1.73$ per share.

Excluding special items, Ford's 2005 full-year after-tax income from continuing operations totaled $\$ 2.5$ billion, or $\$ 1.28$ per share. This compares with year-ago earnings from continuing operations of $\$ 4.3$ billion, or $\$ 2.11$ per share, excluding special items.

Full-year sales and revenue for 2005 was $\$ 178.1$ billion, up from $\$ 171.7$ billion a year ago.

"We accomplished many things in 2005, including the successful launch of the new Ford Fusion, Mercury Milan and Lincoln Zephyr, introduction of the company's new innovation initiative, completion of the sale of Hertz, and an agreement with the UAW to help reduce rising health care costs," said Chairman and Chief Executive Officer Bill Ford. "Iixcluding North America, our automotive operations made great progress in 2005; we must keep working to improve our business in each and every region."

Special items reduced earnings by 6 cents per share in the fourth quarter. The pre-tax effect of these items includes: a charge of $\$ 1.3$ billion for impairment of Jaguar and Land Rover fixed assets; personnel reduction actions of $\$ 962$ million; and the sale of 'The Hertz. Corporation for a total profit of $\$ 1.5$ billion, $\$ 1.4$ billion of which was recorded in the fourth quarter. In addition, the company's repatriation of foreign earnings pursuant to the American Jobs Creation Act of 2004 resulted in a permanent tax savings of about $\$ 250$ million. Largely as a result of these factors and costs associated with Visteon-related restructuring, special items reduced full-year income by 15 cents per share. linally, full-year net income from continuing operations was reduced by 9 cents primarily for a cumulative change in accounting principles related to recent accounting guidance on the recognition of environmental obligations. 


\section{FULL-YEAR HIGHLIGHTS}

Ford Motor Company full-year highlights include:

Launch of corporate innovation initiative, including a commitment to a ten-fold increase in hybrid production by 2010 .

Introduction of initiative to improve collaboration with select global suppliers of key components and consolidate our supply base.

Sale of 'The Hertz Corporation, with proceeds of $\$ 5.6$ billion.

Finalization of Vistcon agreement, which included the creation of a Ford-managed, temporary business entity named Automotive Components Holdings, LLC. 'This entity took ownership from Visteon of 17 plants and six offices, research centers and other facilities. 'This arrangement protects the supply of components to Ford plants, improves the competitiveness of Ford's supply base, and will reduce ford's costs over time.

Cessation of assembly opcrations at Jaguar's Browns I ane facility and consolidation of its assembly operations at Castle Bromwich and closure of Ford's I orain Assembly plant in I.orain, Ohio.

Reduction of total automotive personnel by more than 10,000 during 2005 , through personnel reduction actions and attrition.

Ratification of an agreement with the United Auto Workers (subject to court approval) to reduce the company's health care costs primarily through modifications to the hourly retirec health care plan. 'These actions arc expected to reduce Ford's ovcrall retiree health care and life insurance (OPLBB) obligation by $\$ 5$ billion, with a projected annual cost savings of about $\$ 650$ million on a pre-tax basis. 
$\square \quad$ Establishment of a company contribution limit set at 2006 levels for health care

benefits and a reduction of life insurance benefits for U.S. salaried retirees. 'These actions reduced Ford's overall retiree health care and life insurance (OPEB) obligation by about $\$ 3$ billion, with a projected annual cost savings of about $\$ 400$ million on a pre-tax basis.

\section{FOURTH QUARTER}

In the fourth quarter, the company reported net income of $\$ 124$ million, or 8 cents per share. This compares with fourth quarter net income of $\$ 104$ million, or 6 cents per share, in 2004 . Excluding special items, fourth quarter after-tax income from continuing operations totaled $\$ 511$ million, or 26 cents per share, compared to $\$ 554$ million, or 28 cents per share, a year aģo.

Total sales and revenue in the fourth quarter were $\$ 47.6$ billion, compared to $\$ 44.9$ billion in the year-ago period.

The following discusion of the results of our.-1utomotive sector and Automotive business units is on a fre-tax basis that exiludes speizal items. See table following "Safe Harbor/Rike Faitors" for the nature and amount of these speical items and a reconciliation to G.A.AP.

\section{AUTOMOTIVE SECTOR}

For the full year, Ford's worldwide Automotive sector reported a pre-tax loss of $\$ 1$ billion, compared with pre-tax profit of $\$ 850$ million a year ago. The decline primarily reflected unfavorable cost performance, volume and mix, and exchange, partially offset by net pricing.

For the fourth quarter, Ford's worldwide Automotive sector reported a pre-tax loss of $\$ 12$ million, an improvement of $\$ 458$ million from a pre-tax loss of $\$ 470$ million a year earlier. The improvement primarily reflected favorable volume and mix, net pricing, cost performance and exchange. 
W'orldwide automotive revenue for 2005 was $\$ 154.5$ billion, an improvement from revenue of $\$ 147.1$ billion a year ago. Total fourth-quarter automotive revenue was $\$ 41.8$ billion, an increase of $\$ 3$ billion from a year ago.

Total company vehicle unit sales in 2005 were $6,818,000$, an increase of 20,000 units from 2004. Fourth-quarter vehicle unit sales totaled 1,853,000, an increase of 102,000 units from a year ago.

Automotive cash at Dec. 31,2005 , totaled $\$ 25.1$ billion of cash, marketable securities, loaned securities and short-term Voluntary Employee Benefits Association (VEBA) assets.

\section{THE AMERICAS}

The Americas reported a 2005 full-year pre-tax loss of $\$ 1.2$ billion, compared to a pre-tax profit of $\$ 1.6$ billion a year ago. For the fourth quarter, the Americas had a pre-tax loss of $\$ 15$ million, an improvement of $\$ 411$ million compared to a pre-tax loss of $\$ 426$ million a year earlier.

North America: For 2005, Ford's North America automotive operations reported a pre-tax loss of $\$ 1.6$ billion, a decline of $\$ 3$ billion from 2004 . The decline primarily reflected unfavorable cost performance, lower U.S. market share, lower dealer inventories and adverse exchange. For the year, North America's sales totaled $\$ 81.4$ billion, compared with $\$ 83$ billion a year carlier.

For the fourth quarter, North America automotive operations reported a pre-tax loss of $\$ 143$ million, compared to a pre-tax loss of $\$ 470$ million in 2004 . 'The improvement primarily reflected cost reductions and favorable net pricing, partially offset by operating losses incurred by the former Visteon activities now controlled by Ford. Fourth-quarter sales were $\$ 22.1$ billion, compared with $\$ 21.1$ billion in 2004 . 
South America: Ford's South America automotive opcrations reported a pre-tax profit of $\$ 389$ million, an increase of $\$ 249$ million from a 2004 pre-tax profit of $\$ 140$ million. 'The improvement primarily reflected net pricing and favorable volume, as well as a stronger Brazilian currency. Full-year sales improved to $\$ 4.4$ billion from $\$ 3$ billion in 2004 .

In the fourth quarter, Ford's South America automotive operations posted a pre-tax profit of $\$ 128$ million, an improvement of $\$ 84$ million, compared with a pre-tax profit of $\$ 44$ million in 2004. The improvement primarily reflected favorable net pricing and exchange. Fourthquarter sales were $\$ 1.3$ billion, an improvement from $\$ 899$ million a year ago.

\section{FORD EUROPE AND PREMIER AUTOMO'TIVE GROUP (PAG)}

The combined 2005 full-year pre-tax profit for Ford Europe and P $\Lambda \mathrm{G}$ was $\$ 36$ million. This compares with a loss of $\$ 626$ million for 2004 . For the fourth quarter, Ford Europe and PAG had a combined pre-tax profit of $\$ 112$ million, an improvement from a pre-tax loss of $\$ 324$ million a year ago.

Ford Europe: Ford Europe posted a full-ycar pre-tax profit of $\$ 136$ million, compared with a pre-tax profit of $\$ 114$ million a year ago. The improvement primarily reflected favorable cost performance and exchange, partially offset by unfavorable net pricing and mix. Sales for the year totaled $\$ 30.2$ billion, compared to $\$ 26.5$ billion in 2004 .

For the fourth quarter, Ford Europe reported a pre-tax profit of $\$ 66$ million, an improvement from a pre-tax loss of $\$ 69$ million a year ago. 'The improvement primarily reflected favorable cost performance and higher profits at our operations in l'urkey, partially offset by unfavorable product mix. Fourth-quarter sales totaled $\$ 8.2$ billion, compared to $\$ 7.4$ billion a year ago.

Premier Automotive Group: I'or 2005, P $\backslash G$ reported a full-year pre-tax loss of $\$ 100$ million, an improvement from a pre-tax loss of $\$ 740$ million a year ago. The improvement primarily reflected the impact of new products, primarily at I and Rover, that resulted in a richer mix and improved net pricing. I'ull-year sales for the group totaled $\$ 30$ ).3 billion, compared to $\$ 27.6$ billion in 2004 . 
In the fourth quarter, $P A G$ reported a pre-tax profit of $\$ 46$ million, an improvement of $\$ 301$ million, compared with a pre-tax loss of $\$ 255$ million in the year-ago period. The year-overyear improvement primarily reflected the impact of new Land Rover products, resulting in a richer mix and improved net pricing. Fourth-quarter sales totaled $\$ 8$ billion, compared to $\$ 7.8$ billion a year ago.

\section{ASIA PACIFIC AND AFRICA/MAZDA}

For the full year, Asia Pacific and Africa/Mazda reported a pre-tax profit of $\$ 316$ million, compared with a pre-tax profit of $\$ 163$ million a year ago. In the fourth quarter, Asia Pacific and $A$ frica/Mazda reported a pre-tax loss of $\$ 7$ million, compared with a pre-tax loss of $\$ 22$ million in 2004.

Asia Pacific and Africa: For full-year 2005, Asia Pacific and Africa reported a pre-tax profit of $\$ 61$ million, an improvement of $\$ 16$ million when compared with the year ago period. The improvement primarily reflected favorable exchange and higher volume, which was partially offset by unfavorable vehicle mix and higher costs. Full-year sales totaled $\$ 7.7$ billion, an increase from $\$ 7$ billion in 2004 .

For the fourth quarter, $\Lambda$ sia Pacific and $\Lambda$ frica reported a pre-tax loss of $\$ 39$ million, compared with a pre-tax loss of $\$ 13$ million in the year-ago period. 'I the decline primarily reflected deterioration of results in Ford Australia due to lower volumes and unfavorable mix. Fourth-quarter sales totaled $\$ 1.8$ billion, compared to $\$ 1.6$ billion in 2004 .

Mazda: For full-year 2005, Ford's share of the pre-tax profit of Mazda and associated operations was $\$ 255$ million, compared with $\$ 118$ million a year ago. For the fourth quarter, Ford's share of the pre-tax profit of Mazda and associated operations was a pre-tax-profit of $\$ 32$ million, compared with a pre-tax loss of $\$ 9$ million a year ago. The improvement in both periods primarily reflected gains in our investment in Mazda's convertible bonds, as well as higher operating results at Mazda.

\section{FINANCIAL SERVICES SECTOR}


Financial Services Sector results include The Hertz Corporation through Dec. 21, 2005, the date on which it was sold. For the full year, excluding special items, Ford's Financial Services sector reported a pre-tax profit of $\$ 4.4$ billion, compared with a pre-tax profit of $\$ 5$ billion last year. For the fourth quarter, excluding special items, the Financial Services Sector earned a pre-tax profit of $\$ 881$ million, compared with pre-tax profits of $\$ 1$ billion a year ago.

Ford Motor Credit Company: Ford Motor Credit reported net income of $\$ 2.5$ billion in 2005 , down $\$ 370$ million from a year earlier. On a pre-tax basis from continuing operations, Ford Motor Credit carned \$3.9 billion in 2005, down $\$ 570$ million from 2004.

In the fourth quarter of 2005 , Ford Motor Credit's net income was $\$ 465$ million, down $\$ 78$ million from a year carlier. On a pre-tax basis from continuing operations, Ford Motor Credit earned $\$ 737$ million in the fourth quarter, compared with $\$ 859$ million the previous year. The decrease in earnings in both fourth-quarter and full-year 2005 primarily reflected lower volumes and margins, partially offset by lower credit losses.

T'he Hertz Corporation: Hertz reported a full-year 2005 pre-tax profit of $\$ 569$ million, excluding special items, which was a year-over-year improvement of $\$ 76$ million. Hertz reported a fourth-quarter pre-tax profit of $\$ 121$ million, excluding special items, which was an increase of $\$ 14$ million from the same period in 2004.

Ford Motor Company, a global automotive industry leader based in Dearborn, Mich., manufactures and distributes automobiles in 200 markets across six continents. With about 300,000 employees, the company's core and affiliated automotive brands include Aston Martin, Ford, Jaguar, Land Rover, Lincoln, Mazda, Mercury and Volvo. Its automotive-related services include Ford Motor Credit Company. 


\section{VITA}

Kenneth A. Ryan was born 13 February 1968. He graduated from Belleville 'lownship High School - West in the spring of 1986 and was selected as a member of the National Honor Society.

After graduating high school, he attended St. Louis University - Parks Fingineering School in the fall of 1986 and graduated in 1990 with a Bachelor of Science in Acrospace Engineering (BSAE). Fxpanding his knowledge base, Kenneth enrolled at the University of Missouri - Columbia in the fall of 1990 graduating with a Bachelor of Science degree in Mechanical Engineering (BSML) in 1991 on the Dean's List.

Kenneth then went to work for Vitek Systems of McDonnell Douglas Corp. in St. L.ouis, MO as a research and development engineer. He left Vitek Systems and entered service with the United States Air Force commissioned a $2^{\text {nd }}$ L.T in March 1992. Selected for Flight Training, he went through Lndergraduate Pilot Training (UP'I) flying T-37 Tweets and T-38 Talons finishing first in his class. From UPT, Kenneth was selected to fly Air Superiority fighters accumulating time in $\mathrm{F}^{2}-15$ 's. In 1995, J t Ryan moved to Pensacola, FL. to spend a year in the Air Force / Navy Joint Pilot Exchange Program training in Navy flight squadrons accumulating time in F/ $\mathrm{A}-18^{\prime}$ 's. Capt. Ryan went back to the Mir l'orce's $33^{\text {rd }}$ Fighter Wing based in Ft. Walton Beach, FI, and left Active Duty Air Force in 1998.

Mr. Ryan now works for Ford Motor Company as a Body Construction Enginecr developing the 2001 Explorer Sport 'Trac, the 2002 U152 Explorer, 2006 U251 Explorer, and now is in charge of the door stamping assembly and construction for Ford's $2009 \mathrm{~F}-150$ T'ruck. 